\title{
Molecular Dynamic Study and Synthesis of 1H-benzo[d]imidazole-5-carboxamide Derivatives as Inhibitors for Yellow Fever and Zika Virus Replication
}

\author{
Madonna M. A. Mitry ${ }^{\mathrm{a}}$, Amr M. El-Araby ${ }^{\mathrm{a}}$, Johan Neyts ${ }^{\mathrm{b}}$, Suzanne J. F. Kaptein ${ }^{\mathrm{b}}$, Rabah A. T. Serya ${ }^{\mathrm{a}}$, \\ Nermin Samir ${ }^{* a}$ \\ a Department of Pharmaceutical Chemistry, Faculty of Pharmacy, Ain Shams University, Cairo 11566, Egypt \\ ${ }^{\mathrm{b}}$ Department of Microbiology, Immunology and Transplantation, Rega Institute for Medical Research, Laboratory \\ of Virology and Chemotherapy, Herestraat 49, 3000 Leuven, Belgium
}

\begin{abstract}
Flaviviridae family comprises the flavivirus genotype that represents a significant world health problem as it includes the Yellow fever virus (YFV) and Zika virus (ZIKV) which are responsible for large outbreaks and for which novel therapies are in urgent demand. The benzimidazole scaffold has been widely reported for its antiviral activity, and hence a new series of 1 H-benzo[ $d]$ imidazole-5-carboxamide derivatives (VIIa-x, VIIIa-h \& IXa, b) was designed, synthesized, and biologically evaluated for their antiviral activity. Five Compounds (VIId, VIIe, VIIh, VIIn, and VIIt) showed antiviral activity against YFV in the low micromolar range using the human hepatoma Huh-7 cells and Vero cells. One compound (VIId) exhibited activity on both YFV $\left(\mathrm{EC}_{50}=1.7 \pm 0.8 \mu \mathrm{M}\right)$ and ZIKV $\left(\mathrm{EC}_{50}=4.5 \pm 2.1 \mu \mathrm{M}\right)$. Molecular docking and molecular dynamics simulation studies were conducted to understand the SAR of newly synthesized compounds, to explore the potential target of compound VIId, and to investigate the possible binding mode to its target.
\end{abstract}

Keywords: 1H-benzo[d]imidazole; Flavivirus; Yellow Fever virus; Zika virus; Molecular dynamics simulation.

*Correspondence | Nermin Samir; Department of Pharmaceutical Chemistry, Faculty of Pharmacy, Ain Shams University, Cairo 11566, Egypt. Email: nerminsamir@pharma.asu.edu.eg

Citation | Mitry MMA, El-Araby AM, Neyts J, Kaptein SJF, Serya RAT, Samir N, 2020. Molecular Dynamic Study and Synthesis of 1Hbenzo $[d]$ imidazole-5-carboxamide Derivatives as Inhibitors for Yellow Fever and Zika Virus Replication. Arch Pharm Sci ASU 4(2): 145-180 DOI: $10.21608 /$ aps.2020.34690.1036

Print ISSN: 2356-8380. Online ISSN: 2356-8399.

Received 10 July 2020. Accepted 13 August 2020.

Copyright: ${ }^{\circledR} 2020$ Mitry et al. This is an open-access article licensed under a Creative Commons Attribution 4.0 International License (CC BY 4.0), which permits unrestricted use, distribution, and reproduction in any medium, provided the original author(s) and source are credited.

Published by: Ain Shams University, Faculty of Pharmacy

\section{INTRODUCTION}

The Flaviviridae family comprises a large number of genera representing a major cause of public health problems, mainly the Hepacivirus genus, the Flavivirus genus, and the Pestivirus genus [1-3]. The Hepacivirus genus includes, amongst others, the hepatitis $\mathrm{C}$ virus ( $\mathrm{HCV}$ ), and the pestivirus genus includes the bovine viral diarrhea virus (BVDV) [2]. The Flavivirus genus comprises more than 53 members including those causing large outbreaks in the human population: Dengue virus (DENV), Yellow Fever virus (YFV), and Zika virus (ZIKV).

Flaviviruses began to spread about 75,000 years ago due to human migration from Africa [4]. According to the world health organization (WHO), 200,000 new YFV cases occur annually with outbreaks recorded in 2016-2017 in several countries in Africa and the Americas [5-7]. As for ZIKV, an estimated 440,000-1,300,000 cases 
were recorded in late 2015 during the Brazilian outbreak, and as a result of an increase in ZIKVassociated microcephaly cases in 2016, the WHO declared ZIKV a Public Health Emergency of International Concern $[8,9]$.

Despite the availability of a highly efficacious YFV vaccine (17D vaccine) the recent large YFV outbreaks clearly show that antivirals against YFV and all flaviviruses are desperately needed. Aiming to decrease the viremia during early infection and block the viral replication and growth, various viral proteins are targeted [10]. The flaviviral proteins are classified into structural and non-structural proteins. The structural proteins include the capsid protein (C), the envelope protein (E), and the membrane protein (M) [11-13]. The non-structural proteins include: NS1, NS2A, NS2B, NS3 (serine protease/ helicase enzyme), NS4A, NS4B, NS5 (methyltransferase/ polymerase enzyme) [14-19].

The benzimidazole nucleus has been reported to be involved as a structural unit in many bioactive molecules, such as anticancer agents ${ }^{[20]}$, antioxidants [21], antihypertensives [22], immunomodulatory [23], anti-inflammatory agents [24], CNS stimulants as well as antidepressants, [25] antiparasitic agents, [26] antidiabetics, [27] antimicrobials [28] and antivirals [29]. It is worth noting that most of the reported biologically active compounds comprising a benzimidazole nucleus to have their functional groups at positions 1,2 and/or 5 (or 6) $[25,30,31]$

Various benzimidazole-based compounds were reported to be active leads in the search for new antiviral agents acting against Flaviviridae family members especially yellow fever virus and HCV (Fig. 1) [32-35].

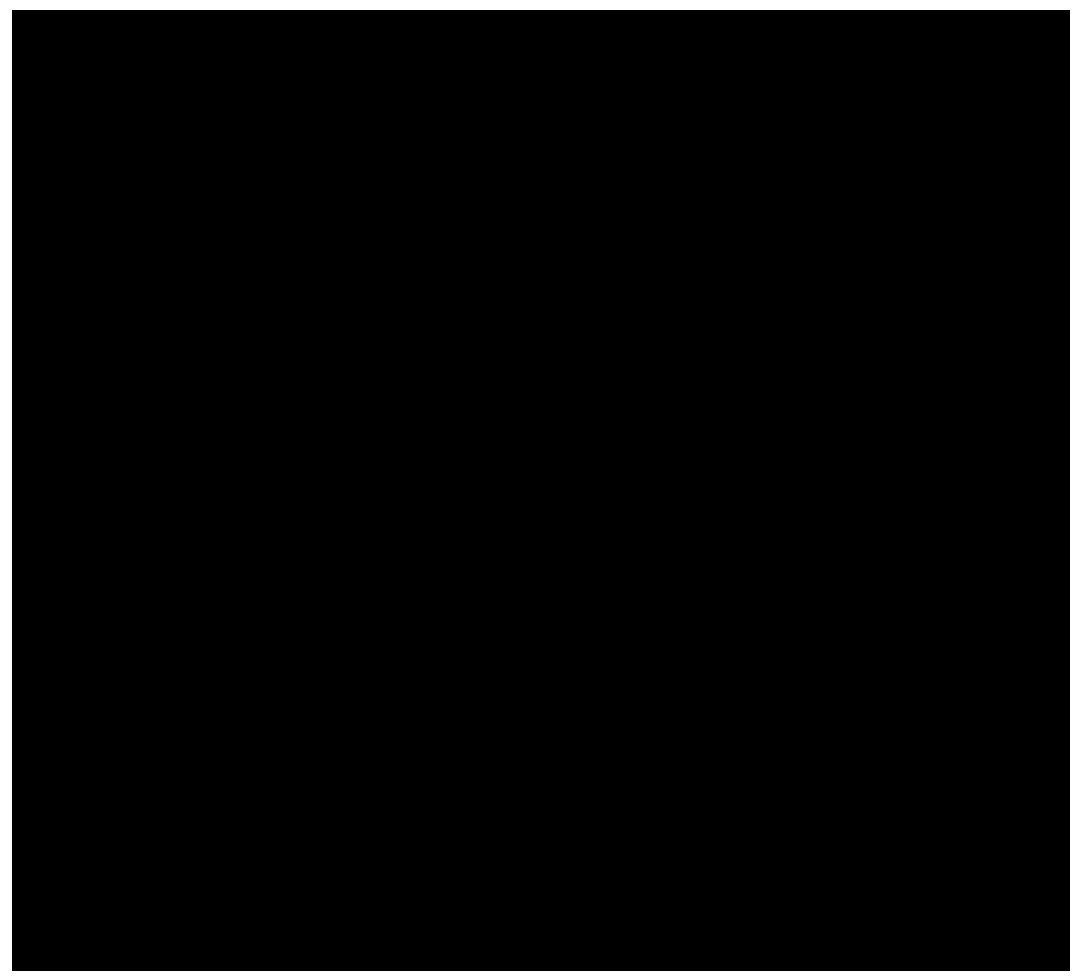

Fig.1. Benzimidazole-based reported anti-Flaviviridae compounds 
Herein, a variety of $1 \mathrm{H}-$ benzo $[d]$ imidazole-5carboxamide derivatives (VIIa-x, VIIIa-h \& IXa, b) were synthesized and biologically evaluated for their anti-YFV activity. Besides, molecular modeling studies (docking and molecular dynamics) of compound VIId which exhibited antiviral activity against both YFV (on Huh-7 and VeroA cells) and ZIKV were conducted to gain insight into its antiviral mechanism. These studies suggested that VIId may be a ZIKV polymerase inhibitor.

\subsection{Rationale and Design}

G. Vitale has reported -as a part of the antiFlaviviridae Project- several derivatives of benzimidazole-based structures which were divided into four series: arylbenzimidazoles, naphthyl benzimidazoles, [36, 37] styrylbenzimidazoles [38] and 5-acetyl-2arylbenzimidazoles [35]. These compounds were assayed against different members of the Flaviviridae family, YFV (Flaviviruses), BVDV (Pestiviruses), and HCV (Hepacivirus). Many of the compounds showed very good anti-YFV with $\mathrm{EC}_{50}$ values ranging from 0.5-27 $\mu \mathrm{M}$ (Fig. 2).
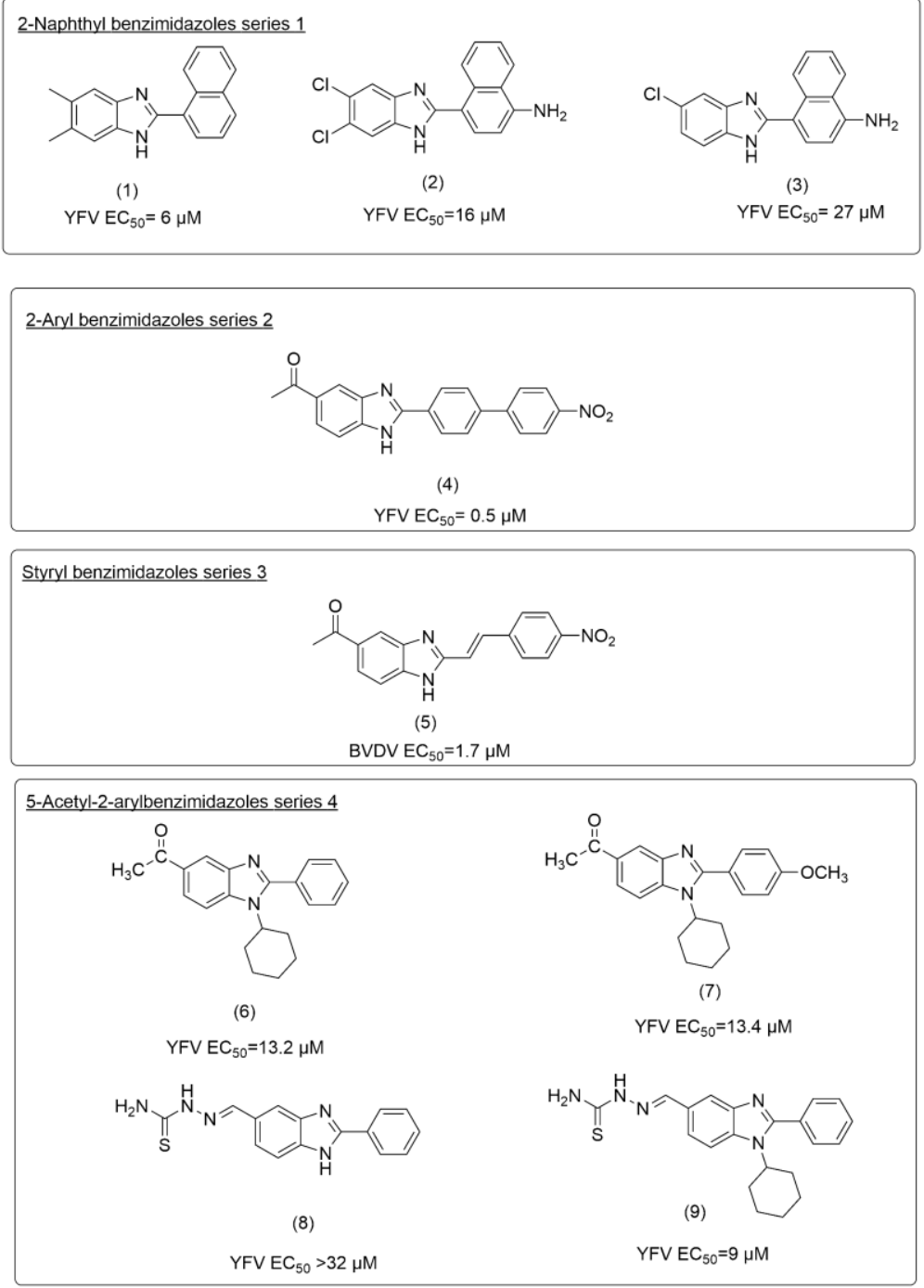
Fig. 2. Benzimidazole-based compounds showing activity against Flaviviridae family

The first series (2-naphthyl benzimidazoles) evaluated the effect of different substituents at positions 5 and 6 of the benzimidazole ring, nearly 3 compounds (1-3) showed activity on YFV.

The second series, (2-aryl benzimidazoles), replacing the 2-naphthalene moiety in series 1 with a 2-[4-R-biphenyl] moiety. Only compound (4) showed anti-YFV activity with scarce chance to conclude a SAR.

As for the third series, (styrylbenzimidazoles), the phenyl ring was separated from the benzimidazole nucleus by an ethylene spacer, and compounds with various substituents at position 5,6 of the benzimidazole nucleus and the phenyl ring were tested. All compounds from this series showed no activity against YFV. Compound $\mathbf{5}$ displayed the highest antiviral activity against BVDV among all active derivatives.

The fourth series (5-acetyl-2arylbenzimidazoles) showed the best antiFlaviviridae activity with about 9 compounds showing antiviral activity ranging between $0.8-8$ $\mu \mathrm{M}$ on YFV, BVDV, and HCV representing the three genera of Flaviviridae family (Flavivirus, Pestivirus, and Hepacivirus) respectively.

SAR studies within the reported compounds demonstrated that:

1) 5-Acetyl group improved the anti-BVDV and anti-YFV activity due to its electronegativity.

2)5-Acetyl group derivatizations to ketoximes, semicarbazones, and thiosemicarbazones improved the potency.

3) Cyclohexyl substituent introduction at position 1 improved the anti-YFV activity better than the unsubstituted derivative and that was obvious in compounds 8 and 9.

Based on the SAR study of the previously reported compounds, in the present study, we were able to design, synthesize and biologically evaluate novel series of benzimidazole derivatives targeting the Flaviviridae family (especially YFV and ZIKV).

Our structure-based design strategy was based on:

1) Keeping the benzimidazole nucleus which is beneficial for anti-viral activity.

2) Keeping the cyclohexyl ring in the N1 position.

3) Exploration of various substituents on the 2-phenyl ring compared to the unsubstituted derivatives.

4) Exploration of various substituents on 5 positions of benzimidazole ring.

Accordingly, three series of compounds were designed based on the modification of the lead compound $\mathbf{4}$, which possesses high potency to be synthesized and biologically evaluated against YFV and ZIKV as shown in (Fig. 3).

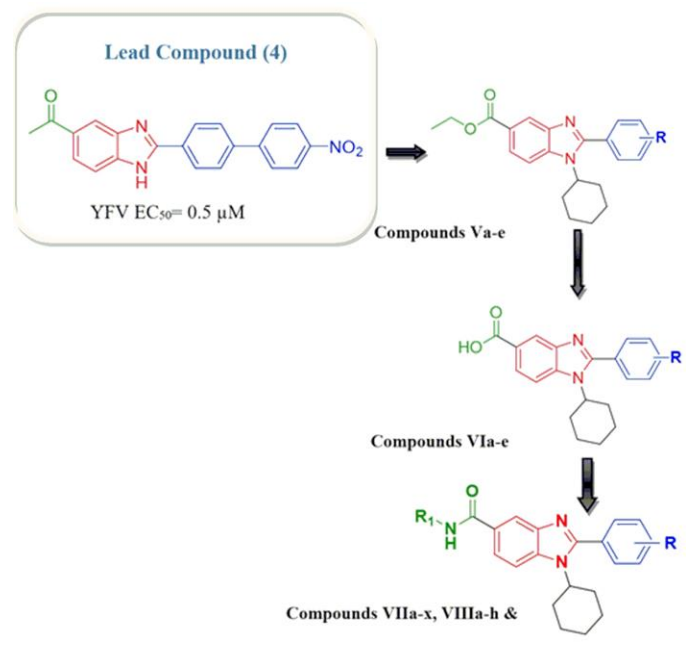

Fig. 3. Design of new anti-Flavivirus agents by bioisosteric modifications of lead compound 4

\section{MATERIALS AND METHODS}

\subsection{Chemistry}


Starting materials and reagents were purchased from Sigma-Aldrich (USA), Loba Chemie (India), and Alfa-Aesar organics and used without further purification. Solvents were purchased from Fisher Scientific and SigmaAldrich and utilized after drying. Reactions were monitored by analytical TLC, performed on silica gel $60 \mathrm{~F}_{254}$ packed on Aluminum sheets, purchased from Merck, visualized under U.V. light (254 nm). For flash chromatography, Merck silica gel 60 was used with a particle size (230400 mesh). Melting points were measured on the Stuart Scientific apparatus. ${ }^{1}$ HNMR spectra were recorded in $\delta$ scale given in ppm on a Bruker 400 $\mathrm{MHz}$ and referred to TMS as an internal reference and ${ }^{13} \mathrm{CNMR}$ spectra were recorded on a Bruker $101 \mathrm{MHz}$ at the Center of Drug Discovery and Research Development, Ain Shams University. EI-MS spectra and Elemental analyses were performed at the Regional Center for Mycology and Biotechnology, Al-Azhar University.

\subsubsection{General procedure to prepare Intermediates I-III}

The starting compound (4-chlorobenzoic acid) was purchased from Sigma-Aldrich (USA) and used as it is. 4-Chlorobenzoic acid (6.24 g, 40 $\mathrm{mmol}$ ) was dissolved in $20 \mathrm{~mL}$ concentrated sulfuric acid portion-wise in an ice bath at $0{ }^{\circ} \mathrm{C}$, then $20 \mathrm{~mL}$ of concentrated nitric acid was added dropwise for 30 minutes at $0{ }^{\circ} \mathrm{C}$. The reaction mixture was left to stir at room temperature for 3 $\mathrm{h}$, then poured dropwise on ice to give a white precipitate. The precipitate was filtered and washed with excess water to get rid of excess acids and left to dry to give the titled compound I as a white powder. To a solution of compound $\mathbf{1}$ $(6 \mathrm{~g}, 29.8 \mathrm{mmol})$ in $48 \mathrm{~mL}$ ethanol, $6 \mathrm{~mL}$ of concentrated sulfuric acid was added dropwise while in an ice bath at $0{ }^{\circ} \mathrm{C}$. Then the reaction mixture was stirred at $70{ }^{\circ} \mathrm{C}$ for $24 \mathrm{~h}$. After the reaction was completed, it was poured on ice/water to give an off-white precipitate. The precipitate was neutralized with sodium carbonate then filtered and washed with excess water and left to dry. The product was crystallized from ethanol to give the titled compound II as an off-white powder. For the preparation of compound III, cyclohexylamine (9.35 mL, $93.3 \mathrm{mmol}, 3$ equivalents) and triethylamine $(9.3 \mathrm{~g})$ were added to a solution of compound II (7.14 g, $31.1 \mathrm{mmol}, 1$ equivalent) in DMSO $(23 \mathrm{~mL})$. The reaction mixture was then stirred at $90{ }^{\circ} \mathrm{C}$ for $4 \mathrm{~h}$. After completion of the reaction, the reaction mixture was poured dropwise on ice with vigorous stirring to give a yellow precipitate. The precipitate was filtered and washed with water and diethyl ether, then left to dry and then crystallized from n-hexane to yield the titled compound III as yellow solid. ${ }^{(39-}$ 41)

\subsubsection{General procedure to prepare Intermediate IV}

A solution of Ethyl 4-(cyclohexyl amino)-3nitrobenzoate III ( $2 \mathrm{~g}, 6.8 \mathrm{mmol})$ and $10 \% \mathrm{Pd} / \mathrm{C}$ $(0.2 \mathrm{~g})$ in ethyl acetate $(100 \mathrm{~mL})$ were placed in a parr bottle and the bottle was placed in the parr hydrogenator apparatus, flushed 3 times with hydrogen and filled with hydrogen (40 psi). The mixture was agitated at room temperature for 30 minutes during which the pressure dropped to approximately $20 \mathrm{psi}$. The bottle was again filled with hydrogen (40 psi), and agitation was continued for $4 \mathrm{~h}$ until no pressure drop is observed. The catalyst was removed by filtration using filter aid (celite) and the filtrate was evaporated under vacuum till complete dryness then crystallized from the diethyl ether to give the titled compound IV as brown crystals [42].

\subsubsection{General procedure to prepare Intermediate compounds Vad}

To a solution of compound III (3 g, 10.27 mmol, 1 equivalent) in $30 \mathrm{~mL}$ DMSO, 
benzaldehyde derivative (1.1 equivalent) and sodium dithionite $(5.3 \mathrm{~g}, 30.81 \mathrm{mmol}, \quad 3$ equivalents) was added. The reaction mixture was stirred at $90{ }^{\circ} \mathrm{C}$ for $7 \mathrm{~h}$. After completion of the reaction, the reaction was poured onto icecold water with vigorous stirring where precipitate was formed. The precipitate was then filtered and crystallized from the appropriate solvent to yield target compounds Va-d.

\subsubsection{Ethyl 1-cyclohexyl-2-phenyl-1H- benzo $[d]$ imidazole-5-carboxylate (Va)}

The product was crystallized from ethanol to yield the titled compound $\mathbf{V a}$ as white powder (2.7 g, 72.78\%); m.p. $128-132{ }^{\circ} \mathrm{C}$ as reported [43]; ${ }^{1}$ HNMR (400 MHz, DMSO- $d_{6}$ ) $\delta 8.29(\mathrm{~d}$, $J=1.5 \mathrm{~Hz}, 1 \mathrm{H}$, benzimidazole $\mathrm{H}), 8.05(\mathrm{~m}, 2 \mathrm{H}$, ArH), 7.93 (dd, $J=8.7,1.5 \mathrm{~Hz}, 1 \mathrm{H}$, benzimidazole $\mathrm{H}), 7.66(\mathrm{~d}, J=8 \mathrm{~Hz}, 1 \mathrm{H}$, benzimidazole $\mathrm{H}$ ), 7.64 (m, 3H, ArH), 4.32 (q, J= $7.1 \mathrm{~Hz}, 2 \mathrm{H}$, ester), 4.04 (q, 1H, cyclohexyl), 2.39-2.13 (m, 2H, cyclohexyl), 2.00-1.79 (m, $4 \mathrm{H}$, cyclohexyl), 1.69-1.53 (m, 1H, cyclohexyl), 1.36 (t, $J=7.1 \mathrm{~Hz}, 3 \mathrm{H}$, ester), $1.27(\mathrm{~m}, 3 \mathrm{H}$, cyclohexyl); FT-IR(U max, $\left.\mathbf{c m}^{-\mathbf{1}}\right): 3124(\mathrm{CH}$ aromatic), 2937 (CH aliphatic), 1698( $\mathrm{C}=\mathrm{O}$ ester); MS $($ Mwt $=348.44), \mathrm{m} / \mathrm{z}$ (\% rel. int.): 348.19 $\left(\mathrm{M}^{+}, 91 \%\right), 349.2\left(\mathrm{M}^{+1}, 25.3 \%\right)$; Anal. Calcd for $\mathrm{C}_{22} \mathrm{H}_{24} \mathrm{~N}_{2} \mathrm{O}_{2}$ : C, 75.83; H, 6.94; N, 8.04; Found: C, 76.14; H, 7.03; N, 8.22.

\subsubsection{Ethyl 1-cyclohexyl-2-(4- methoxyphenyl)-1H-benzo[ $d]$ imidazole-5- carboxylate (Vb).}

The product was crystallized from hexane to yield the titled compound $\mathbf{V b}$ as an off-white powder (2.8 g, 72.11\%); m.p. $114-118{ }^{\circ} \mathrm{C}$; ${ }^{1}$ HNMR (400 MHz, DMSO- $\left.d_{6}\right) \delta 8.24(\mathrm{~d}, J=1.5$ $\mathrm{Hz}, 1 \mathrm{H}$, benzimidazole $\mathrm{H}), 7.90(\mathrm{dd}, J=8.7,1.5$ $\mathrm{Hz}, 1 \mathrm{H}$, benzimidazole $\mathrm{H}), 7.82(\mathrm{dd}, J=8.6,1.7$ $\mathrm{Hz}, 2 \mathrm{H}, 4-\mathrm{OMe} \mathrm{ArH}), 7.60$ (d, J= $8 \mathrm{~Hz}, 1 \mathrm{H}$, benzimidazole $\mathrm{H}$ ), 7.14 (dd, $J=8.6,1.7,2 \mathrm{H}, 4$ OMe ArH) 4.32 (q, $J=7.1 \mathrm{~Hz}, 2 \mathrm{H}$, ester), 4.04 (q, 1H, cyclohexyl), 3.86 (s, 3H, methoxy), 2.39-2.13 (m, 2H, cyclohexyl), 2.00-1.79 (m, $4 \mathrm{H}$, cyclohexyl), 1.69-1.53 (m, 1H, cyclohexyl), $1.36(\mathrm{t}, J=7.1 \mathrm{~Hz}, 3 \mathrm{H}$, ester), $1.27(\mathrm{~m}, 3 \mathrm{H}$, cyclohexyl); MS $(\mathrm{Mwt}=378.46), \mathrm{m} / \mathrm{z}(\%$ rel. int.): $378.19\left(\mathrm{M}^{+}, 91 \%\right), 379.2\left(\mathrm{M}^{+1}, 25.3 \%\right)$; Anal. Calcd for $\mathrm{C}_{23} \mathrm{H}_{26} \mathrm{~N}_{2} \mathrm{O}_{3}$ : C,72.99; H, 6.92; N, 7.40; Found: C, 73.11; H, 7.03; N,7.51.

\subsubsection{Ethyl 1-cyclohexyl-2-(2- methoxyphenyl)-1H-benzo[ $[d]$ imidazole-5- carboxylate (Vc)}

The product was crystallized from hexane to yield the titled compound $\mathbf{V c}$ as an off-white powder (2.7 g, 67\%); m.p. 108-110 ${ }^{\circ} \mathrm{C}$; ${ }^{1} \mathbf{H N M R}$

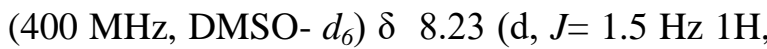
benzimidazole $\mathrm{H}$ ), $7.92(\mathrm{dd}, J=8.5,1.5 \mathrm{~Hz}, 1 \mathrm{H}$, benzimidazole $\mathrm{H}), 7.86(\mathrm{~d}, J=8.9 \mathrm{~Hz}, 1 \mathrm{H}, 2-\mathrm{O}$ $\mathrm{Me} A \mathrm{ArH}), \quad 7.63-7.55$ (d, $J=8 \mathrm{~Hz} 1 \mathrm{H}$, benzimidazole $\mathrm{H}), 7.46(\mathrm{~d}, J=7.3 \mathrm{~Hz}, 1 \mathrm{H}, 2$ OMe ArH), 7.24 (d, J= 8.4 Hz, 1H, 2-OMe ArH), 7.14 (t, $J=7.6 \mathrm{~Hz}, 1 \mathrm{H}, 2-\mathrm{OMe} \operatorname{ArH}), 4.32$ (q, $J=$ $7.1 \mathrm{~Hz}, 2 \mathrm{H}$, ester), 4.04 (q, 1H, cyclohexyl), 3.81 (s, 3H, methoxy), 2.39-2.13 (m, 2H, cyclohexyl), 2.00-1.79 (m, 4H, cyclohexyl), 1.69-1.53 (m, $1 \mathrm{H}$, cyclohexyl), $1.36(\mathrm{t}, J=7.1 \mathrm{~Hz}, 3 \mathrm{H}$, ester), 1.27 (m, 3H, cyclohexyl); MS (Mwt= 378.46), $\mathrm{m} / \mathrm{z}$ (\% rel. int.): $378.22\left(\mathrm{M}^{+}, 82 \%\right), 379.2\left(\mathrm{M}^{+1}\right.$, 25.7\%); Anal. Calcd for $\mathrm{C}_{23} \mathrm{H}_{26} \mathrm{~N}_{2} \mathrm{O}_{3}$ : C, 72.87 ; H, 7.11; N, 7.45; Found: C, 73.11; H, 7.03; N, 7.51 .

\subsubsection{Ethyl 1-cyclohexyl-2-(4- hydroxyphenyl)-1H-benzo $[d]$ imidazole-5- carboxylate (Vd)}

The product was crystallized from hexane to yield the titled compound $\mathbf{V d}$ as an off-white powder (2.5 g, 64.43\%); m.p. $164-165{ }^{\circ} \mathrm{C}$; ${ }^{1}$ HNMR (400 MHz, DMSO- $\left.d_{6}\right) \delta 10.00(\mathrm{~s}, 1 \mathrm{H}$, $\mathrm{OH} \mathrm{D}_{2} \mathrm{O}$ exchangeable), $8.2(\mathrm{~d}, J=1.5 \mathrm{~Hz} 1 \mathrm{H}$, benzimidazole $\mathrm{H}$ ), 8.11 (dd, $J=8.7,2.8 \mathrm{~Hz}, 2 \mathrm{H}$, 4-OH ArH), $7.93(\mathrm{dd}, J=8.5,1.5 \mathrm{~Hz}, 1 \mathrm{H}$, benzimidazole $\mathrm{H}), 7.85(\mathrm{dd}, J=8.8,2.8 \mathrm{~Hz}, 2 \mathrm{H}$, 
4-OH ArH), $7.56-7.51(\mathrm{~d}, J=8 \mathrm{~Hz} 1 \mathrm{H}$, benzimidazole $\mathrm{H}$ ), 4.32 (q, $J=7.1 \mathrm{~Hz}, 2 \mathrm{H}$, ester), 4.2 (q, 1H, cyclohexyl) 2.39-2.13 (m, 2H, cyclohexyl), $2.00-1.79$ (m, 4H, cyclohexyl), $1.69-1.53(\mathrm{~d}, J=12.5 \mathrm{~Hz}, 1 \mathrm{H}$, cyclohexyl), 1.36 $(\mathrm{t}, \quad J=7.1 \mathrm{~Hz}, 3 \mathrm{H}$, ester $), 1.27(\mathrm{~m}, 3 \mathrm{H}$, cyclohexyl); MS $(\mathrm{Mwt}=364.44), \mathrm{m} / \mathrm{z}(\% \mathrm{rel}$. int.): $364.22\left(\mathrm{M}^{+}, 82 \%\right), 365.2\left(\mathrm{M}^{+1}, 24.7 \%\right)$; Anal. Calcd for $\mathrm{C}_{22} \mathrm{H}_{24} \mathrm{~N}_{2} \mathrm{O}_{3}$ : C, 72.50; H, 6.64; N, 7.69; Found: C, 73.08; H, 6.79; N, 7.91.

\subsubsection{Ethyl 1-cyclohexyl-2-(4-nitrophenyl)- 1H-benzo $[d]$ imidazole-5-carboxylate (Ve)}

A solution of Ethyl 3-amino-4(cyclohexylamino) benzoate IV $(0.5 \mathrm{~g}, 1.8 \mathrm{mmol}$, 1 equivalent), 4-nitrobenzaldhyde (0.2 g, 1.8 mmol, lequivalent) and $\mathrm{Na}$ acetate $(0.15 \mathrm{~g}, 1.8$ mmol, 1 equivalent) in absolute ethanol was stirred at $70{ }^{\circ} \mathrm{C}$ for $4 \mathrm{~h}$, the precipitate was filtered, washed with diethyl ether and left to dry to give the titled compound $\mathbf{V e}$ as an orange powder. The product was crystallized from hexane to yield the titled compound Ve as orange powder. yield: 93.35\%; ${ }^{1} \mathbf{H}$ NMR $(400 \mathrm{MHz}$, DMSO- $\left.d_{6}\right) \delta 8.36(\mathrm{dd}, J=8.7,1.7 \mathrm{~Hz}, 2 \mathrm{H}, 4-$ $\left.\mathrm{NO}_{2} \mathrm{ArH}\right), 8.30(\mathrm{~d}, J=1.5 \mathrm{~Hz}, 1 \mathrm{H}$, benzimidazole $\mathrm{H}), 8.02$ (dd, $J=8.6,1.7 \mathrm{~Hz}, 2 \mathrm{H}, 4-\mathrm{NO}_{2} \mathrm{ArH}$ ), 7.80-7.77 (dd, $J=8.5,1.5 \mathrm{~Hz}, 1 \mathrm{H}$, benzimidazole $\mathrm{H}), 7.74(\mathrm{~d}, J=8 \mathrm{~Hz}, 1 \mathrm{H}$, benzimidazole $\mathrm{H})$, , 4.96 (p, 1H, cyclohexyl), 4.26 (q, $J=7.1 \mathrm{~Hz}, 2 \mathrm{H}$, ester), 2.23 (m, 2H, cyclohexyl), 1.96 (d, $J=10.0$ $\mathrm{Hz}, 2 \mathrm{H}$, cyclohexyl), 1.73 (m, 2H, cyclohexyl), 1.62 (d, 1H, cyclohexyl), $1.38(\mathrm{~d}, J=10.0 \mathrm{~Hz}$, $3 \mathrm{H}$, cyclohexyl), 1.31 (t, $J=7.1 \mathrm{~Hz}, 3 \mathrm{H}$, ester); MS (Mwt=393.44), $\mathrm{m} / \mathrm{z}$ (\% rel. int.): $393.19\left(\mathrm{M}^{+}\right.$, 82\%), $394.20\left(\mathrm{M}^{+1}, 24.9 \%\right)$; Anal. Calcd for $\mathrm{C}_{22} \mathrm{H}_{23} \mathrm{~N}_{3} \mathrm{O}_{4}$ : C, 67.16; H, 5.89; N, 10.68; Found: C, 67.43; H, 6.08; N, 11.03 .

\subsubsection{General procedure to prepare Intermediates VIa-d}

To a solution of $\mathrm{LiOH} \mathrm{H}_{2} \mathrm{O}(1.17 \mathrm{~g}, 28.1$ mmol, 2 equivalents) in ethanol $(50 \%, 100 \mathrm{~mL})$, the respective ethyl ester Va-d $(14.08$ mmol, 1 equivalent) was added. The mixture was stirred under reflux for $2 \mathrm{~h}$. The resulting solution was cooled to $0{ }^{\circ} \mathrm{C}$ in an ice bath and $10 \% \mathrm{HCl}$ was added dropwise with stirring till precipitate was formed. The precipitate was filtered, washed with water, and recrystallized from diethyl ether to yield the titled compounds VIa-d as white powders.

\subsubsection{1-Cyclohexyl-2-phenyl-1H- benzo $[d]$ imidazole-5-carboxylic acid (VIa).}

The titled compound VIa was separated as white crystals (3.2 g, 71\%); m.p. $270{ }^{\circ} \mathrm{C} ;{ }^{1} \mathbf{H}$ NMR $\left(400 \mathrm{MHz}, \mathrm{DMSO}-d_{6}\right) \delta 13-12.5(\mathrm{~s}, 1 \mathrm{H}$, $\mathrm{COOH} \mathrm{D}_{2} \mathrm{O}$ exchangeable ) $8.26(\mathrm{~d}, J=1.5 \mathrm{~Hz}$, $1 \mathrm{H}$, benzimidazole $\mathrm{H}$ ), 7.97 (dd, $J=8.7,1.5 \mathrm{~Hz}$, $1 \mathrm{H}$, benzimidazole $\mathrm{H}), 7.88(\mathrm{dd}, J=8.5,1.7 \mathrm{~Hz}$, $2 \mathrm{H}, \mathrm{ArH}), 7.67$ (d, $J=8 \mathrm{~Hz}, 1 \mathrm{H}$, benzimidazole H), 7.61 (d, $J=3.7 \mathrm{~Hz}, 3 \mathrm{H}, \mathrm{ArH}), 4.27$ (q, $J=8.5$ $\mathrm{Hz}, \quad 1 \mathrm{H}$, cyclohexyl), 2.35-2.20 (m, 2H, cyclohexyl), 1.95-1.88 (m, 2H, cyclohexyl), 1.84 $(\mathrm{m}, 2 \mathrm{H}$, cyclohexyl), $1.64(\mathrm{~d}, J=12.5 \mathrm{~Hz}, 1 \mathrm{H}$, cyclohexyl), 1.32-1.11 (m, 3H, cyclohexyl); FTIR (U max, $\left.\mathbf{c m}^{-1}\right)$ : 3449-2980 (OH carboxylic), 3010 ( $\mathrm{CH}$ aromatic), 2936 ( $\mathrm{CH}$ aliphatic), 1686 $(\mathrm{C}=\mathrm{O}$ acid $)$; $\mathbf{M S}(\mathrm{Mwt}=320.38), \mathrm{m} / \mathrm{z}$ (\% rel. int. $)$ : $320.15\left(\mathrm{M}^{+}, 92 \%\right), 321.16\left(\mathrm{M}^{+1}, 25.3 \%\right)$; Anal. Calcd for $\mathrm{C}_{20} \mathrm{H}_{20} \mathrm{~N}_{2} \mathrm{O}_{2}$ : C, 74.98; H, 6.29; N, 8.74; Found: C, 75.11; H, 6.42; N, 9.02.

\subsubsection{1-Cyclohexyl-2-(4-methoxyphenyl)-1H- benzo $[d]$ imidazole-5-carboxylic acid (VIb)}

The titled compound VIb was separated as white crystals (3.3 g, 72.74\%); m.p. $298{ }^{\circ} \mathrm{C} ;{ }^{1} \mathbf{H}$ NMR $\left(400 \mathrm{MHz}, \mathrm{DMSO}-d_{6}\right) \delta 12.76(\mathrm{~s}, 1 \mathrm{H}$, $\mathrm{COOH} \mathrm{D}_{2} \mathrm{O}$ exchangeable), $8.24(\mathrm{~d}, J=1.5 \mathrm{~Hz}$, $1 \mathrm{H}$, benzimidazole $\mathrm{H}), 7.90(\mathrm{dd}, J=8.7,1.5 \mathrm{~Hz}$, $1 \mathrm{H}$, benzimidazole $\mathrm{H}), 7.82(\mathrm{dd}, J=8.6,1.7 \mathrm{~Hz}$, 2H, 4-OMe ArH), 7.60 (d, $J=8 \mathrm{~Hz}, 1 \mathrm{H}$, benzimidazole $\mathrm{H}$ ), 7.14 (dd, $J=8.6,1.7 \mathrm{~Hz}, 2 \mathrm{H}$, 4-OMe ArH), 4.29 (q, $J=8.5 \mathrm{~Hz}, 1 \mathrm{H}$, cyclohexyl), 3.86 (s, 3H, methoxy) 2.27 (m, $2 \mathrm{H}$, 
cyclohexyl), 1.97-1.78 (m, 4H, cyclohexyl), 1.63-1.58 (d, 1H, cyclohexyl), 1.29 (d, 3H, cyclohexyl); MS (Mwt= 350.41), $\mathrm{m} / \mathrm{z}$ (\% rel. int.): $350.22\left(\mathrm{M}^{+}, 87 \%\right), 351.19\left(\mathrm{M}^{+1}, 23.7 \%\right)$; Anal. Calcd for $\mathrm{C}_{21} \mathrm{H}_{22} \mathrm{~N}_{2} \mathrm{O}_{3}$ : C, 71.98; $\mathrm{H}, 6.33$; N, 7.99; Found: C, 72.16; H, 6.52; N, 8.22.

\subsubsection{1-Cyclohexyl-2-(2-methoxyphenyl)-1H- benzo $[d]$ imidazole-5-carboxylic acid (VIc)}

The titled compound VIc was separated as white crystals (3.1 g, 68.33\%); m.p. 292-293 ${ }^{\circ} \mathrm{C} ;{ }^{1} \mathbf{H}$ NMR (400 MHz, DMSO-d $\left.d_{6}\right) \delta 12.84$ (s, $1 \mathrm{H}, \mathrm{COOH} \mathrm{D}_{2} \mathrm{O}$ exchangeable), 8.23 (d, $J=1.5$ $\mathrm{Hz}, 1 \mathrm{H}$, benzimidazole $\mathrm{H}), 7.92(\mathrm{dd}, J=8.8,1.5$ $\mathrm{Hz}, 1 \mathrm{H}$, benzimidazole $\mathrm{H}), 7.86(\mathrm{~d}, J=8.9 \mathrm{~Hz}$, 1H, 2-OMe ArH), $7.63-7.55$ (d, J= $8 \mathrm{~Hz}, 1 \mathrm{H}$, benzimidazole $\mathrm{H}), 7.46(\mathrm{~d}, J=7.3 \mathrm{~Hz}, 1 \mathrm{H}, 2-$ OMe ArH), 7.24 (d, J= 8.4 Hz, 1H, 2-OMe ArH), 7.14 (t, $J=7.6 \mathrm{~Hz}, 1 \mathrm{H}, 2-\mathrm{OMe} A r H), 4.37$ (q, 1H, cyclohexyl), 3.81 (s, 3H, methoxy), $2.29-2.06$ (m, 2H, cyclohexyl), $1.82(\mathrm{~m}, 4 \mathrm{H}$, cyclohexyl), 1.62 (d, $J=12.4 \mathrm{~Hz}, 1 \mathrm{H}$, cyclohexyl), 1.21 (m, $3 \mathrm{H}$, cyclohexyl); MS $(\mathrm{Mwt}=350.41), \mathrm{m} / \mathrm{z}(\% \mathrm{rel}$. int.): $350.16\left(\mathrm{M}^{+}, 84 \%\right), 351.17\left(\mathrm{M}^{+1}, 23.1 \%\right)$; Anal. Calcd for $\mathrm{C}_{21} \mathrm{H}_{22} \mathrm{~N}_{2} \mathrm{O}_{3}$ : C, 71.98; $\mathrm{H}, 6.33$; N, 7.99; Found: C, 72.11; H, 6.41; N, 8.09.

\subsubsection{1-Cyclohexyl-2-(4-hydroxyphenyl)-1H- benzo $[d]$ imidazole-5-carboxylic acid (VId)}

The titled compound VId was separated as white crystals (3 g, 66.3\%); m.p. $340{ }^{\circ} \mathrm{C}$; ${ }^{1}$ HNMR (400 MHz, DMSO- $d_{6}$ ) $\delta 12.56(\mathrm{~s}, 1 \mathrm{H}$, $\mathrm{COOH} \mathrm{D}_{2} \mathrm{O}$ exchangeable), $10.00(\mathrm{~s}, 1 \mathrm{H}, \mathrm{OH}$ $\mathrm{D}_{2} \mathrm{O}$ exchangeable), $8.21(\mathrm{~d}, J=1.5 \mathrm{~Hz} 1 \mathrm{H}$, benzimidazole $\mathrm{H}$ ), 8.11 (dd, $J=8.7,2.8 \mathrm{~Hz}, 2 \mathrm{H}$, 4-OH ArH), 7.91 (dd, $J=8.6,1.5 \mathrm{~Hz}, 1 \mathrm{H}$, benzimidazole $\mathrm{H}), 7.85(\mathrm{dd}, J=8.8,2.8 \mathrm{~Hz}, 2 \mathrm{H}$, 4-OH ArH), 7.56-7.51 (d, $J=8 \mathrm{~Hz} 1 \mathrm{H}$, benzimidazole $\mathrm{H}$ ), 4.27 (q, 1H, cyclohexyl) 2.39 - 2.21 (m, 2H, cyclohexyl), 1.9-1.79 (m, 4H, cyclohexyl), $1.69-1.62(\mathrm{~d}, J=12.5 \mathrm{~Hz}, 1 \mathrm{H}$, cyclohexyl), 1.25 (m, 3H, cyclohexyl); MS $(\mathrm{Mwt}=336.38), \mathrm{m} / \mathrm{z}$ (\% rel. int.): $336.16\left(\mathrm{M}^{+}, 88\right.$
\%), $337.17\left(\mathrm{M}^{+1}, 22.9 \%\right)$; Anal. Calcd for $\mathrm{C}_{20} \mathrm{H}_{20} \mathrm{~N}_{2} \mathrm{O}_{3}$ : C, 71.41; H, 5.99; N, 8.33; Found: C, 71.91; H, 6.22; N, 8.59.

\subsubsection{1-Cyclohexyl-2-(4-nitrophenyl)-1H- benzo[d]imidazole-5-carboxylic acid (VIe)}

Yield: $47.38 \%$ To a solution of $\mathrm{LiOH}_{2} \mathrm{H}_{2} \mathrm{O}$ $(0.1 \mathrm{~g}, 2.53 \mathrm{mmol}, 2$ equivalents) in methanol $(66 \%, 100 \mathrm{~mL})$, the respective ethyl ester Ve $(0.5$ $\mathrm{g}, 1.26 \mathrm{mmol}, 1$ equivalent) was added. The mixture was heated under reflux for $24 \mathrm{~h}$. The resulting solution was cooled to $0{ }^{\circ} \mathrm{C}$ in ice bath and anhydrous glacial acetic acid was added drop wise with stirring then poured on ice with vigorous stirring till precipitate was formed. The precipitate was filtered, washed with water and crystallized from diethyl ether to yield the titled compound VIe as red powder. ${ }^{1} \mathbf{H}$ NMR (400 $\mathrm{MHz}$, DMSO- $\left.d_{6}\right) \delta 12.8\left(\mathrm{~s}, 1 \mathrm{H}, \mathrm{COOH} \mathrm{D}_{2} \mathrm{O}\right.$ exchangeable), $8.36(\mathrm{dd}, J=8.7,1.7 \mathrm{~Hz}, 2 \mathrm{H}, 4$ $\left.\mathrm{NO}_{2} \mathrm{ArH}\right), 8.30(\mathrm{~d}, J=1.5 \mathrm{~Hz}, 1 \mathrm{H}$, benzimidazole $\mathrm{H}), 8.02\left(\mathrm{~d}, J=8.7,1.7 \mathrm{~Hz}, 2 \mathrm{H}, 4-\mathrm{NO}_{2} \mathrm{ArH}\right), 7.80$ - $7.77(\mathrm{dd}, J=8.5,1.5 \mathrm{~Hz}, 1 \mathrm{H}$, benzimidazole $\mathrm{H})$, 7.74 (d, $J=8 \mathrm{~Hz}, 1 \mathrm{H}$, benzimidazole $\mathrm{H}$ ), 4.96 (p, $1 \mathrm{H}$, cyclohexyl), 2.23 (m, 2H, cyclohexyl), 1.96 (d, J= 10.0 Hz, 2H, cyclohexyl), $1.73(\mathrm{~m}, 2 \mathrm{H}$, cyclohexyl), 1.62 (d, 1H, cyclohexyl), 1.38 (d, J= $10.0 \mathrm{~Hz}, 3 \mathrm{H}$, cyclohexyl); MS (Mwt = 365.38), $\mathrm{m} / \mathrm{z}$ (\% rel. int.): $365.16\left(\mathrm{M}^{+}, 71 \%\right), 366.17\left(\mathrm{M}^{+1}\right.$, $14.1 \%$ ); Anal. Calcd for $\mathrm{C}_{20} \mathrm{H}_{19} \mathrm{~N}_{3} \mathrm{O}_{4}$ : C, 65.74; H, 5.24; N, 11.50; Found: C, 65.86; H, 5.39; N, 11.62 .

\subsubsection{General procedure to prepare compounds (VIIa-x)}

A suspension of the appropriate acid derivative VIa-e (3.14 $\mathrm{mmol}, 1$ equivalent) in dry DCM $(15 \mathrm{~mL})$ was cooled to $0{ }^{\circ} \mathrm{C}$ in an ice bath and thionyl chloride ( $5 \mathrm{~mL}, 4$ equivalent) was added dropwise with stirring, the reaction mixture was stirred under reflux for 2-4 h. The solvent was then evaporated under vacuum giving brownish solid of the respective acid 
chloride that was used directly without further purification.

To a stirring solution of the appropriate acid chloride ( $1 \mathrm{mmol}, 1$ equivalent) in dry DCM (20 $\mathrm{mL})$ at $0{ }^{\circ} \mathrm{C}$, a solution of appropriate amine (4.39 mmol, 1.4 equivalent) (cyclohexylamine, aniline, benzylamine, 2-methyl-4-nitro aniline, 3,4-dichloro aniline, 2-phenylethylamine, isobutyl amine, 4-fluoro aniline, 3-chloro aniline, and butylamine), respectively, for compounds (VIIa-j) and cyclohexylamine, aniline, benzylamine, 2-methyl-4-nitro aniline, isobutyl amine, and cyclopropyl amine, respectively, for compounds (VIIk-p) and aniline, benzylamine, 2-methyl-4-nitro aniline, 3,4-dichloro aniline, 2-phenylethylamine), respectively, for compounds (VIIq-u) and cyclohexylamine, aniline, and benzylamine, for compounds (VIIv-x) in dry DCM (2 mL) and 4 drops of TEA was added dropwise. Then the ice bath was removed, and the reaction is left to stir at room temperature for $48-72 \mathrm{~h}$. The reaction mixture was poured to ice $/ \mathrm{H}_{2} \mathrm{O} / 10 \% \mathrm{HCl}$ with vigorous stirring where precipitate was formed. The precipitate was filtered and purified using flash chromatography (the system used: hexane: ethyl acetate $=6: 1$ then changed to $4: 1$ and finally 2:1) to give the titled compounds (VIIa-u). As for compounds (VIIv-x), the flash chromatography system used was hexane: ethyl acetate $=9: 1$ then changed to $8: 1$ and finally $6: 1$.

\subsubsection{N,1-Dicyclohexyl-2-phenyl-1H- benzo $[d]$ imidazole-5-carboxamide (VIIa)}

The titled compound VIIa is white powder (0.3 g, 76.71\%); m.p. 222-224 ${ }^{\circ} \mathrm{C}$ (charring); ${ }^{1} \mathbf{H}$ NMR (400 MHz, DMSO- $\left.d_{6}\right) \delta 8.25(\mathrm{~s}, 1 \mathrm{H}, \mathrm{NH}$ $\mathrm{D}_{2} \mathrm{O}$ exchangeable $), 8.20(\mathrm{~d}, J=1.5 \mathrm{~Hz}, 1 \mathrm{H}$, benzimidzole $\mathrm{H}), 7.89(\mathrm{dd}, J=8.6,1.5 \mathrm{~Hz}, 1 \mathrm{H}$, benzimidazole $\mathrm{H}), 7.80(\mathrm{dd}, J=8.7,1.7 \mathrm{~Hz}, 1 \mathrm{H}$, ArH), 7.70-7.63 (d, $J=8 \mathrm{~Hz}, 1 \mathrm{H}$, benzimidazole $\mathrm{H})$, 7.61-7.58 (m, 4H, $\operatorname{ArH}), 4.27(\mathrm{p}, 1 \mathrm{H}$, cyclohexyl), 3.81 (q, $J=7.6 \mathrm{~Hz}, 1 \mathrm{H}$, cyclohexyl),
2.35-2.20 (m, 2H, cyclohexyl), $1.95-1.80(\mathrm{~m}$, $6 \mathrm{H}$, cyclohexyl), 1.75 (dd, $J=9.5,3.8 \mathrm{~Hz}, 2 \mathrm{H}$, cyclohexyl), 1.65-1.58 (m, 2H, cyclohexyl), 1.42 - 1.13 (m, 8H, cyclohexyl); MS (Mwt= 401.5), $\mathrm{m} / z$ (\% rel. int.): 401.25 ( $\left.\mathrm{M}^{+}, 79 \%\right), 402.25\left(\mathrm{M}^{+1}\right.$, $28.51 \%$ ); Anal. Calcd for $\mathrm{C}_{26} \mathrm{H}_{31} \mathrm{~N}_{3} \mathrm{O}$ : C, 77.77; H, 7.78; N, 10.46; Found: C, 77.91; H, 7.89; N, 10.58 .

\subsubsection{1-Cyclohexyl-N,2-diphenyl-1H- benzo $[d]$ imidazole-5-carboxamide (VIIb)}

The titled compound VIIb is white powder (0.25 g, 64.9\%); m.p. $100-102^{\circ} \mathrm{C} ;{ }^{1} \mathbf{H}$ NMR (400 $\mathrm{MHz}$, DMSO-d $\left.d_{6}\right) \delta 10.25\left(\mathrm{~s}, 1 \mathrm{H}, \quad \mathrm{NH} \quad \mathrm{D}_{2} \mathrm{O}\right.$ exchangeable), 8.41 (d, $J=1.5 \mathrm{~Hz}, 1 \mathrm{H}$, benzimidazole $\mathrm{H}), 8.00(\mathrm{dd}, J=8.6,1.5 \mathrm{~Hz}, 1 \mathrm{H}$, benzimidazole $\mathrm{H}), 7.91(\mathrm{~d}, J=8 \mathrm{~Hz}, 1 \mathrm{H}$, benzimidazole $\mathrm{H}), 7.84(\mathrm{~d}, J=8.0 \mathrm{~Hz}, 2 \mathrm{H}, \mathrm{ArH})$, 7.69 (dd, $J=6.6,3.1 \mathrm{~Hz}, 2 \mathrm{H}, \mathrm{NH}-\mathrm{Ar} \underline{\mathrm{H}}), 7.62(\mathrm{q}$, $J=2.9 \mathrm{~Hz}, 3 \mathrm{H}, \mathrm{ArH}), 7.37$ (t, $J=7.7 \mathrm{~Hz}, 2 \mathrm{H}$, NH-Ar $\underline{H}), 7.11(\mathrm{t}, J=7.5 \mathrm{~Hz}, 1 \mathrm{H}, \mathrm{NH}-\mathrm{Ar} \underline{\mathrm{H}})$, 4.37-4.23 (m, 1H, cyclohexyl), 2.37-2.23 (m, 2H, cyclohexyl), 2.02-1.79 (m, 4H, cyclohexyl), 1.65 (d, $J=12.3 \mathrm{~Hz}, 1 \mathrm{H}$, cyclohexyl), $1.33-1.19$ (m, 3H, cyclohexyl); MS $(\mathrm{Mwt}=395.5), \mathrm{m} / \mathrm{z}(\%$ rel. int.): $395.2\left(\mathrm{M}^{+}, 81 \%\right), 396.2\left(\mathrm{M}^{+1}, 29.3 \%\right)$; Anal. Calcd for $\mathrm{C}_{26} \mathrm{H}_{25} \mathrm{~N}_{3} \mathrm{O}: \mathrm{C}, 78.96 ; \mathrm{H}, 6.37$; N, 10.62; Found: C, 79.12; H, 6.45; N, 10.87.

\subsubsection{N-Benzyl-1-cyclohexyl-2-phenyl-1H- benzo $[d]$ imidazole-5-carboxamide (VIIc)}

The titled compound VIIc is white powder (0.29 g, 72.71\%); m.p. 184-186 ${ }^{\circ} \mathrm{C} ;{ }^{1} \mathbf{H}$ NMR $\left(400 \mathrm{MHz}, \mathrm{DMSO}-d_{6}\right) \delta 9.08\left(\mathrm{~s}, 1 \mathrm{H}, \mathrm{NH} \mathrm{D_{2 } \mathrm { O }}\right.$ exchangeable $), 8.29(\mathrm{~d}, \quad J=1.5 \mathrm{~Hz}, 1 \mathrm{H}$, benzimidazole $\mathrm{H}), 7.94(\mathrm{dd}, J=8.7,1.5 \mathrm{~Hz}, 1 \mathrm{H}$, benzimidazole $\mathrm{H}), 7.85(\mathrm{~d}, J=8 \mathrm{~Hz}, 1 \mathrm{H}$, benzimidazole $\mathrm{H}$ ), 7.71-7.55 ( $\mathrm{m}, 5 \mathrm{H}, \mathrm{ArH}), 7.35$ (d, $J=4.6 \mathrm{~Hz}, 4 \mathrm{H}, \mathrm{ArH}), 7.26(\mathrm{~d}, J=7.2 \mathrm{~Hz}, 1 \mathrm{H}$, ArH), $4.53(\mathrm{~d}, J=5.6 \mathrm{~Hz}, 2 \mathrm{H}$, benzyl), $4.37-$ 4.15 (m, 1H, cyclohexyl), 2.29 (q, $J=12.3 \mathrm{~Hz}$, $2 \mathrm{H}$, cyclohexyl), 1.98-1.75 (m, 4H, cyclohexyl), $1.63(\mathrm{~d}, J=12.0 \mathrm{~Hz}, 1 \mathrm{H}$, cyclohexyl), 1.32 (dd, 
$J=52.6,11.6 \mathrm{~Hz}, 3 \mathrm{H}$, cyclohexyl); $\mathrm{MS}(\mathrm{Mwt}=$ 409.52), $\mathrm{m} / \mathrm{z}$ (\% rel. int.): $409.22\left(\mathrm{M}^{+}, 94 \%\right)$, $410.22\left(\mathrm{M}^{+1}, 29.6 \%\right)$; Anal. Calcd for $\mathrm{C}_{27} \mathrm{H}_{27} \mathrm{~N}_{3} \mathrm{O}$ : C, 79.19; H, 6.65; N, 10.26; Found: C, 79.05; H, 6.81; N, 10.49 .

\subsubsection{1-Cyclohexyl-N-(2-methyl-4- nitrophenyl)-2-phenyl-1H-benzo $[d]$ imidazole- 5-carboxamide (VIId)}

The titled compound VIId is white powder (0.3 g, 67.77\%); m.p. 124-126 ${ }^{\circ} \mathrm{C} ;{ }^{1} \mathbf{H}$ NMR (400 MHz, DMSO- $\left.d_{6}\right) \delta 10.09\left(\mathrm{~s}, 1 \mathrm{H}, \mathrm{NH} \mathrm{D_{2 } \mathrm { O }}\right.$ exchangeable $), 8.43(\mathrm{~d}, J=1.5 \mathrm{~Hz}, 1 \mathrm{H}$, benzimidazole $\mathrm{H}), \quad 8.21 \quad(\mathrm{~s}, \quad 1 \mathrm{H}, \quad 2-\mathrm{Me}-4-$ $\left.\mathrm{NO}_{2} \mathrm{ArH}\right), 8.14$ (d, J= $8.9 \mathrm{~Hz}, 1 \mathrm{H}, 2-\mathrm{Me}-4-$ $\left.\mathrm{NO}_{2} \mathrm{ArH}\right), 8.03$ (d, $J=8.7 \mathrm{~Hz}, 1 \mathrm{H}, 2-\mathrm{Me}-4-$ $\mathrm{NO}_{2} \mathrm{ArH}$ ), 7.92 (dd, $J=8.6,1.8 \mathrm{~Hz}, 1 \mathrm{H}$, benzimidazole $\mathrm{H}), 7.87(\mathrm{~d}, J=8 \mathrm{~Hz}, 1 \mathrm{H}$, benzimidazole $\mathrm{H}$ ), 7.72-7.67 (m, 2H, ArH), 7.64-7.60 (m, 3H, ArH), 4.31 (p, J=5.8 Hz, 1H, cyclohexyl), 2.45 (s, 3H, methyl), 2.31 (dt, $J=$ $16.8,7.3 \mathrm{~Hz}, 2 \mathrm{H}$, cyclohexyl), $2.00-1.91$ (m, $2 \mathrm{H}$, cyclohexyl), $1.87(\mathrm{~d}, J=13.1 \mathrm{~Hz}, 2 \mathrm{H}$, cyclohexyl), 1.66 (d, $J=12.3 \mathrm{~Hz}, 1 \mathrm{H}$, cyclohexyl), 1.34-1.22 (m, 2H, cyclohexyl), 0.86 (td, $J=8.4,7.7,2.7 \mathrm{~Hz}, 1 \mathrm{H}$, cyclohexyl). $;{ }^{13} \mathbf{C}$ NMR $\left(101 \mathrm{MHz}, \mathrm{DMSO}-d_{6}\right) \delta 166.3,155.5$, $144.5,143.3,140.4,137.2,134.3,130.8,130.5$, $129.9,129.3,127.9,126.1,125.9,122.7,122.0$, 120.0, 113.5, 57.3, 31.0, 26.0, 24.8, 18.4; MS $(\mathrm{Mwt}=454.5), \mathrm{m} / \mathrm{z}$ (\%rel. int.): $455.2 \quad\left(\mathrm{M}^{+}\right.$, $36.8 \%)$, 454.21 (100\%); Anal. Calcd for $\mathrm{C}_{27} \mathrm{H}_{26} \mathrm{~N}_{4} \mathrm{O}_{3}$ : C, 71.35; H, 5.77; N, 12.33; Found: C, 71.18; H, 5.89; N, 12.6.

\subsubsection{1-Cyclohexyl-N-(3,4-dichlorophenyl)- 2-phenyl-1H-benzo $[d]$ imidazole-5carboxamide (VIIe)}

The titled compound VIIe is white powder (0.4 g, 88.44\%); m.p. 136-138 ${ }^{\circ} \mathrm{C}$ (charring); ${ }^{1} \mathbf{H}$ NMR $\left(400 \mathrm{MHz}, \mathrm{DMSO}-d_{6}\right) \delta 10.51(\mathrm{~s}, 1 \mathrm{H}, \mathrm{NH}$ $\mathrm{D}_{2} \mathrm{O}$ exchangeable), $8.42(\mathrm{~d}, J=1.6 \mathrm{~Hz}, 1 \mathrm{H}$, ArH), 8.23 (d, $J=1.5 \mathrm{~Hz}, 1 \mathrm{H}$, benzimidazole $\mathrm{H}$ ), $8.03(\mathrm{~d}, J=8.6 \mathrm{~Hz}, 1 \mathrm{H}, \mathrm{ArH}), 7.90$ (dd, $J=8.5$, $1.5 \mathrm{~Hz}, 1 \mathrm{H}$, benzimidazole $\mathrm{H}$ ), $7.83(\mathrm{dd}, J=9.0$, $2.5 \mathrm{~Hz}, 1 \mathrm{H}, \mathrm{ArH}), 7.71-7.68(\mathrm{~d}, J=8 \mathrm{~Hz}, 1 \mathrm{H}$, benzimidazole $\mathrm{H}), 7.64(\mathrm{~s}, 1 \mathrm{H}, \mathrm{ArH}), 7.62(\mathrm{~d}, J=$ $4.0 \mathrm{~Hz}, \quad 4 \mathrm{H}, \quad \operatorname{ArH}), \quad 4.46-4.12(\mathrm{~m}, 1 \mathrm{H}$, cyclohexyl), $2.31(\mathrm{td}, J=13.7,10.0 \mathrm{~Hz}, 2 \mathrm{H}$, cyclohexyl), 1.98 - 1.91 (m, 2H, cyclohexyl), 1.9 -1.81 (m, 2H, cyclohexyl), 1.74-1.54 (m, 1H, cyclohexyl), 1.53-1.19 (m, 3H, cyclohexyl); ${ }^{13} \mathbf{C}$ NMR (101 MHz, DMSO- $\left.d_{6}\right) \delta 166.5,155.5$, $143.2,140.1,136.6,131.3,130.9,130.8,130.5$, $129.9,129.3,128.2,125.3,122.6,121.8,120.7$, $119.8,113.4,57.3,31.0,26.0,24.8$; $\mathbf{M S}(\mathrm{Mwt}=$ 464.39), $\mathrm{m} / z$ (\% rel. int.): $465.08\left(\mathrm{M}^{+}, 30.51 \%\right)$, 303.15 (100\%); Anal. Calcd for $\mathrm{C}_{26} \mathrm{H}_{23} \mathrm{Cl}_{2} \mathrm{~N}_{3} \mathrm{O}$ : C, 67.25; H, 4.99; N, 9.05; Found: C, 67.49; H, $5.12 ; \mathrm{N}, 9.21$.

\subsubsection{1-Cyclohexyl-N-phenethyl-2-phenyl- 1H-benzo[d] imidazole-5-carboxamide (VIIf)}

The titled compound VIIf is white powder (0.28 g, 67.88\%); m.p. 176-178 ${ }^{\circ} \mathrm{C} ;{ }^{1} \mathbf{H}$ NMR $\left(400 \mathrm{MHz}, \mathrm{DMSO}-d_{6}\right) \delta 8.60\left(\mathrm{~s}, 1 \mathrm{H}, \mathrm{NH} \mathrm{D_{2 } \mathrm { O }}\right.$ exchangeable), $8.22(\mathrm{~d}, J=1.5 \mathrm{~Hz}, 1 \mathrm{H}$, benzimidazole $\mathrm{H}), 7.92(\mathrm{dd}, J=8.6,1.5 \mathrm{~Hz}, 1 \mathrm{H}$, benzimidazole $\mathrm{H}), 7.79(\mathrm{~d}, J=8.5 \mathrm{~Hz}, 1 \mathrm{H}, \mathrm{ArH})$, $7.68-7.65$ (d, $J=8 \mathrm{~Hz}$, benzimidazole $\mathrm{H}), 7.62-$ 7.59 (m, 4H, ArH) 7.39-7.23 (m, 4H, ArH), 7.21 (t, $J=7.1 \mathrm{~Hz}, 1 \mathrm{H}, \mathrm{ArH}), 4.27$ (p, $J=6.5 \mathrm{~Hz}, 1 \mathrm{H}$, cyclohexyl), 3.53 (q, $J=6.8 \mathrm{~Hz}, 2 \mathrm{H}$, $\left.\mathrm{NHCH}_{2} \mathrm{CH}_{2}\right), 2.89$ (t, $J=7.4 \mathrm{~Hz}, \quad 2 \mathrm{H}$, $\left.\mathrm{NHCH}_{2} \underline{\mathrm{CH}}_{2}\right), 2.37-2.21$ (m, 2H, cyclohexyl), $1.97-1.80$ (m, 4H, cyclohexyl), 1.63 (d, $J=12.4$ $\mathrm{Hz}, 1 \mathrm{H}$, cyclohexyl) 1.25 (d, J=13.5 Hz, 3H, cyclohexyl); MS (Mwt= 423.55), $\mathrm{m} / \mathrm{z}$ (\% rel. int.): $423.23\left(\mathrm{M}^{+}, 76 \%\right), 424.23\left(\mathrm{M}^{+1}, 31.4 \%\right)$; Anal. Calcd for $\mathrm{C}_{28} \mathrm{H}_{29} \mathrm{~N}_{3} \mathrm{O}: \mathrm{C}, 79.4 ; \mathrm{H}, 6.9 ; \mathrm{N}$, 9.92; Found: C, 79.63; H, 7.04; N, 10.13.

\subsubsection{1-Cyclohexyl-N-isobutyl-2-phenyl-1H- benzo $[d]$ imidazole-5-carboxamide (VIIg)}

The titled compound VIIg is white powder (0.27 g, 73.83\%); m.p. $118-120{ }^{\circ} \mathrm{C} ;{ }^{1} \mathbf{H}$ NMR 
$\left(400 \mathrm{MHz}, \mathrm{DMSO}-d_{6}\right) \delta(\mathrm{ppm}) 8.48(\mathrm{t}, J=5.8 \mathrm{~Hz}$, $1 \mathrm{H}, \mathrm{NH} \mathrm{D}_{2} \mathrm{O}$ exchangeable), $8.24(\mathrm{~d}, J=1.5 \mathrm{~Hz}$, $1 \mathrm{H}$, benzimidazole $\mathrm{H}), 7.91(\mathrm{dd}, J=8.6,1.5 \mathrm{~Hz}$, $1 \mathrm{H}$, benzimidazole $\mathrm{H}), 7.80(\mathrm{dd}, J=8.6,1.7 \mathrm{~Hz}$, $1 \mathrm{H}, \quad \mathrm{ArH}), \quad 7.69-7.65(\mathrm{~d}, \quad J=8 \mathrm{~Hz}, 1 \mathrm{H}$, benzimidazole $\mathrm{H}), 7.62-7.55(\mathrm{~m}, 4 \mathrm{H}, \mathrm{ArH})$, 4.27 (p, $J=6.8 \mathrm{~Hz}, 1 \mathrm{H}$, cyclohexyl), 3.13 (d, $J=$ $7.0 \mathrm{~Hz}, 2 \mathrm{H}$, isobutyl), 2.29 (q, 2H, cyclohexyl) $2.27(\mathrm{~m}, 1 \mathrm{H}$, isobutyl), 1.96-1.81 (m, 4H, cyclohexyl), 1.64 (d, $J=12.4 \mathrm{~Hz}, 1 \mathrm{H}$, cyclohexyl), 1.46-1.32 (m, 1H, cyclohexyl), 1.27 (ddd, $J=16.8,8.5,3.5 \mathrm{~Hz}, 2 \mathrm{H}$, cyclohexyl), 0.91 (d, $J=6.7 \mathrm{~Hz}, 6 \mathrm{H}$, isobutyl); MS (Mwt $=375.51$ ), $m / z$ (\% rel. int.): $375.23\left(\mathrm{M}^{+}, 79 \%\right), 376.23\left(\mathrm{M}^{+1}\right.$, 27.1\%); Anal. Calcd for $\mathrm{C}_{24} \mathrm{H}_{29} \mathrm{~N}_{3} \mathrm{O}: \mathrm{C}, 76.76 ; \mathrm{H}$, 7.78; N, 11.19; Found: C, 76.95; H, 7.90; N, 11.34 .

2.1.5.8. 1-Cyclohexyl-N-(4-fluorophenyl)-2phenyl-1H-benzo $[d]$ imidazole-5-carboxamide (VIIh)

The titled compound VIIh is white powder (0.3 g, 74.5\%); m.p. 112-114 ${ }^{\circ} \mathrm{C} ;{ }^{1} \mathbf{H}$ NMR (400 $\left.\mathrm{MHz}, \mathrm{DMSO}-d_{6}\right) \delta(\mathrm{ppm}) 9.06\left(\mathrm{~s}, 1 \mathrm{H}, \mathrm{NH} \mathrm{D} \mathrm{D}_{2} \mathrm{O}\right.$ exchangeable $), 8.26(\mathrm{~d}, J=1.5 \mathrm{~Hz}, 1 \mathrm{H}$, benzimidazole $\mathrm{H}), 7.91(\mathrm{dd}, J=8.6,1.5 \mathrm{~Hz}, 1 \mathrm{H}$, benzimidazole $\mathrm{H}), 7.82(\mathrm{~d}, J=8 \mathrm{~Hz}, 1 \mathrm{H}$, benzimidazole $\mathrm{H}), 7.61(\mathrm{~d}, J=8.7 \mathrm{~Hz}, 2 \mathrm{H}, 4-\mathrm{F}$ ArH), 7.37-7.33 (m, 4H, ArH), 7.28-7.23 (m, $1 \mathrm{H}, \operatorname{ArH}), 7.15(\mathrm{~d}, J=8.7 \mathrm{~Hz}, 2 \mathrm{H}, 4-\mathrm{F} \mathrm{ArH})$, $4.33-4.24$ (m, 1H, cyclohexyl), $2.37-2.23(\mathrm{~m}$, $2 \mathrm{H}$, cyclohexyl), $1.88(\mathrm{t}, J=15.7 \mathrm{~Hz}, 4 \mathrm{H}$, cyclohexyl), 1.65 (d, $J=12.3 \mathrm{~Hz}, 1 \mathrm{H}$, cyclohexyl), 1.46-1.19 (m, 3H, cyclohexyl); ${ }^{13} \mathbf{C}$ NMR (101 MHz， DMSO- $\left.d_{6}\right) \quad \delta 165.3,156.8$, $143.3,136.4,130.9,130.4,129.9,1293,128.7$, 126.8, 122.6, 122.6, 119.6, 115.7, 115.5, 113.3, 57.3, 31.1, 26.0, 24.9; MS $(\mathrm{Mwt}=413.49), \mathrm{m} / \mathrm{z}$ (\%rel. int.): $413.09\left(\mathrm{M}^{+}, 10 \%\right), 303.00$ (100\%); Anal. Calcd for $\mathrm{C}_{26} \mathrm{H}_{24} \mathrm{FN}_{3} \mathrm{O}$ : C, 75.52; $\mathrm{H}, 5.85$; N, 10.16; Found: C, 75.68; H, 5.94; N, 10.37 .

2.1.5.9. N-(3-Chlorophenyl)-1-cyclohexyl-2phenyl-1H-benzo $[d]$ imidazole-5-carboxamide
(VIIi)

The titled compound VIIi is white powder (0.32 g, 76.42\%); m.p. 114-116 ${ }^{\circ} \mathrm{C}$; ${ }^{1} \mathbf{H}$ NMR (400 MHz, DMSO- $\left.d_{6}\right) \delta(\mathrm{ppm}) 10.42(\mathrm{~s}, 1 \mathrm{H}, \mathrm{NH}$ $\mathrm{D}_{2} \mathrm{O}$ exchangeable), $8.41(\mathrm{~d}, J=1.5 \mathrm{~Hz}, 1 \mathrm{H}$, benzimidazole $\mathrm{H}), 8.04(\mathrm{~m}, 1 \mathrm{H}, \operatorname{ArH}), 8.01$ (s, 1H, 3-Cl ArH), 7.90 (dd, $J=8.6,1.6 \mathrm{~Hz}, 1 \mathrm{H}$, benzimidazole $\mathrm{H}), 7.78(\mathrm{~d}, J=8.3 \mathrm{~Hz}, 1 \mathrm{H}, 3-\mathrm{Cl}$ ArH), $7.72-7.67(\mathrm{~d}, J=8 \mathrm{~Hz} \mathrm{1H}$, benzimiazole H), $7.64-7.60$ (m, 4H, ArH), 7.40 (t, J=8.1 Hz, 1H, 3-Cl ArH), 7.16 (d, J= 8.2 Hz, 1H, 3-Cl ArH), 4.30 (p, J=6.8 Hz, 1H, cyclohexyl), $2.41-$ $2.18(\mathrm{~m}, 2 \mathrm{H}$, cyclohexyl), $1.94(\mathrm{~d}, J=11.9 \mathrm{~Hz}$, $2 \mathrm{H}$, cyclohexyl), $1.86(\mathrm{~d}, J=13.1 \mathrm{~Hz}, 2 \mathrm{H}$, cyclohexyl), 1.65 (d, $J=12.5 \mathrm{~Hz}, 1 \mathrm{H}$, cyclohexyl), 1.35-1.20 (m, 3H, cyclohexyl); MS $(\mathrm{Mwt}=429.94), \mathrm{m} / \mathrm{z}$ (\% rel. int.): $429.16\left(\mathrm{M}^{+}\right.$, 54\%), $430.16\left(\mathrm{M}^{+1}, 29.2 \%\right), 431.16\left(\mathrm{M}^{+2}\right.$, $32.3 \%$ ); Anal. Calcd for $\mathrm{C}_{26} \mathrm{H}_{24} \mathrm{ClN}_{3} \mathrm{O}: \mathrm{C}, 72.63$; H, 5.63; N, 9.77; Found: C, 72.80; H, 5.75; N, 9.89 .

\subsubsection{N-Butyl-1-cyclohexyl-2-phenyl-1H- benzo[d]imidazole-5-carboxamide (VIIj)}

The titled compound VIIj is white powder (0.26 g, 71.09\%); m.p. 88-90 C ${ }^{\circ} ;{ }^{1}$ H NMR (400 $\mathrm{MHz}, \quad$ DMSO- $\left.d_{6}\right) \quad \delta \quad 8.46 \quad\left(\mathrm{~s}, \quad 1 \mathrm{H}, \quad \mathrm{NH} \quad \mathrm{D}_{2} \mathrm{O}\right.$ exchangeable ), $8.22(\mathrm{~d}, J=1.5 \mathrm{~Hz}, 1 \mathrm{H}$, benzimidazole $\mathrm{H}), 7.91(\mathrm{dd}, J=8.6,1.5 \mathrm{~Hz}, 1 \mathrm{H}$, benzimidazole $\mathrm{H}), 7.79$ (d, $J=8.5 \mathrm{~Hz}, 1 \mathrm{H}, \mathrm{ArH})$, 7.68-7.64 (d, $J=8 \mathrm{~Hz}, 1 \mathrm{H}$, benzimidazole $\mathrm{H})$, 7.63-7.58 (m, 4H, ArH), 4.26 (p, J= $6.8 \mathrm{~Hz}, 1 \mathrm{H}$, cyclohexyl), 3.30 (d, J=6.5 Hz, 2H, butyl), 2.36$2.22(\mathrm{~m}, 2 \mathrm{H}$, cyclohexyl), 1.95-1.80 (m, 4H, cyclohexyl), 1.68-1.60 (m, 2H, butyl), 1.54 (t, $J=$ $7.4 \mathrm{~Hz}, 1 \mathrm{H}$, cyclohexyl), 1.35 (q, J= $7.1 \mathrm{~Hz}, 2 \mathrm{H}$, butyl), 1.25 (d, J=15.3 Hz, 3H, cyclohexyl), 0.92 (t, $J=7.2 \mathrm{~Hz}, 3 \mathrm{H}$, butyl); MS (Mwt=375.51), $\mathrm{m} / \mathrm{z}$ 
(\%rel. int.): $375.23\left(\mathrm{M}^{+}, 72 \%\right), 376.23\left(\mathrm{M}^{+1}\right.$, 27.1\%); Anal. Calcd for $\mathrm{C}_{24} \mathrm{H}_{29} \mathrm{~N}_{3} \mathrm{O}: \mathrm{C}, 76.76$; $\mathrm{H}$, 7.78; N, 11.19; Found: C, 76.59; H, 7.94; N, 11.32 .

\subsubsection{N,1-Dicyclohexyl-2-(4- methoxyphenyl)-1H-benzo[ $d]$ imidazole-5- carboxamide (VIIk)}

The titled compound VIIk is white powder (0.27 g, 69.93\%); m.p. 120-122 ${ }^{\circ} \mathrm{C} ;{ }^{1} \mathbf{H}$ NMR $\left(400 \mathrm{MHz}, \mathrm{DMSO}-d_{6}\right) \delta 8.21\left(\mathrm{~s}, 1 \mathrm{H}, \mathrm{NH} \mathrm{D_{2 } \mathrm { O }}\right.$ exchangeable $), 8.17(\mathrm{~d}, J=1.5 \mathrm{~Hz}, 1 \mathrm{H}$, benzimidazole $\mathrm{H}), 7.86(\mathrm{dd}, J=8.6,1.7 \mathrm{~Hz}, 2 \mathrm{H}$, 4-OMe ArH), 7.76 (dd, $J=8.5,1.7 \mathrm{~Hz}, 1 \mathrm{H}$, benzimidazole $\mathrm{H}), 7.60(\mathrm{~d}, J=8 \mathrm{~Hz}, 1 \mathrm{H}$, benzimidazole $\mathrm{H}$ ), $7.15(\mathrm{dd}, J=8.6,1.7 \mathrm{~Hz}, 2 \mathrm{H}$, 4-OMe ArH), 4.27 (p, $J=6.6 \mathrm{~Hz}, 1 \mathrm{H}$, cyclohexyl), 3.87 (s, 3H, methoxy), $3.80(\mathrm{~m}, 1 \mathrm{H}$, cyclohexyl), 2.29 (m, 2H, cyclohexyl), $1.94-$ $1.82(\mathrm{~m}, 6 \mathrm{H}$, cyclohexyl), 1.77 (d, J=9.5 Hz, 2H, cyclohexyl), 1.64 (m, 2H, cyclohexyl), 1.32 (dt, $J=25.0,12.3 \mathrm{~Hz}, 6 \mathrm{H}$, cyclohexyl), 1.13 (d, $J=$ $25.3 \mathrm{~Hz}, 2 \mathrm{H}$, cyclohexyl); ${ }^{13} \mathbf{C}$ NMR (101 MHz, DMSO- $\left.d_{6}\right) \delta 166.1,160.8,154.9,143.3,135.9$, $131.3,128.9,123.1,122.0,118.9,114.7,112.8$, 57.1, 55.8, 48.89, 33.0, 31.0, 26.0, 25.8, 25.5, 24.9; MS (Mwt= 431.57), $\mathrm{m} / \mathrm{z}$ (\%rel. int.): 431.22 $\left(\mathrm{M}^{+}, 61 \%\right), 432.22\left(\mathrm{M}^{+1}, 30.33 \%\right)$; Anal. Calcd for $\mathrm{C}_{27} \mathrm{H}_{33} \mathrm{~N}_{3} \mathrm{O}_{2}: \mathrm{C}, 75.14 ; \mathrm{H}, 7.71 ; \mathrm{N}, 9.74$; Found: C, 75.02; H, 7.8; N, 9.87

\subsubsection{1-Cyclohexyl-2-(4-methoxyphenyl)-N- phenyl-1H-benzo[ $d]$ imidazole-5-carboxamide (VIII)}

The titled compound VIII is white powder (0.3 g, 78.8 \%); m.p. $154-156{ }^{\circ} \mathrm{C} ;{ }^{1} \mathbf{H}$ NMR (400 $\mathrm{MHz}$, DMSO- $\left.d_{6}\right) \quad \delta 10.24\left(\mathrm{~s}, 1 \mathrm{H}, \quad \mathrm{NH} \quad \mathrm{D}_{2} \mathrm{O}\right.$ exchangeable $), 8.37(\mathrm{~d}, \quad J=1.5 \mathrm{~Hz}, 1 \mathrm{H}$, benzimidazole $\mathrm{H}), 7.97(\mathrm{dd}, J=8.7,1.5 \mathrm{~Hz}, 1 \mathrm{H}$, benzimidazole $\mathrm{H}), 7.88(\mathrm{~d}, J=8 \mathrm{~Hz}, 1 \mathrm{H}$, benzimidazole $\mathrm{H}), 7.82(\mathrm{dd}, J=8.6,1.7 \mathrm{~Hz}, 2 \mathrm{H}$, 4-OMe ArH ), $7.66-7.59$ (m, 2H, ArH), 7.36 (t,
$J=7.9 \mathrm{~Hz}, 2 \mathrm{H}, \mathrm{ArH}), 7.19-7.15(\mathrm{dd}, J=8.6,1.7$ $\mathrm{Hz}, 2 \mathrm{H}, 4-\mathrm{OMe} \mathrm{ArH}), 7.10$ (t, J= $7.4 \mathrm{~Hz}, 1 \mathrm{H}$, ArH), $4.31(\mathrm{~m}, 1 \mathrm{H}$, cyclohexyl), 3.87 (s, 3H, methoxy), 2.31 (q, $J=12.3 \mathrm{~Hz}, 2 \mathrm{H}$, cyclohexyl), $1.98-1.81$ (m, 4H, cyclohexyl), 1.66 (d, $J=12.2$ $\mathrm{Hz}, \quad 1 \mathrm{H}$, cyclohexyl), 1.49-1.21 (m, 3H, cyclohexyl); MS (Mwt= 425.52), $\mathrm{m} / \mathrm{z}(\% \mathrm{rel}$. int.): $425.22\left(\mathrm{M}^{+}, 78 \%\right), 426.21\left(\mathrm{M}^{+1}, 30.4 \%\right)$; Anal. Calcd for $\mathrm{C}_{27} \mathrm{H}_{27} \mathrm{~N}_{3} \mathrm{O}_{2}$ : C, 76.21; H, 6.40; N, 9.87; Found: C, 76.33; H, 6.51; N, 9.91.

\subsubsection{N-Benzyl-1-cyclohexyl-2-(4- methoxyphenyl)-1H-benzo[d $]$ imidazole-5- carboxamide (VIIm)}

The titled compound VIIm is white powder (0.29 g, 73.75\%); m.p. 184-186 ${ }^{\circ} \mathrm{C}$; ${ }^{1} \mathbf{H}$ NMR (400 MHz, DMSO- $d_{6}$ ) $\delta(\mathrm{ppm}) 9.06(\mathrm{t}, J=6.0 \mathrm{~Hz}$, $1 \mathrm{H}, \mathrm{NH} \mathrm{D}_{2} \mathrm{O}$ exchangeable $), 8.26(\mathrm{~d}, J=1.5 \mathrm{~Hz}$, $1 \mathrm{H}$, benzimidazole $\mathrm{H}), 7.91(\mathrm{dd}, J=8.6,1.5 \mathrm{~Hz}$, $1 \mathrm{H}$, benzimidazole $\mathrm{H}), 7.82(\mathrm{dd}, J=8.6,1.7 \mathrm{~Hz}$, 2H, 4-OMe ArH), 7.67-7.53 (d, J= $8 \mathrm{~Hz}, 1 \mathrm{H}$, benzimidzole $\mathrm{H}), 7.35-7.34(\mathrm{~m}, 4 \mathrm{H}, \mathrm{ArH}), 7.25$ (dq, $J=7.8,2.9 \mathrm{~Hz}, 1 \mathrm{H}, \mathrm{ArH}), 7.21-7.06$ (dd, $J=$ 8.6, $1.7 \mathrm{~Hz}, 2 \mathrm{H}, 4-\mathrm{OMe} \mathrm{ArH}), 4.53$ (d, $J=5.9$ $\mathrm{Hz}, 2 \mathrm{H}$, benzyl), 4.28 (p, J= $6.6 \mathrm{~Hz}, 1 \mathrm{H}$, cyclohexyl), 3.87 (s, 3H, methoxy), $2.38-2.22$ (m, 2H, cyclohexyl), $1.88(\mathrm{t}, J=15.7 \mathrm{~Hz}, 4 \mathrm{H}$, cyclohexyl), 1.65 (d, $J=12.3 \mathrm{~Hz}, 1 \mathrm{H}$, cyclohexyl), 1.46-1.17 (m, 3H, cyclohexyl); MS $(\mathrm{Mwt}=439.55), \mathrm{m} / \mathrm{z}$ (\% rel. int.): $439.23\left(\mathbf{M}^{+}\right.$, $77 \%), 440.23\left(\mathrm{M}^{+1}, 30.7 \%\right)$; Anal. Calcd for $\mathrm{C}_{28} \mathrm{H}_{29} \mathrm{~N}_{3} \mathrm{O}_{2}: \mathrm{C}, 76.51 ; \mathrm{H}, 6.65$; N, 9.56; Found: C, 76.49; H, 6.78; N, 9.78.

\subsubsection{1-Cyclohexyl-2-(4-methoxyphenyl)-N- (2-methyl-4-nitrophenyl)-1H- benzo $[d]$ imidazole-5-carboxamide (VIIn)}

The titled compound VIIn is white powder (0.32 g, 73.82\%); m.p. $142-144{ }^{\circ} \mathrm{C} ;{ }^{1} \mathbf{H}$ NMR $\left(400 \mathrm{MHz}, \mathrm{DMSO}-d_{6}\right) \delta 10.07\left(\mathrm{~s}, 1 \mathrm{H}, \mathrm{NH} \mathrm{D} \mathrm{D}_{2} \mathrm{O}\right.$ exchangeable $), 8.40(\mathrm{~d}, J=1.5 \mathrm{~Hz}, 1 \mathrm{H}$, benzimidazole $\mathrm{H}), \quad 8.21 \quad(\mathrm{~s}, \quad 1 \mathrm{H}, \quad 2-\mathrm{Me}-4-$ $\left.\mathrm{NO}_{2} \mathrm{ArH}\right), 8.13$ (dd, $J=8.9 \mathrm{~Hz}, 2 \mathrm{H}, 2-\mathrm{Me}-4-$ 
$\left.\mathrm{NO}_{2} \mathrm{ArH}\right), 8.02-7.98(\mathrm{dd}, J=8.5,1.5 \mathrm{~Hz}, 1 \mathrm{H}$, benzimidazole $\mathrm{H}), 7.89(\mathrm{dd}, J=8.6,1.7 \mathrm{~Hz}, 2 \mathrm{H}$, 4-OMe ArH), 7.64 (d, $J=8.0 \mathrm{~Hz}, 1 \mathrm{H}$, benzimidazole $\mathrm{H}$ ), 7.17 (dd, $J=8.6,1.7 \mathrm{~Hz}, 2 \mathrm{H}$, 4-OMe ArH), 4.31 (p, $J=6.7 \mathrm{~Hz}, 1 \mathrm{H}$, cyclohexyl), 3.88 (s, 3H, methoxy), 2.45 (s, 3H, methyl), 2.32 (m, 2H, cyclohexyl), $1.99-1.81$ $(\mathrm{m}, 4 \mathrm{H}, \quad$ cyclohexyl), 1.70-1.62 (d, 1H, cyclohexyl), $1.36-1.22$ (m, 3H, cyclohexyl); ${ }^{13} \mathbf{C}$ NMR (101 MHz, DMSO- $\left.d_{6}\right) \delta$ 166.8, 161.2, 154.9, 140.4, 138.6, 136.0, 137.2, 133.3, 131.4, $129.1,127.7,126.9,125.8,124.9,121.0,119.8$, 114.7, 111.8, 62.8, 55.8, 31.0, 26.0, 24.8, 18.4; MS (Mwt= 484.55), $\mathrm{m} / z$ (\%rel. int.): $484.19\left(\mathrm{M}^{+}\right.$, 75.97\%); Anal. Calcd for $\mathrm{C}_{28} \mathrm{H}_{28} \mathrm{~N}_{4} \mathrm{O}_{4}$ : C, 69.41; H, 5.82; N, 11.56; Found: C, 69.52; H, 5.97; N, 11.75 .

\subsubsection{1-Cyclohexyl-N-isobutyl-2-(4- methoxyphenyl)-1H-benzo[ $d]$ imidazole-5- carboxamide (VIIo)}

The titled compound VIIo is white powder (0.25 g, 68.91\%); m.p. 116-118 ${ }^{\circ} \mathrm{C} ;{ }^{\mathbf{1}} \mathbf{H}$ NMR $\left(400 \mathrm{MHz}, \mathrm{DMSO}-d_{6}\right) \delta 8.89(\mathrm{t}, J=5.8 \mathrm{~Hz}, 1 \mathrm{H}$, $\mathrm{NH} \mathrm{D}_{2} \mathrm{O}$ exchangeable), $8.42(\mathrm{~d}, J=1.5 \mathrm{~Hz}, 1 \mathrm{H}$, benzimidazole $\mathrm{H}$ ), 8.25 (dd, $J=8.5,1.5 \mathrm{~Hz}, 1 \mathrm{H}$, benzimidazole $\mathrm{H}$ ), $8.08-7.86$ (dd, $J=8.6,1.7$ $\mathrm{Hz}, 2 \mathrm{H}, 4-\mathrm{OMe} \mathrm{ArH}), 7.68$ (d, J=8Hz, 1H, benzimidazole $\mathrm{H}$ ), 7.23 (dd, $J=8.6,1.7 \mathrm{~Hz}, 2 \mathrm{H}$, 4-OMe ArH), 4.29 (p, J= $6.6 \mathrm{~Hz}, 1 \mathrm{H}$, cyclohexyl), $4.14(\mathrm{q}, J=7.0 \mathrm{~Hz}, 2 \mathrm{H}$, isobutyl), $3.40(\mathrm{~s}, 3 \mathrm{H}$, methoxy), 2.34(m, 1H, isobutyl) 2.27- 2.22 (m, 2H, cyclohexyl), $1.95-1.81$ (m, 4H, cyclohexyl), 1.64 (d, J= $12.2 \mathrm{~Hz}, 1 \mathrm{H}$, cyclohexyl), 1.21-1.19 (m, 3H, cyclohexyl), 0.85 (d, $J=6.7 \mathrm{~Hz}, 6 \mathrm{H}$, isobutyl); MS $(\mathrm{Mwt}=405.53)$, $\mathrm{m} / \mathrm{z}$ (\% rel. int.): $405.21\left(\mathrm{M}^{+}, 81 \%\right), 406.24\left(\mathrm{M}^{+1}\right.$, 28.1\%); Anal. Calcd for $\mathrm{C}_{25} \mathrm{H}_{31} \mathrm{~N}_{3} \mathrm{O}_{2}$ : C, 74.04; H, 7.70; N, 10.36; Found: C, 74.21; H, 7.89; N, 10.19 .

\subsubsection{1-Cyclohexyl-N-cyclopropyl-2-(4- methoxyphenyl)-1H-benzo[ $d]$ imidazole-5- carboxamide (VIIp)}

The titled compound VIIp is white powder (0.24 g, 68.87\%); m.p. $120-122{ }^{\circ} \mathrm{C}$ (charring); ${ }^{1}$ H NMR (400 MHz, DMSO- $\left.d_{6}\right) \delta 8.43(\mathrm{~d}, J=$ $4.2 \mathrm{~Hz}, 1 \mathrm{H}, \mathrm{NH} \mathrm{D}_{2} \mathrm{O}$ exchangeable), 8.17 (d, $J=$ $1.5 \mathrm{~Hz}, 1 \mathrm{H}$, benzimidazole $\mathrm{H}$ ), 7.87 (dd, $J=8.7$, $1.5 \mathrm{~Hz}, 1 \mathrm{H}$, benzimidazole $\mathrm{H}), 7.75(\mathrm{dd}, J=8.5$, $1.6 \mathrm{~Hz}, 2 \mathrm{H}, 4-\mathrm{OMe} \mathrm{ArH}), 7.60$ (d, $J=8 \mathrm{~Hz}, 1 \mathrm{H}$, benzimidazole $\mathrm{H}), 7.15(\mathrm{dd}, J=8.6,1.7 \mathrm{~Hz}, 2 \mathrm{H}$, 4-OMe ArH), 4.32 - 4.23 (m, 1H, cyclohexyl), 3.86 (s, 3H, methoxy), $2.88(\mathrm{dq}, J=7.3,3.7 \mathrm{~Hz}$, $1 \mathrm{H}$, cyclopropyl), 2.28 (q, $J=11.9,11.2 \mathrm{~Hz}, 2 \mathrm{H}$, cyclohexyl), 1.92-1.81 (m, 4H, cyclohexyl), 1.64 (d, $J=12.3 \mathrm{~Hz}, 1 \mathrm{H}$, cyclohexyl), 1.27 (d, $J=13.6$ $\mathrm{Hz}, 3 \mathrm{H}$, cyclohexyl), 0.70 (dt, $J=6.9,3.1 \mathrm{~Hz}, 2 \mathrm{H}$, cyclopropyl), 0.63-0.58 (m, 2H, cyclopropyl); MS (Mwt= 389.49), $\mathrm{m} / \mathrm{z}$ (\% rel. int.): $389.21\left(\mathbf{M}^{+}\right.$, 69\%), $390.21\left(\mathrm{M}^{+1}, 27.1 \%\right)$; Anal. Calcd for $\mathrm{C}_{24} \mathrm{H}_{27} \mathrm{~N}_{3} \mathrm{O}_{2}$ : C, 74.01; H, 6.99; N, 10.79; Found: C, 74.04; H, 7.12; N, 10.95 .

\subsubsection{1-Cyclohexyl-2-(2-methoxyphenyl)-N- phenyl-1H-benzo $[d]$ imidazole-5-carboxamide (VIIq)}

The titled compound VIIq is white powder (0.3 g, 78.8\%); m.p. 122-124 ${ }^{\circ} \mathrm{C} ;{ }^{1} \mathbf{H}$ NMR (400 $\mathrm{MHz}$, DMSO- $\left.d_{6}\right) \delta 10.23\left(\mathrm{~s}, 1 \mathrm{H}, \quad \mathrm{NH} \quad \mathrm{D}_{2} \mathrm{O}\right.$ exchangeable $), 8.39(\mathrm{~d}, J=1.5 \mathrm{~Hz}, 1 \mathrm{H}$, benzimidazole $\mathrm{H}), 7.96(\mathrm{~d}, J=7.9 \mathrm{~Hz}, 1 \mathrm{H}, 2-$ OMe ArH), 7.92-7.87 (dd, $J=8.5,1.5 \mathrm{~Hz}, 1 \mathrm{H}$, benzimidazole $\mathrm{H}$ ), 7.84 (t, $J=7.9 \mathrm{~Hz}, 1 \mathrm{H}, 2-\mathrm{OMe}$ ArH), 7.60 (td, $J=8.0,1.9 \mathrm{~Hz}, 2 \mathrm{H}, \operatorname{ArH}), 7.47$ (d, $J=8 \mathrm{~Hz}, 1 \mathrm{H}$, benzimidazole $\mathrm{H}), 7.37$ (t, $J=7.9$ $\mathrm{Hz}, 1 \mathrm{H}, 2-\mathrm{OMe} \mathrm{ArH}), 7.25$ (d, $J=7.8 \mathrm{~Hz}, 1 \mathrm{H}, 2-$ OMe ArH), 7.15 (t, $J=7.5 \mathrm{~Hz}, 2 \mathrm{H}, \mathrm{ArH}), 7.10$ (t, $J=7.5 \mathrm{~Hz}, 1 \mathrm{H}, \mathrm{ArH}), 3.89$ (p, J= $6.8 \mathrm{~Hz}, 1 \mathrm{H}$, cyclohexyl), 3.83 (s, 3H, methoxy), $2.23(\mathrm{~m}, 2 \mathrm{H}$, cyclohexyl), 1.9-1.84 (m, 4H, cyclohexyl), 1.63 $(\mathrm{d}, J=12.5 \mathrm{~Hz}, 1 \mathrm{H}$, cyclohexyl), $1.25(\mathrm{~m}, 3 \mathrm{H}$, cyclohexyl); MS (Mwt= 425.52), $\mathrm{m} / \mathrm{z}(\% \mathrm{rel}$. int.): $425.21\left(\mathrm{M}^{+}, 100 \%\right), 426.21\left(\mathrm{M}^{+1}, 30.4 \%\right)$; Anal. Calcd for $\mathrm{C}_{27} \mathrm{H}_{27} \mathrm{~N}_{3} \mathrm{O}_{2}$ : C, 76.21; H, 6.40; N, 9.87; Found: C, 76.40; H, 6.52; N, 9.98.

2.1.5.18.

N-Benzyl-1-cyclohexyl-2-(2- 
methoxyphenyl)-1H-benzo[ $[d]$ imidazole-5carboxamide (VIIr)

The titled compound VIIr is white powder (0.28 g, 71.2\%); m.p. 136-138 ${ }^{\circ} \mathrm{C} ;{ }^{1} \mathbf{H}$ NMR (400 MHz, DMSO- $\left.d_{6}\right) \delta 9.06(\mathrm{t}, J=6.1 \mathrm{~Hz}, 1 \mathrm{H}, \mathrm{NH}$ $\mathrm{D}_{2} \mathrm{O}$ exchangeable), $8.27(\mathrm{~d}, J=1.5 \mathrm{~Hz}, 1 \mathrm{H}$, benzimidazole $\mathrm{H}), 7.90(\mathrm{~d}, J=7.8 \mathrm{~Hz}, 1 \mathrm{H}, 2-$ OMe ArH), 7.84 (dd, J= 8.5, $1.5 \mathrm{~Hz}, 1 \mathrm{H}$, benzimidazole $\mathrm{H}$ ), 7.59 (t, $J=7.8 \mathrm{~Hz}, 1 \mathrm{H}, 2-\mathrm{OMe}$ $\operatorname{ArH}), 7.45(\mathrm{~d}, J=8 \mathrm{~Hz}, 1 \mathrm{H}$, benzimidazole $\mathrm{H})$, $7.38-7.31$ (m, 5H, ArH), 7.25 (d, J=7.8 Hz, 1H, 2-OMe ArH), 7.14 (t, $J=7.8 \mathrm{~Hz}, 1 \mathrm{H}, 2-\mathrm{OMe}$ $\operatorname{ArH}), 4.53$ (d, J= $\left.5.9 \mathrm{~Hz}, 2 \mathrm{H}, \mathrm{NHCH}_{2}\right), 3.86$ (p, $J=6.8 \mathrm{~Hz}, 1 \mathrm{H}$, cyclohexyl), $3.81(\mathrm{~s}, 3 \mathrm{H}$, methoxy), 2.20 (m, 2H, cyclohexyl), 1.83 (m, 4H, cyclohexyl), 1.62 (d, $J=12.4 \mathrm{~Hz}, 1 \mathrm{H}$, cyclohexyl), 1.25 (m, 3H, cyclohexyl); MS $(\mathrm{Mwt}=439.55), \mathrm{m} / \mathrm{z}$ (\% rel. int.): $439.23\left(\mathbf{M}^{+}\right.$, 88\%), $440.23\left(\mathrm{M}^{+1}, 30.7 \%\right)$; Anal. Calcd for $\mathrm{C}_{28} \mathrm{H}_{29} \mathrm{~N}_{3} \mathrm{O}_{2}$ : C, 76.51; H, 6.65; N, 9.56; Found: C, 76.64; H, 6.71; N, 9.70.

2.1.5.19. 1-Cyclohexyl-2-(2-methoxyphenyl)-N(2-methyl-4-nitrophenyl)-1H-

benzo $[d]$ imidazole-5-carboxamide (VIIs)

The titled compound VIIs is yellow powder (0.3 g, 69.2 \%); m.p. $120-122{ }^{\circ} \mathrm{C} ;{ }^{1} \mathbf{H}$ NMR (400 $\mathrm{MHz}$, DMSO- $\left.d_{6}\right) \delta 10.25\left(\mathrm{~s}, 1 \mathrm{H}, \quad \mathrm{NH} \quad \mathrm{D}_{2} \mathrm{O}\right.$ exchangeable $), 8.38(\mathrm{~d}, J=1.5 \mathrm{~Hz}, 1 \mathrm{H}$, benzimidazole $\mathrm{H}), \quad 8.26 \quad(\mathrm{~s}, \quad 1 \mathrm{H}, \quad 2-\mathrm{Me}-4-$ $\left.\mathrm{NO}_{2} \mathrm{ArH}\right), 8.11$ (d, $J=8.9 \mathrm{~Hz}, 1 \mathrm{H}, 2-\mathrm{Me}-4-$ $\left.\mathrm{NO}_{2} \mathrm{ArH}\right), 7.97$ (d, $J=8.7 \mathrm{~Hz}, 1 \mathrm{H}, 2-\mathrm{Me}-4-$ $\mathrm{NO}_{2} \mathrm{ArH}$ ), 7.89 (dd, $J=8.6,1.5 \mathrm{~Hz}, 1 \mathrm{H}$, benzimidazole $\mathrm{H}$ ), 7.84 (t, $J=7.8 \mathrm{~Hz}, 1 \mathrm{H}, 2-\mathrm{OMe}$ ArH), 7.61-7.58 (d, $J=8 \mathrm{~Hz}, 1 \mathrm{H}$, benzimidazole H), 7.47 (d, J= 7.4 Hz, 1H, 2-OMe ArH), 7.25 (d, $J=8.4 \mathrm{~Hz}, 1 \mathrm{H}, 2-\mathrm{OMe} \mathrm{ArH}), 7.14$ (t, $J=7.5 \mathrm{~Hz}$, $1 \mathrm{H}, 2-\mathrm{OMe} \mathrm{ArH}), 3.89$ (p, $J=6.8 \mathrm{~Hz}, 1 \mathrm{H}$, cyclohexyl), 3.82 (s, 3H, methoxy), 2.45 (s, 3H, methyl), 2.27 (m, 2H, cyclohexyl), $1.91-1.8$ (m, $4 \mathrm{H}$, cyclohexyl), $1.63(\mathrm{~d}, J=12.5 \mathrm{~Hz}, 1 \mathrm{H}$, cyclohexyl), 1.23 (d, 3H, cyclohexyl); MS $(\mathrm{Mwt}=484.55), \mathrm{m} / \mathrm{z}$ (\%rel. int.): $484.21\left(\mathrm{M}^{+}\right.$,
31.8\%); Anal. Calcd for $\mathrm{C}_{28} \mathrm{H}_{28} \mathrm{~N}_{4} \mathrm{O}_{4}$ : C, 69.41; H, 5.82; N, 11.56; Found: C, 69.70; H, 5.98; N, 11.49 .

\subsubsection{1-Cyclohexyl-N-(3,4-dichlorophenyl)-} 2-(2-methoxyphenyl)-1H-benzo[ $d]$ imidazole-5carboxamide (VIIt)

The titled compound VIIt is off-white powder (0.31 g, 70\%); m.p. $198-200{ }^{\circ} \mathrm{C} ;{ }^{1} \mathbf{H}$ NMR $\left(400 \mathrm{MHz}, \mathrm{DMSO}-d_{6}\right) \delta 10.49(\mathrm{~s}, 1 \mathrm{H}, \mathrm{NH}$ $\mathrm{D}_{2} \mathrm{O}$ exchangeable), $8.40(\mathrm{~s}, 1 \mathrm{H}, 3,4-\mathrm{diCl} \mathrm{ArH})$, $8.24(\mathrm{~d},=1.5 \mathrm{~Hz}, 1 \mathrm{H}$, benzimidazole $\mathrm{H}), 7.97(\mathrm{~d}$, $J=8.6 \mathrm{~Hz}, 1 \mathrm{H}, 3,4-\mathrm{diCl} \mathrm{ArH}$ ), 7.89 (dd, $J=8.6$, $1.5 \mathrm{~Hz}, 1 \mathrm{H}$, benzimidazole $\mathrm{H}), 7.84(\mathrm{t}, J=7.8 \mathrm{~Hz}$, 1H, 2-OMe ArH), 7.63-7.62 (d, 1H, 3,4-diCl ArH ), 7.61-7.58 (d, $J=8 \mathrm{~Hz}, 1 \mathrm{H}$, benzimidazole H), 7.47 (d, $J=7.4 \mathrm{~Hz}, 1 \mathrm{H}, 2-\mathrm{OMe} \mathrm{ArH}), 7.25$ (d, $J=8.4 \mathrm{~Hz}, 1 \mathrm{H}, 2-\mathrm{OMe} \mathrm{ArH}), 7.15$ (t, $J=7.5 \mathrm{~Hz}$, 1H, 2-OMe ArH), 3.89 (q, $J=6.8 \mathrm{~Hz}, 1 \mathrm{H}$, cyclohexyl), 3.82 (s, 3H, methoxy), 2.22 (m, 2H, cyclohexyl), 1.91-1.72 (m, 4H, cyclohexyl), 1.63 (d, $J=12.5 \mathrm{~Hz}, 1 \mathrm{H}$, cyclohexyl), $1.23(\mathrm{~d}, 3 \mathrm{H}$, cyclohexyl); ${ }^{13}$ C NMR (101 MHz, DMSO- $\left.d_{6}\right) \delta$ $166.5,157.6,153.4,143.5,140.1,139.4,136.3$, $132.4,131.7,130.9,127.8,125.2,123.7,122.4$, $121.8,121.2,120.7,119.6,112.9,111.9,57.5$, 55.8, 31.0, 26.0, 24.8.; MS $(\mathrm{Mwt}=494.4), \mathrm{m} / \mathrm{z}$ (\%rel. int.): $494.79\left(\mathrm{M}^{+}, 14.1 \%\right), 495.13\left(\mathrm{M}^{+2}\right.$, 64.3\%), 493.13 (100\%); Anal. Calcd for $\mathrm{C}_{27} \mathrm{H}_{25} \mathrm{Cl}_{2} \mathrm{~N}_{3} \mathrm{O}_{2}$ : C, 65.59; H, 5.10; N, 8.5; Found: $\mathrm{C}, 65.70 ; \mathrm{H}, 5.23 ; \mathrm{N}, 8.6$.

\subsubsection{1-Cyclohexyl-2-(2-methoxyphenyl)-N- phenethyl-1H-benzo $[d]$ imidazole-5- carboxamide (VIIu)}

The titled compound VIIu is white powder (0.32 g, $78.86 \%)$; m.p. $90-92{ }^{\circ} \mathrm{C} ;{ }^{1} \mathbf{H}$ NMR $(400$ $\left.\mathrm{MHz}, \mathrm{DMSO}-d_{6}\right) \delta 8.55(\mathrm{t}, J=5.6 \mathrm{~Hz}, 1 \mathrm{H}, \mathrm{NH}$ $\mathrm{D}_{2} \mathrm{O}$ exchangeable), $8.17(\mathrm{~d}, J=1.5 \mathrm{~Hz}, 1 \mathrm{H}$, benzimidazole $\mathrm{H}$ ), 7.87 (dd, $J=8.5,1.5 \mathrm{~Hz}, 1 \mathrm{H}$, benzimidazole $\mathrm{H}), 7.78-7.75(\mathrm{~d}, J=7.8 \mathrm{~Hz}, 1 \mathrm{H}$, 2-OMe ArH), 7.59 (t, $J=7.9 \mathrm{~Hz}, 1 \mathrm{H}, 2-\mathrm{OMe}$ ArH), $7.44(\mathrm{~d}, J=8 \mathrm{~Hz}, 1 \mathrm{H}$, benzimidazole $\mathrm{H})$, 
7.34-7.24 (m, 5H, ArH), $7.22(\mathrm{~d}, J=7.8 \mathrm{~Hz}, 1 \mathrm{H}$, 2-OMe ArH) $7.14(\mathrm{t}, J=7.9 \mathrm{~Hz}, 1 \mathrm{H}, 2-\mathrm{OMe}$ ArH), 3.84 (p, $J=6.8 \mathrm{~Hz}, 1 \mathrm{H}$, cyclohexyl), 3.81 (s, 3H, methoxy), 3.52 (q, $J=6.8 \mathrm{~Hz}, 2 \mathrm{H}$, $\left.\mathrm{NHCH}_{2} \mathrm{CH}_{2}\right), 2.89 \quad(\mathrm{t}, \quad J=7.4 \mathrm{~Hz}, 2 \mathrm{H}$, $\left.\mathrm{NHCH}_{2} \mathrm{CH}_{2}\right), 2.20$ (m, 2H, cyclohexyl), 1.83 (m, 4H, cyclohexyl), $1.60(\mathrm{~d}, J=12.5 \mathrm{~Hz}, 1 \mathrm{H}$, cyclohexyl), 1.21 (m, 3H, cyclohexyl); ${ }^{13} \mathbf{C}$ NMR $\left(101 \mathrm{MHz}, \mathrm{DMSO}-d_{6}\right) \delta 166.9,157.6,152.9$, $143.5,140.2,135.6,132.4,132.3,129.2,128.8$, $128.4,126.5,121.9,121.2,120.0,118.9,112.6$, 111.8, 100.0, 57.4, 55.8, 41.5, 35.7, 31.0, 26.0, 25.0; MS (Mwt= 453.58), $\mathrm{m} / z$ (\%rel. int.): 453.35 $\left(\mathrm{M}^{+}, 100 \%\right), 454.39\left(\mathrm{M}^{+1}, 32.30 \%\right)$; Anal. Calcd for $\mathrm{C}_{29} \mathrm{H}_{31} \mathrm{~N}_{3} \mathrm{O}_{2}: \mathrm{C}, 76.79 ; \mathrm{H}, 6.89 ; \mathrm{N}, 9.26$; Found: C, 76.90; H, 6.94; N, 9.45.

\subsubsection{N,1-Dicyclohexyl-2-(4-nitrophenyl)- 1H-benzo $[d]$ imidazole-5-carboxamide (VIIv)}

The titled compound VIIv is buff powder (0.28 g, 63.34\%); m.p. 112-114 ${ }^{\circ} \mathrm{C} ;{ }^{1} \mathbf{H}$ NMR $\left(400 \mathrm{MHz}, \mathrm{DMSO}-d_{6}\right) \delta(\mathrm{ppm}) 8.44(\mathrm{dd}, J=8.5$, $\left.1.7 \mathrm{~Hz}, 2 \mathrm{H}, 4-\mathrm{NO}_{2} \mathrm{ArH}\right), 8.29(\mathrm{~d}, J=1.5 \mathrm{~Hz}, 1 \mathrm{H}$, benzimidazole $\mathrm{H}$ ), 8.24 (dd, $J=8.5,1.5 \mathrm{~Hz}, 1 \mathrm{H}$, benzimidazole $\mathrm{H}$ ), $7.98(\mathrm{dd}, J=8.7,1.8 \mathrm{~Hz}, 2 \mathrm{H}$, 4- $\left.\mathrm{NO}_{2} \mathrm{ArH}\right), 7.94$ (s, $1 \mathrm{H}, \mathrm{NH} \mathrm{D}_{2} \mathrm{O}$ exchangeable), $7.83(\mathrm{~d}, J=8 \mathrm{~Hz}, 1 \mathrm{H}$, benzimidazole $\mathrm{H}$ ), 4.27 (m, $1 \mathrm{H}$, cyclohexyl), 3.80 (q, $J=7.5 \mathrm{~Hz}, 1 \mathrm{H}$, cyclohexyl), 2.34-2.24 (m, 2H, cyclohexyl), 1.96 (m, 3H, cyclohexyl), 1.85 (m, 3H, cyclohexyl), 1.80-1.71 (m, 2H, cyclohexyl), 1.63 (d, $J=11.4$ $\mathrm{Hz}, 2 \mathrm{H}$, cyclohexyl), 1.34 (q, $J=11.2,9.6 \mathrm{~Hz}$, $5 \mathrm{H}$, cyclohexyl), $1.15(\mathrm{~d}, J=12.5 \mathrm{~Hz}, 1 \mathrm{H}$, cyclohexyl), $0.83(\mathrm{td}, J=9.8,8.9,5.1 \mathrm{~Hz}, 2 \mathrm{H}$, cyclohexyl); ${ }^{13} \mathbf{C}$ NMR (101 MHz, DMSO- $\left.d_{6}\right) \delta$ 157.4, 156.1, 152.9, 148.6, 136.8, 136.1, 131.4, $129.5,124.4,119.5,115.4,113.3,57.5,54.9$, 48.9, 33.0, 31.1, 25.9, 25.8, 25.5; MS (Mwt= 446.5), $\mathrm{m} / \mathrm{z}$ (\% rel. int.): $446.11\left(\mathrm{M}^{+}, 49 \%\right)$, $447.22\left(\mathrm{M}^{+1}\right.$, 59.76\%); Anal. Calcd for $\mathrm{C}_{26} \mathrm{H}_{30} \mathrm{~N}_{4} \mathrm{O}_{3}$ : C,69.93; H, 6.77; N, 12.55; Found: C, 70.1; H, 6.89; N,12.78.

\subsubsection{1-Cyclohexyl-2-(4-nitrophenyl)-N-}

phenyl-1H benzo $[d]$ imidazole-5-carboxamide (VIIw)

The titled compound VIIw is buff powder (0.32 g, $73.38 \%$ ); m.p. 130-132 ${ }^{\circ} \mathrm{C} ;{ }^{1} \mathbf{H}$ NMR $\left(400 \mathrm{MHz}, \mathrm{DMSO}-d_{6}\right) \delta 10.28\left(\mathrm{~s}, 1 \mathrm{H}, \mathrm{NH} \mathrm{D_{2 } \mathrm { O }}\right.$ exchangeable), $8.46(\mathrm{dd}, J=8.6,1.7 \mathrm{~Hz}, 2 \mathrm{H}, 4-$ $\left.\mathrm{NO}_{2} \mathrm{ArH}\right), 8.44(\mathrm{~d}, J=1.5 \mathrm{~Hz}, 1 \mathrm{H}$, benzimidazole $\mathrm{H}), 8.06(\mathrm{dd}, J=8.7,1.5 \mathrm{~Hz}, 1 \mathrm{H}$, benzimidazole H), 8.02-7.99 (m, 2H, ArH), 7.94 (dd, $J=8.7$, $\left.1.8 \mathrm{~Hz}, 2 \mathrm{H}, 4-\mathrm{NO}_{2} \mathrm{ArH}\right), 7.84(\mathrm{~d}, J=8.0 \mathrm{~Hz}, 1 \mathrm{H}$, benzimidazole $\mathrm{H}$ ), 7.37 (t, $J=7.8 \mathrm{~Hz}, 2 \mathrm{H}, \mathrm{ArH}$ ), $7.11(\mathrm{t}, J=7.5 \mathrm{~Hz}, 1 \mathrm{H}, \mathrm{ArH}), 4.30(\mathrm{~m}, 1 \mathrm{H}$, cyclohexyl), 2.37-2.26 (m, 2H, cyclohexyl), 1.99 (d, $J=12.3 \mathrm{~Hz}, 2 \mathrm{H}$, cyclohexyl), 1.86 (d, $J=12.3$ $\mathrm{Hz}, 2 \mathrm{H}$, cyclohexyl), $1.66(\mathrm{~d}, J=11.6 \mathrm{~Hz}, 1 \mathrm{H}$, cyclohexyl), 1.47-1.23 (m, 3H, cyclohexyl); MS $(\mathrm{Mwt}=440.49), \mathrm{m} / \mathrm{z}$ (\% rel. int.): $440.18\left(\mathrm{M}^{+}\right.$, 66.21\%), $441.19\left(\mathrm{M}^{+1}, 29.76 \%\right)$; Anal. Calcd for $\mathrm{C}_{26} \mathrm{H}_{24} \mathrm{~N}_{4} \mathrm{O}_{3}$ : C, 70.89; H, 5.49; N, 12.72; Found: C, 71.08; H, 5.67; N, 12.64 .

\subsubsection{N-benzyl-1-cyclohexyl-2-(4- nitrophenyl)-1H-benzo[ $[d]$ imidazole-5- carboxamide (VIIx)}

The titled compound VIIx is brown powder (0.25 g, $55.5 \%$ ); m.p. 126-128 ${ }^{\circ} \mathrm{C}$; ${ }^{1} \mathbf{H}$ NMR (400 MHz, DMSO- $\left.d_{6}\right) \delta 9.04(\mathrm{t}, J=5.9 \mathrm{~Hz}, 1 \mathrm{H}$, $\mathrm{NH} \mathrm{D}_{2} \mathrm{O}$ exchangeable), $8.4(\mathrm{dd}, J=8.7,1.9 \mathrm{~Hz}$, $\left.2 \mathrm{H}, 4-\mathrm{NO}_{2} \mathrm{ArH}\right), 8.27(\mathrm{~d}, J=1.5 \mathrm{~Hz}, 1 \mathrm{H}$, benzimidazole $\mathrm{H}$ ), 8.14 (dd, $J=8.5,1.5 \mathrm{~Hz}, 1 \mathrm{H}$, benzimidazole $\mathrm{H}), 7.98(\mathrm{dd}, J=8.7,1.8 \mathrm{~Hz}, 2 \mathrm{H}$, 4- $\left.\mathrm{NO}_{2} \mathrm{ArH}\right), 7.83(\mathrm{~d}, J=8 \mathrm{~Hz}, 1 \mathrm{H}$, benzimidazole $\mathrm{H}), 7.71-7.55(\mathrm{~m}, 5 \mathrm{H}, \mathrm{ArH}), 4.51(\mathrm{~d}, J=5.6 \mathrm{~Hz}$, 2H, benzyl), 4.27 (m, 1H, cyclohexyl), $2.27-$ $2.24(\mathrm{~m}, 2 \mathrm{H}$, cyclohexyl), 1.98-1.8 (m, 4H, cyclohexyl), $1.63(\mathrm{~d}, \quad J=12.5 \mathrm{~Hz}, 1 \mathrm{H}$, cyclohexyl), 1.32 (m, 3H, cyclohexyl); MS $(\mathrm{Mwt}=$ 454.52), $\mathrm{m} / \mathrm{z}$ (\%rel. int.): 454.20 $\left(\mathrm{M}^{+}, 82.27 \%\right), 455.20\left(\mathrm{M}^{+}, 30.8 \%\right)$; Anal. Calcd for $\mathrm{C}_{27} \mathrm{H}_{26} \mathrm{~N}_{4} \mathrm{O}_{3}$ : C, 71.35; $\mathrm{H}, 5.77 ; \mathrm{N}, 12.33$; Found: C, 71.49; H, 5.89; N, 12.50 .

\subsubsection{General procedure to prepare}




\section{compounds (VIIIa-h)}

A mixture of 1-cyclohexyl-2-substituted-1Hbenzo $[d]$ imidazole-5-carboxylic acid (VIa-d) (0.33 mmol, 1 equivalent), the amine (0.33 mmol, 1 equivalent), 2-(1H-Benzotriazole-1-yl)1,1,3,3-tetramethyluranium tetrafluoroborate (TBTU) (0.214 g, $0.66 \mathrm{mmol}, 2$ equivalent) and 4-(Dimethylamino)pyridine (DMAP) $(0.07 \mathrm{~g}$, $0.66 \mathrm{mmol}, 2$ equivalent) was stirred in dry DMF under $\mathrm{N}_{2}$ atmosphere for $24 \mathrm{~h}$. The mixture was poured on ice $/ \mathrm{H}_{2} \mathrm{O}$ with continuous stirring, the resulting solid was filtered and washed with $\mathrm{H}_{2} \mathrm{O}$ several times and allowed to dry. The solid was purified using flash chromatography (twice) (the system used: hexane: ethyl acetate $=6: 1$ then changed to $4: 1$ and finally $2: 1$ ) to give the titled compounds (VIIIa-h).

\subsubsection{1 (S)-Ethyl 2-(1-cyclohexyl-2-(2-} methoxyphenyl)-1H-benzo[ $d]$ imidazole-5carboxamido)-3-phenylpropanoate (VIIIa)

The titled compound VIIIa is white powder (0.16 g, 84.65 \%); m.p. 88-90 ${ }^{\circ} \mathrm{C} ;{ }^{1}$ H NMR (400 $\left.\mathrm{MHz}, \mathrm{DMSO}-d_{6}\right) \delta 8.80(\mathrm{~d}, J=7.7 \mathrm{~Hz}, 1 \mathrm{H}, \mathrm{NH}$ $\mathrm{D}_{2} \mathrm{O}$ exchangeable), $8.20(\mathrm{~d}, J=1.5 \mathrm{~Hz}, 1 \mathrm{H}$, benzimidazole $\mathrm{H}), 7.88(\mathrm{dd}, J=8.7,1.5 \mathrm{~Hz}, 1 \mathrm{H}$, benzimidazole $\mathrm{H}), 7.73(\mathrm{~d}, J=8 \mathrm{~Hz}, 1 \mathrm{H}$, benzimidazole $\mathrm{H}), 7.60(\mathrm{td}, J=8.0,7.3,1.8 \mathrm{~Hz}$, 1H, 2-OMe ArH), 7.45 (dd, $J=7.4,1.7 \mathrm{~Hz}, 1 \mathrm{H}$, 2-OMe ArH), 7.34 (d, $J=7.2 \mathrm{~Hz}, 1 \mathrm{H}, 2-\mathrm{OMe}$ ArH), 7.29 (d, $J=7.4 \mathrm{~Hz}, 1 \mathrm{H}, 2-\mathrm{OMe} \operatorname{ArH}), 7.26$ $(\mathrm{d}, J=4.9 \mathrm{~Hz}, 2 \mathrm{H}, \operatorname{ArH}), 7.24-7.19(\mathrm{~m}, 1 \mathrm{H}$, ArH), 7.14 (t, J= $7.5 \mathrm{~Hz}, 2 \mathrm{H}, \mathrm{ArH}), 4.67$ (q, $J=$ $\left.7.5 \mathrm{~Hz}, 1 \mathrm{H},-\underline{\mathrm{CHCH}_{2}}\right), 4.11(\mathrm{q}, J=7.1 \mathrm{~Hz}, 2 \mathrm{H},-$ $\left.\mathrm{OCH}_{2} \mathrm{CH}_{3}\right), 3.85-3.82(\mathrm{p}, J=6.2 \mathrm{~Hz}, 1 \mathrm{H}$, cyclohexyl), 3.81 (s, $\left.3 \mathrm{H},-\mathrm{OCH}_{3}\right), 3.19-3.13$ (d, $\left.J=10 \mathrm{~Hz}, 2 \mathrm{H}, \quad-\mathrm{CHCH}_{2}\right), 2.20 \quad(\mathrm{~m}, 2 \mathrm{H}$, cyclohexyl), 1.83 (m, 4H, cyclohexyl), 1.62 (d, $J=12.5 \mathrm{~Hz}, 1 \mathrm{H}$, cyclohexyl), 1.37 (d, $J=13.3 \mathrm{~Hz}$, $3 \mathrm{H}$, cyclohexyl), $1.15(\mathrm{t}, J=7.1 \mathrm{~Hz}, 3 \mathrm{H},-$ $\left.\mathrm{OCH}_{2} \mathrm{CH}_{3}\right)$; MS (Mwt= 525.64), $\mathrm{m} / \mathrm{z}$ (\% rel. int.): $525.26\left(\mathrm{M}^{+}, 78.2 \%\right), 526.27\left(\mathrm{M}^{+1}, 35.2 \%\right)$; Anal. Calcd for $\mathrm{C}_{32} \mathrm{H}_{35} \mathrm{~N}_{3} \mathrm{O}_{4}$ : C, 73.12; H, 6.71; N, 7.99;
Found: C, 73.18; H, 6.74; N, 8.12.

\subsubsection{2 (S)-Ethyl 2-(1-cyclohexyl-2-(4- methoxyphenyl)-1H-benzo[ $d]$ imidazole-5- carboxamido)-3-phenylpropanoate (VIIIb)}

The titled compound VIIIb is white powder (0.15 g, $79.36 \%)$; m.p. $96-98{ }^{\circ} \mathrm{C} ;{ }^{1} \mathbf{H}$ NMR (400 $\left.\mathrm{MHz}, \mathrm{DMSO}-d_{6}\right) \delta 8.81(\mathrm{~d}, J=7.6 \mathrm{~Hz}, 1 \mathrm{H}, \mathrm{NH}$ $\mathrm{D}_{2} \mathrm{O}$ exchangeable), $8.21(\mathrm{~d}, J=1.5 \mathrm{~Hz}, 1 \mathrm{H}$, benzimidazole $\mathrm{H}), 8.19(\mathrm{dd}, J=8.7,1.5 \mathrm{~Hz}, 1 \mathrm{H}$, benzimidazole $\mathrm{H}), 7.89(\mathrm{dd}, J=8.6,1.7 \mathrm{~Hz}, 2 \mathrm{H}$, 4-OMe ArH), 7.73 (d, $J=8 \mathrm{~Hz}, 1 \mathrm{H}$, benzimidazole $\mathrm{H}), 7.61(\mathrm{t}, J=9.4 \mathrm{~Hz}, 1 \mathrm{H}, \mathrm{ArH})$, 7.30 (dt, $J=16.8,9.5 \mathrm{~Hz}, 4 \mathrm{H}, \mathrm{ArH}), 7.16$ (dd, $J=$ 8.6, 1.7 Hz, 2H, 4-OMe ArH), 4.67 (q, $J=7.5 \mathrm{~Hz}$, $\left.1 \mathrm{H},-\mathrm{CHCH}_{2}\right), 4.29(\mathrm{p}, \quad J=6.2 \mathrm{~Hz}, 1 \mathrm{H}$, cyclohexyl), $4.16-4.05$ (q, $\left.2 \mathrm{H},-\mathrm{OCH}_{2} \mathrm{CH}_{3}\right)$, 3.35 (s, 3H, methoxy), 3.16 (d, J=10.0 Hz, 2H, $\left.\mathrm{CHCH}_{2}\right), 2.27$ (m, 2H, cyclohexyl), $1.97-1.76$ (m, 4H, cyclohexyl), 1.65 (d, J= $12.5 \mathrm{~Hz}, 1 \mathrm{H}$, cyclohexyl), 1.32-1.21 (m, 3H, cyclohexyl), 1.16 (t, $\left.J=7 \mathrm{~Hz}, 3 \mathrm{H},-\mathrm{OCH}_{2} \mathrm{CH}_{3}\right) ; \mathbf{M S}(\mathrm{Mwt}=525.64)$, $\mathrm{m} / \mathrm{z}$ (\% rel. int.): $525.27\left(\mathrm{M}^{+}, 32.7 \%\right)$; Anal. Calcd for $\mathrm{C}_{32} \mathrm{H}_{35} \mathrm{~N}_{3} \mathrm{O}_{4}: \mathrm{C}, 73.12 ; \mathrm{H}, 6.71 ; \mathrm{N}, 7.99$; Found: C, 73.40; H, 6.89; N, 8.06.

\subsubsection{N-(6-Chlorobenzo[d]thiazol-2-yl)-1- cyclohexyl-2-phenyl-1H-benzo[ $d]$ imidazole-5- carboxamide (VIIIc).}

The titled compound VIIIc is white powder (0.15 g, $78.32 \%)$; m.p. 178-180 ${ }^{\circ} \mathrm{C}$ (charring); ${ }^{1}$ H NMR $\left(400 \mathrm{MHz}\right.$, DMSO- $\left.d_{6}\right) \delta 8.58(\mathrm{~s}, 1 \mathrm{H}$, $\mathrm{NH} \mathrm{D}_{2} \mathrm{O}$ exchangeable), $8.18(\mathrm{~d}, J=1.5 \mathrm{~Hz}, 1 \mathrm{H}$, benzimidazole $\mathrm{H}), 8.06$ (s, $1 \mathrm{H}$, benzothiazole $\mathrm{H})$, $7.7(\mathrm{~d}, 1 \mathrm{H}$, benzothiazole $\mathrm{H}), 7.79$ (dd, $J=8.7$, $1.5 \mathrm{~Hz}, 1 \mathrm{H}$, benzimidazole $\mathrm{H}), 7.69(\mathrm{~d}, J=8 \mathrm{~Hz}$, $1 \mathrm{H}$, benzimidazole $\mathrm{H}), 7.65-7.60(\mathrm{~m}, 5 \mathrm{H}, \mathrm{ArH})$, $7.50(\mathrm{dd}, J=8.6,2.2 \mathrm{~Hz}, 1 \mathrm{H}$, benzothiazole $\mathrm{H}$ ), 4.29 (p, $J=6.2 \mathrm{~Hz}, 1 \mathrm{H}$, cyclohexyl), $2.37-2.24$ $(\mathrm{m}, 2 \mathrm{H}$, cyclohexyl), $1.99-1.91(\mathrm{~m}, 2 \mathrm{H}$, cyclohexyl), $1.86(\mathrm{~d}, \quad J=12.8 \mathrm{~Hz}, 2 \mathrm{H}$, cyclohexyl), 1.65 (d, $J=12.3 \mathrm{~Hz}, 1 \mathrm{H}$, cyclohexyl), 1.33-1.18 (m, 3H, cyclohexyl); MS 
$(\mathrm{Mwt}=487.02), \mathrm{m} / \mathrm{z}$ (\%rel. int.): $486.3 \quad\left(\mathrm{M}^{+}\right.$, 100\%), $488.13\left(\mathrm{M}^{+1}, 36.9 \%\right), 489.13\left(\mathrm{M}^{+2}\right.$, $10.9 \%) ;$ Anal. Calcd for $\mathrm{C}_{27} \mathrm{H}_{23} \mathrm{ClN}_{4} \mathrm{OS}$ : C, 66.59; H, 4.76; N, 11.50; Found: C, 66.75; H, $4.89 ; \mathrm{N}, 11.64$.

\subsubsection{1-Cyclohexyl-N-(6- nitrobenzo[d]thiazol-2-yl)-2-phenyl-1H- benzo[d]imidazole-5-carboxamide (VIIId)}

The titled compound VIIId is yellow powder (0.15 g, $76.65 \%$ ); m.p. $182-184{ }^{\circ} \mathrm{C} ;{ }^{1} \mathbf{H}$ NMR $\left(400 \mathrm{MHz}, \mathrm{DMSO}-d_{6}\right) \delta 8.64(\mathrm{~d}, J=2.6 \mathrm{~Hz}, 1 \mathrm{H}$, $\mathrm{NH} \quad \mathrm{D}_{2} \mathrm{O}$ exchangeable $), \quad 8.25 \quad(\mathrm{~s}, \quad 1 \mathrm{H}$, benzothiazole $\mathrm{H}), 8.10$ (dd, $J=8.9,2.5 \mathrm{~Hz}, 1 \mathrm{H}$, benzothiazole $\mathrm{H}), 7.97(\mathrm{~d}, J=1.5 \mathrm{~Hz}, 1 \mathrm{H}$, benzimidazole $\mathrm{H}$ ), 7.88 (dd, $J=8.5,1.5 \mathrm{~Hz}, 1 \mathrm{H}$, benzimidazole $\mathrm{H}), 7.67(\mathrm{~d}, J=8 \mathrm{~Hz}, 1 \mathrm{H}$, benzimidazole $\mathrm{H}$ ), 7.64-7.58 (m, 5H, ArH), 7.49 $(\mathrm{d}, J=8.9 \mathrm{~Hz}, 1 \mathrm{H}$, benzothiazole $\mathrm{H}), 4.27$ (p, $J=$ $6.3 \mathrm{~Hz}, 1 \mathrm{H}$, cyclohexyl), $2.34-2.21(\mathrm{~m}, 2 \mathrm{H}$, cyclohexyl), $1.89(\mathrm{~m}, 4 \mathrm{H}$, cyclohexyl), $1.64(\mathrm{~d}$, $J=12.2 \mathrm{~Hz}, 1 \mathrm{H}$, cyclohexyl), $1.26(\mathrm{~m}, 3 \mathrm{H}$, cyclohexyl); MS (Mwt= 497.57), $\mathrm{m} / \mathrm{z}(\% \mathrm{rel}$. int.): $497.15\left(\mathrm{M}^{+}, 88 \%\right), 498.16\left(\mathrm{M}^{+1}, 29.6 \%\right)$; Anal. Calcd for $\mathrm{C}_{27} \mathrm{H}_{23} \mathrm{~N}_{5} \mathrm{O}_{3} \mathrm{~S}$ : C, 65.17; H, 4.66; N, 14.08; Found: C, 65.41; H, 4.88; N, 14.21.

\subsubsection{N,1-Dicyclohexyl-2-(4-hydroxyphenyl)- 1H-benzo $[d]$ imidazole-5-carboxamide (VIIIe)}

The titled compound VIIIe is white powder (0.12 g, $76.73 \%$ ); m.p. 240-242 ${ }^{\circ} \mathrm{C} ;{ }^{1} \mathbf{H}$ NMR $\left(400 \mathrm{MHz}, \mathrm{DMSO}-d_{6}\right) \delta 9.99\left(\mathrm{~s}, 1 \mathrm{H}, \mathrm{OH} \mathrm{D}_{2} \mathrm{O}\right.$ exchangeable $), \quad 8.19 \quad\left(\mathrm{~s}, \quad 1 \mathrm{H}, \quad \mathrm{NH} \quad \mathrm{D}_{2} \mathrm{O}\right.$ exchangeable $), 8.16(\mathrm{~d}, J=1.5 \mathrm{~Hz}, 1 \mathrm{H}$, benzimidazole $\mathrm{H}$ ), 7.84 (dd, $J=8.5,1.5 \mathrm{~Hz}, 1 \mathrm{H}$, benzimidazole $\mathrm{H}), 7.75(\mathrm{dd}, J=8.7,2.8 \mathrm{~Hz}, 2 \mathrm{H}$, 4-OH ArH), 7.48 (d, $J=8 \mathrm{~Hz}, 1 \mathrm{H}$, benzimidazole H), 6.96 (dd, $J=8.7,2.8 \mathrm{~Hz}, 2 \mathrm{H}, 4-\mathrm{OH} \mathrm{ArH})$, 4.29 (p, $J=6.6 \mathrm{~Hz}, 1 \mathrm{H}$, cyclohexyl), $3.79(\mathrm{~m}, 1 \mathrm{H}$, cyclohexyl), 2.28 (m, 2H, cyclohexyl), 1.87 (m, $6 \mathrm{H}$, cyclohexyl), 1.76 (d, $J=9.5 \mathrm{~Hz}, 2 \mathrm{H}$, cyclohexyl), 1.64 (t, $J=11.8 \mathrm{~Hz}, 2 \mathrm{H}$, cyclohexyl), 1.32 (dt, $J=23.0,12.0 \mathrm{~Hz}, 7 \mathrm{H}$, cyclohexyl), 1.17 (d, $1 \mathrm{H}, \quad$ cyclohexyl) ${ }^{\mathbf{1 3}} \mathbf{C} \quad$ NMR (101 $\mathbf{M H z}$, DMSO- $\left.d_{6}\right) \delta 166.1,159.3,155.4,143.3,135.9$, $131.3,128.9,121.9,121.4,118.8,116.0,112.7$, 57.1, 48.8, 33.0, 31.0, 26.0, 25.8, 25.5, 24.9; MS $(\mathrm{Mwt}=417.54), \mathrm{m} / \mathrm{z}$ (\%rel. int.): $417.23\left(\mathrm{M}^{+}\right.$, 29.14\%), $418.23\left(\mathrm{M}^{+1}, 100 \%\right)$; Anal. Calcd for $\mathrm{C}_{26} \mathrm{H}_{31} \mathrm{~N}_{3} \mathrm{O}_{2}$ : C, 74.79; H, 7.48; N, 10.06; Found: C, 74.95; H, 7.53; N, 10.27.

\subsubsection{1-Cyclohexyl-2-(4-hydroxyphenyl)-N- phenyl-1H-benzo $[d]$ imidazole-5-carboxamide (VIIIf)}

The titled compound VIIIf is white powder (0.11 g, 71.37\%); m.p. 204-206 ${ }^{\circ} \mathrm{C}$; ${ }^{1} \mathbf{H}$ NMR $\left(400 \mathrm{MHz}, \mathrm{DMSO}-d_{6}\right) \delta 10.22\left(\mathrm{~s}, 1 \mathrm{H}, \mathrm{NH} \mathrm{\textrm {D } _ { 2 } \mathrm { O }}\right.$ exchangeable), $\quad 10.01 \quad\left(\mathrm{~s}, \quad 1 \mathrm{H}, \quad \mathrm{OH} \quad \mathrm{D}_{2} \mathrm{O}\right.$ exchangeable $), 8.36(\mathrm{~d}, J=1.5 \mathrm{~Hz}, 1 \mathrm{H}$, benzimidazole $\mathrm{H}), 7.95(\mathrm{dd}, J=8.5,1.5 \mathrm{~Hz}, 1 \mathrm{H}$, benzimidazole $\mathrm{H}), 7.87(\mathrm{~d}, J=8 \mathrm{~Hz}, 1 \mathrm{H}$, benzimidazole $\mathrm{H}$ ), $7.83(\mathrm{dd}, J=8.4,2.7 \mathrm{~Hz}, 2 \mathrm{H}$, 4-OH ArH), 7.51 (d, J=8.5 Hz, 2H, ArH), 7.36 (t, $J=7.8 \mathrm{~Hz}, 3 \mathrm{H}, \mathrm{ArH}), 6.97$ (dd, $J=8.5,2.7 \mathrm{~Hz}$, 2H, 4-OH ArH), 4.27 (m, 1H, cyclohexyl), 2.37$2.26(\mathrm{~m}, 2 \mathrm{H}$, cyclohexyl), $1.89(\mathrm{t}, J=14.6 \mathrm{~Hz}$, 4H, cyclohexyl), 1.66 (d, J= $12.5 \mathrm{~Hz}, 1 \mathrm{H}$, cyclohexyl), 1.36-1.26 (m, 3H, cyclohexyl); ${ }^{13} \mathbf{C}$ NMR (101 MHz, DMSO- $\left.d_{6}\right) \delta 166.2,159.4$, $155.7,143.3,139.4,136.4,131.4,129.0,128.7$, $123.9,122.2,121.3,120.8,119.3,116.0,113.1$, 57.2, 31.0, 26.0, 24.9; MS $(\mathrm{Mwt}=411.5), \mathrm{m} / \mathrm{z}(\%$ rel. int.): $411.13\left(\mathrm{M}^{+}, 52 \%\right), 412.15\left(\mathrm{M}^{+1}\right.$, $33.72 \%$ ); Anal. Calcd for $\mathrm{C}_{26} \mathrm{H}_{25} \mathrm{~N}_{3} \mathrm{O}_{2}$ : C, 75.89; H, 6.12; N, 10.21; Found: C, 75.96; H, 6.27; N, 10.3 .

2.1.6.7

N-Benzyl-1-cyclohexyl-2-(4hydroxyphenyl)-1H-benzo[ $d]$ imidazole-5carboxamide (VIIIg)

The titled compound VIIIg is white powder (0.13 g, 81.56\%); m.p. 264-266 ${ }^{\circ} \mathrm{C}$; ${ }^{1} \mathbf{H}$ NMR (400 MHz, DMSO- $\left.d_{6}\right) \delta 10.01\left(\mathrm{~s}, 1 \mathrm{H}, \mathrm{OH} \mathrm{D}_{2} \mathrm{O}\right.$ exchangeable), $9.05\left(\mathrm{t}, J=5.9 \mathrm{~Hz}, 1 \mathrm{H}, \mathrm{NH} \mathrm{D}_{2} \mathrm{O}\right.$ exchangeable), 8.24 (d, $J=1.5 \mathrm{~Hz}, 1 \mathrm{H}$, 
benzimidazole $\mathrm{H}$ ), 7.89 (dd, $J=8.6,1.5 \mathrm{~Hz}, 1 \mathrm{H}$, benzimidazole $\mathrm{H}), 7.81(\mathrm{dd}, J=8.7,1.7 \mathrm{~Hz}, 2 \mathrm{H}$, 4-OH ArH), 7.51-7.46 (m, 1H, ArH), 7.36-7.33 $(\mathrm{m}, 4 \mathrm{H}, \quad \operatorname{ArH}), 7.25(\mathrm{~d}, J=8 \mathrm{~Hz}, 1 \mathrm{H}$, benzimidazole $\mathrm{H}), 6.99-6.93(\mathrm{dd}, J=8.7,2.8 \mathrm{~Hz}$, 2H, 4-OH ArH), 4.52 (d, J=6.0 Hz, 2H, $\left.\mathrm{NHCH}_{2}\right), 4.35-4.24(\mathrm{~m}, 1 \mathrm{H}$, cyclohexyl), 2.29 (qd, $J=11.7,11.2,5.3 \mathrm{~Hz}, 2 \mathrm{H}$, cyclohexyl), 1.92$1.80(\mathrm{~m}, 4 \mathrm{H}$, cyclohexyl), $1.65(\mathrm{~d}, J=12.0 \mathrm{~Hz}$, $1 \mathrm{H}$, cyclohexyl), 1.37 (m, 3H, cyclohexyl); MS $(\mathrm{Mwt}=425.52), \mathrm{m} / \mathrm{z}$ (\%rel. int.): $425.21\left(\mathrm{M}^{+}\right.$, $100 \%)$, $426.21\left(\mathrm{M}^{+1}, 30.14 \%\right)$; Anal. Calcd for $\mathrm{C}_{27} \mathrm{H}_{27} \mathrm{~N}_{3} \mathrm{O}_{2}$ : C, 76.21; H, 6.40; N, 9.87; Found: C, 76.34; H, 6.49; N, 9.98.

\subsubsection{1-Cyclohexyl-2-(4-hydroxyphenyl)-N- (2-methyl-4-nitrophenyl)-1H- benzo $[d]$ imidazole-5-carboxamide (VIIIh)}

The titled compound VIIIh is buff powder (0.15 g, 85.11\%); m.p. 252-254 ${ }^{\circ} \mathrm{C}$; ${ }^{1} \mathbf{H}$ NMR $\left(400 \mathrm{MHz}, \mathrm{DMSO}-d_{6}\right) \delta 10.06\left(\mathrm{~s}, 1 \mathrm{H}, \mathrm{OH} \mathrm{D} \mathrm{D}_{2} \mathrm{O}\right.$ exchangeable $), \quad 8.38 \quad\left(\mathrm{~s}, \quad 1 \mathrm{H}, \quad \mathrm{NH} \quad \mathrm{D}_{2} \mathrm{O}\right.$ exchangeable $), 8.21(\mathrm{~d}, J=1.5 \mathrm{~Hz}, 1 \mathrm{H}$, benzimidazole $\mathrm{H}), 8.13(\mathrm{dd}, J=8.7,2.8 \mathrm{~Hz}, 2 \mathrm{H}$, 4-OH ArH), 7.98 (dd, $J=8.6,1.5 \mathrm{~Hz}, 1 \mathrm{H}$, benzimidazole $\mathrm{H}), 7.88(\mathrm{~d}, J=8.2 \mathrm{~Hz}, 1 \mathrm{H}, \mathrm{ArH})$, 7.51 (d, J=8.2 Hz, 1H, ArH), 7.40 (s, 1H, ArH), 7.29 (d, $J=8 \mathrm{~Hz}, 1 \mathrm{H}$, benzimidazole $\mathrm{H}), 6.98(\mathrm{dd}$, $J=8.8,3.1 \mathrm{~Hz}, 2 \mathrm{H}, 4-\mathrm{OH} \mathrm{ArH}), 4.33(\mathrm{~m}, 1 \mathrm{H}$, cyclohexyl), 2.44 (s, 3H, methyl), $2.38-2.26$ (m, $2 \mathrm{H}$, cyclohexyl), $1.89(\mathrm{t}, J=14.6 \mathrm{~Hz}, 4 \mathrm{H}$, cyclohexyl), 1.66 (d, $J=11.7 \mathrm{~Hz}, 1 \mathrm{H}$, cyclohexyl), 1.36-1.26 (m, 3H, cyclohexyl); ${ }^{13} \mathbf{C}$ NMR (101 MHz, DMSO- $\left.d_{6}\right) \delta$ 166.3, 159.4, $155.9,144.4,143.9,143.3,136.7,134.19,131.3$, $127.8,126.0,125.8,122.3,122.0,121.2,119.6$, $116.1,113.3,57.2,31.0,26.0,24.9,18.4$; MS $(\mathrm{Mwt}=470.52), \mathrm{m} / \mathrm{z}(\%$ rel. int. $): 470.22\left(\mathrm{M}^{+}\right.$, $50.52 \%), 319.43$ (100\%); Anal. Calcd for $\mathrm{C}_{27} \mathrm{H}_{26} \mathrm{~N}_{4} \mathrm{O}_{4}$ : C, 68.92; H, 5.57; N, 11.91; Found: C, 69.08; H, 5.73; N, 12.08 .

\subsubsection{General procedure to prepare compounds (IXa, b)}

$\mathrm{Na}$ metal (5 mmol, 10 equivalent) was added to methanol $(20 \mathrm{~mL})$ at $0{ }^{\circ} \mathrm{C}$ to produce sodium methoxide which was added dropwise on a mixture of ester Ve $(0.2 \mathrm{~g}, 0.5 \mathrm{mmol}, 1$ equivalent) and appropriate amine (2-methyl-4nitro aniline and 3,4-dichloro aniline ), respectively, ( $2.54 \mathrm{mmol}, 5$ equivalent) while in an ice bath, then the ice bath was removed and the reaction was refluxed for $24 \mathrm{~h}$. The solvent was then evaporated under vacuum and the concentrate was poured on ice $/ \mathrm{H}_{2} \mathrm{O} / 10 \% \mathrm{HCl}$ with vigorous stirring where precipitate was formed, The precipitate was filtered and purified using flash chromatography (the system used: hexane: ethyl acetate $=9: 1$ then changed to $8: 1$ and finally 6:1) to give the titled compounds (IXa, b).

\subsubsection{1-Cyclohexyl-N-(2-methyl-4- nitrophenyl)-2-(4-nitrophenyl)-1H- benzo $[d]$ imidazole-5-carboxamide (IXa)}

The titled compound IXa is buff powder (0.18 g, $70.89 \%)$; m.p. 126-128 ${ }^{\circ} \mathrm{C}$ (charring); ${ }^{1}$ H NMR (400 MHz, DMSO- $\left.d_{6}\right) \delta 8.49-8.44$ $\left(\mathrm{dd}, J=8.7,1.7 \mathrm{~Hz}, 2 \mathrm{H}, 4-\mathrm{NO}_{2} \mathrm{ArH}\right), 8.39$ (s, 1H, $\mathrm{NH} \mathrm{D}_{2} \mathrm{O}$ exchangeable), $8.22(\mathrm{~d}, J=1.5 \mathrm{~Hz}, 1 \mathrm{H}$, benzimidazole $\mathrm{H}), \quad 8.14 \quad(\mathrm{~s}, \quad 1 \mathrm{H}, \quad 2-\mathrm{Me}-4$ $\left.\mathrm{NO}_{2} \mathrm{ArH}\right), 8.07(\mathrm{~d}, J=8.7 \mathrm{~Hz}, 1 \mathrm{H}, 2-\mathrm{Me}-4$ $\mathrm{NO}_{2} \mathrm{ArH}$ ), $8.04-7.93$ (dd, $J=8.7,1.8 \mathrm{~Hz}, 2 \mathrm{H}, 4$ $\left.\mathrm{NO}_{2} \mathrm{ArH}\right), \quad 7.87$ (dd, J=8.5, $1.5 \mathrm{~Hz}, 1 \mathrm{H}$, benzimidazole $\mathrm{H}$ ), 7.36 (d, $J=8.7 \mathrm{~Hz}, 1 \mathrm{H}, 2-\mathrm{Me}$ 4- $\left.\mathrm{NO}_{2} \mathrm{ArH}\right), 7.07$ (d, $J=8 \mathrm{~Hz}, 1 \mathrm{H}$, benzimidazole H), 3.77 (p, J=6.3 Hz, 1H, cyclohexyl), 2.45 (s, $3 \mathrm{H}$, methyl), 2.34 (m, 2H, cyclohexyl), 1.99-1.86 (m, 4H, cyclohexyl), $1.66(\mathrm{~d}, J=12.3 \mathrm{~Hz}, 1 \mathrm{H}$, cyclohexyl), 1.25 (d, 3H, cyclohexyl); MS 
$(\mathrm{Mwt}=499.52), \mathrm{m} / \mathrm{z}$ (\% rel. int.): $499.19\left(\mathrm{M}^{+}\right.$, 43\%), $500.19\left(\mathrm{M}^{+1}, 29.8 \%\right)$; Anal. Calcd for $\mathrm{C}_{27} \mathrm{H}_{25} \mathrm{~N}_{5} \mathrm{O}_{5}$ : C, 64.92; H, 5.04; N, 14.02; Found: C, 65.13; H, 5.21; N, 13.97.

\subsubsection{1-Cyclohexyl-N-(3,4-dichlorophenyl)-2- (4-nitrophenyl)-1H-benzo[d]imidazole-5- carboxamide (IXb)}

The titled compound $\mathbf{I X b}$ is buff powder $(0.15$ g, 57.93\%); m.p. $156-158{ }^{\circ} \mathrm{C} ;{ }^{1} \mathbf{H}$ NMR (400 $\mathrm{MHz}$, DMSO- $\left.d_{6}\right) \delta 9.05\left(\mathrm{~m}, 1 \mathrm{H}, \quad \mathrm{NH} \quad \mathrm{D}_{2} \mathrm{O}\right.$ exchangeable), 8.33 ( dd, $J=8.5,1.6 \mathrm{~Hz}, 2 \mathrm{H}, 4-$ $\left.\mathrm{NO}_{2} \mathrm{ArH}\right), 8.13(\mathrm{~d}, J=1.5 \mathrm{~Hz}, 1 \mathrm{H}$, benzimidazole $\mathrm{H}), 7.90(\mathrm{dd}, J=8.6,1.5 \mathrm{~Hz}, 1 \mathrm{H}$, benzimidazole $\mathrm{H}), 7.88(\mathrm{~d}, J=8 \mathrm{~Hz}, 1 \mathrm{H}$, benzimidazole $\mathrm{H}), 7.86$ (d, $J=2.2 \mathrm{~Hz}, 1 \mathrm{H}, 3,4 \mathrm{diClArH}$ ), 7.85 (s, 1H, 3,4 diClArH), 7.78 (dd, $J=8.8,1.7 \mathrm{~Hz}, 2 \mathrm{H}, 4-$ $\left.\mathrm{NO}_{2} \mathrm{ArH}\right), 7.05(\mathrm{~d}, J=9.1 \mathrm{~Hz}, 1 \mathrm{H}, 3,4 \mathrm{diClArH})$, 4.14 (p, $J=6.8 \mathrm{~Hz}, 1 \mathrm{H}$, cyclohexyl), 1.98 (d, $J=$ $6.6 \mathrm{~Hz}, 2 \mathrm{H}$, cyclohexyl), $1.71(\mathrm{~d}, J=11.7 \mathrm{~Hz}, 4 \mathrm{H}$, cyclohexyl), 1.62 (d, $J=12.8 \mathrm{~Hz}, 1 \mathrm{H}$, cyclohexyl), 1.46 (m, 3H, cyclohexyl); MS $(\mathrm{Mwt}=509.38), \mathrm{m} / \mathrm{z}$ (\% rel. int.): $510.19\left(\mathrm{M}^{+}\right.$, 63.9\%), $511.11\left(\mathrm{M}^{+2}, 18.5 \%\right), 508.11(100 \%)$; Anal. Calcd for $\mathrm{C}_{26} \mathrm{H}_{22} \mathrm{Cl}_{2} \mathrm{~N}_{4} \mathrm{O}_{3}$ : C, 61.31; $\mathrm{H}$, 4.35; N, 11.00; Found: C, 61.49; H, 4.52; N, 10.89 .

\subsection{Biological Evaluation}

The antiviral activity against both YFV and ZIKV was determined using a CPE-based assay. For YFV assay using Huh-7 cells, cells were seeded in 96-well plates at a density $5.5 \times 103$ cells/well in $100 \mu \mathrm{L}$ culture medium: Dulbecco's modified Eagle's medium (DMEM) supplemented with $10 \%$ fetal bovine serum (FBS), 1\% non-essential amino acids (NEAA) and 2\% HEPES. Cells could adhere overnight in a $\mathrm{CO}_{2}$ incubator at $37{ }^{\circ} \mathrm{C}$. The next day, compounds were serially diluted in the culture medium. $100 \mu \mathrm{l} /$ well of YFV diluted in assay medium (DMEM supplemented with $2 \%$ FCS,
$1 \%$ NEAA, and 2\% HEPES) was added to the 96-well plates, after which plates were incubated for 4 days at $37{ }^{\circ} \mathrm{C}$. For YFV assays using Vero cells, cells were seeded at a density of $2 \times 104$ cells/well in $100 \mu \mathrm{L}$ culture media (MEM Rega3, $10 \%$ FBS, $2 \mathrm{mM}$ L-glutamine, and $0.075 \%$ sodium bicarbonate) in 96-well plates. The next day, the culture medium was removed and 100 $\mu \mathrm{L} /$ well of assay medium (same as culture medium except that $10 \%$ FBS was replaced by $2 \%$ FBS) containing serial dilution of the compounds was added to the 96-well plates followed by an incubation period of 7 days. A potential toxic effect on the host cells was tested in parallel assays using the same protocol except that virus infection was omitted. In both antiviral and metabolic assays, the colorimetric readout was performed by using the MTS/PMS method, as described previously. ${ }^{[44]}$ CPE-based assays for ZIKV were performed as described previously [45]. The 50\% effective concentration $\left(\mathrm{EC}_{50}\right.$; the compound concentration that is required to protect $50 \%$ of the cells from virus-induced $\mathrm{CPE}$ ) and the $50 \%$ cytotoxic concentration $\left(\mathrm{CC}_{50}\right.$; the concentration that reduces the number of viable cells by $50 \%$ ) were determined using logarithmic interpolation, as described previously [44].

\subsection{Molecular Modelling}

\subsubsection{Molecular Docking}

Molecular docking was performed using AutoDock Vina version 1.1.2 [46]. First, the protein (PDB ID: 5WZ3) was prepared using Discovery Studio 2.5 protein preparation protocol, and missing loops were added. Both protein and ligand files were converted to AutoDock's PDBQT format. The XYZ coordinates were chosen to be 24.1, 72.6, and 130.1, respectively. An equal length of X, Y, and $\mathrm{Z}$ axes was chosen to be 15 angstroms. A random seed number and standard exhaustiveness were used. Nine poses were generated where the best pose showed a binding affinity of -5.6 
$\mathrm{kcal} / \mathrm{mol}$.

\subsubsection{Molecular Dynamics Simulations}

Molecular dynamics simulations were performed using Sybyl-X molecular modeling software. The simulation length was adjusted to 500 ps. The time step was set to 2 fs. An NTV ensemble was used with a temperature adjusted to $310 \mathrm{~K}$. Boltzmann distribution was used to calculate the initial velocities and a random seed was used. At the end of the simulation, the total energy vs. time plot was generated to visualize energy changes. Molecular graphics of the docked poses and molecular dynamics were generated using Maestro visualizer.

\section{Results and Discussion}

\subsection{Chemistry}

The designed compounds were synthesized according to the chemical pathways outlined in schemes 1 and 2 .

The 2-substituted-1H-benzo[ $d]$ imidazole nucleus was constructed in 4 steps starting by nitration of 4-chloro benzoic acid to give the 4chloro-3-nitrobenzoic acid (I) [39] followed by Fischer esterification of the carboxylic acid moiety using ethanol to give ethyl 4-chloro-3nitrobenzoate (II) [40]. Subsequently, the nucleophilic substitution of chloride with cyclohexylamine in the presence of DMSO and TEA was carried out to yield ethyl 4(cyclohexylamine)-3-nitrobenzoate (III) [41]. Finally, the reductive cyclization method was used in the presence of sodium dithionite as a reducing agent for the nitro group followed by cyclization using the appropriate aldehyde in a one-pot reaction ${ }^{[42]}$ to afford the ethyl 1cyclohexyl-2-substituted-1H-benzo[ $d]$ imidazole5-carboxylate derivatives (Va-d). Compound Ve was prepared by a different method, first by reduction of the nitro group in compound (III) via catalytic hydrogenation using palladium on activated charcoal ( $\mathrm{Pd} / \mathrm{C})$ and hydrogenator ${ }^{[43]}$ to give Ethyl 3-amino-4-(cyclohexylamine) benzoate (IV) followed by its condensation with 4-nitro benzaldehyde in the presence of sodium acetate in ethanol ${ }^{[47]}$ to give the ethyl 1cyclohexyl-2-(4-nitrophenyl)-1H-

benzo $[d]$ imidazole-5-carboxylate derivative Ve.

The preparation of the targeted 1-cyclohexyl$N$-substituted-2-substituted phenyl-1Hbenzo[ $[d$ imidazole-5-carboxamide derivatives was carried out firstly by hydrolysis of the 5carboxylate group using $\mathrm{LiOH}_{2} \mathrm{H}_{2} \mathrm{O}$ in ethanol $/ \mathrm{H}_{2} \mathrm{O}$ or methanol $/ \mathrm{H}_{2} \mathrm{O}$ to yield the carboxylic acid derivative (VIa-e) [48] followed by the preparation of carboxamide derivatives by two methods.

1- Activation of carboxylic acids (VIa-e) to their corresponding acid chlorides using thionyl chloride in dry DCM solvent followed by immediate addition of the corresponding amine in presence of TEA base to yield the compounds (VIIa-x) [49].

2- Direct coupling of the carboxylic acid derivatives (VIa-d) with the appropriate amine in presence of 2-(1H-Benzotriazole-1-yl)-1,1,3,3tetramethyluranium tetrafluoroborate (TBTU), 4 (Dimethylamino) pyridine (DMAP) in DMF, under $\mathrm{N}_{2}$ atmosphere to yield compounds VIIIah [50]. 
Eventually, synthesis of amides directly from esters and amines has been utilized for the preparation of the final two derivatives (IX a, b) using $\mathrm{Na}$ metal in absolute ethanol to prepare sodium ethoxide which was added immediately to compound Ve and the corresponding amines.

Scheme 1: preparation of ethyl 1-cyclohexyl-2-substituted-1H-benzo[d]imidazole-5-carboxylate intermediates (Va-e)

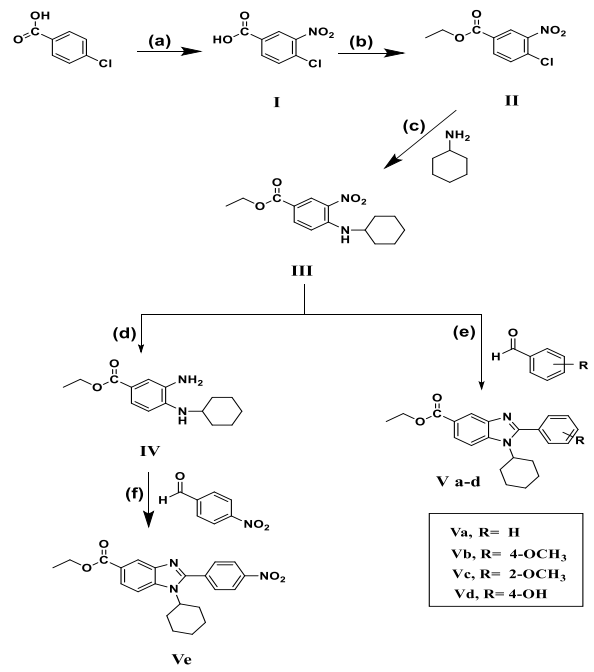

Scheme 1, Reagents \& Conditions: (a) $\mathrm{H}_{2} \mathrm{SO}_{4}, \mathrm{HNO}_{3}$, rt, $3 \mathrm{~h}$ (b) $\mathrm{H}_{2} \mathrm{SO}_{4}$, ethanol, $70{ }^{\circ} \mathrm{C}, 24 \mathrm{~h}$ (c) TEA, DMSO, $90{ }^{\circ} \mathrm{C}, 4 \mathrm{~h}$ (d) $\mathrm{H}_{2}, 10 \% \mathrm{Pd} / \mathrm{C}$, ethyl acetate (e) $\mathrm{Na}_{2} \mathrm{~S}_{2} \mathrm{O}_{4}$, DMSO, $90{ }^{\circ} \mathrm{C}, 7 \mathrm{~h}$ (f) Na acetate, ethanol, $70{ }^{\circ} \mathrm{C}, 4 \mathrm{~h}$.

Scheme 2: preparation of 1-cyclohexyl- $N$-substituted-2-substituted phenyl-1H-benzo $[d]$ imidazole-5carboxamides (VII a-x), (VIII a-h) and (IXa, b)
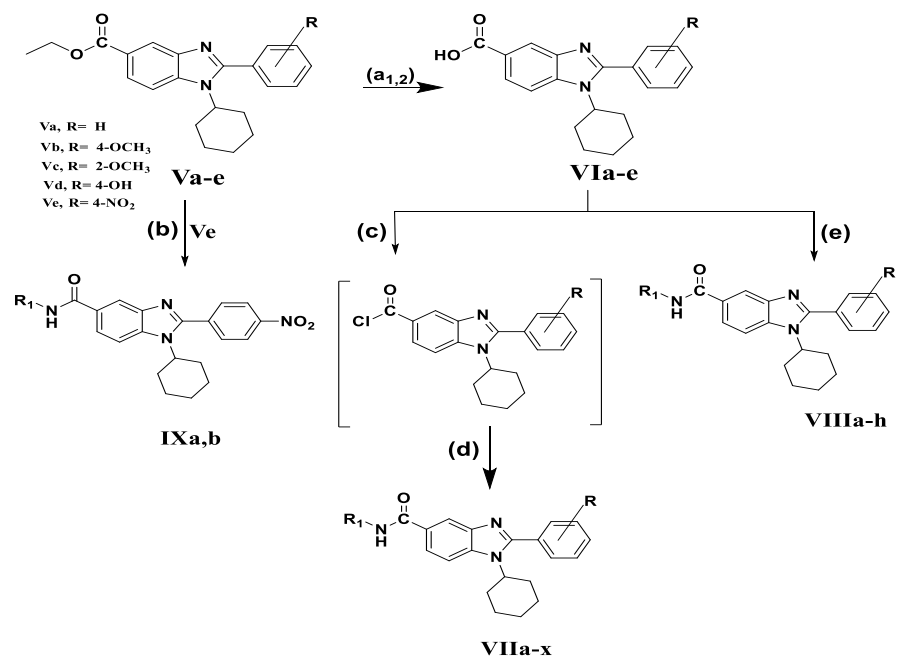

Scheme 2, Reagents \& Conditions: (a) 1-LiOH. $\mathrm{H}_{2} \mathrm{O}$, EtOH, $\mathrm{H}_{2} \mathrm{O}$, reflux, 2 h for compounds (VIa-d), 2- $\mathrm{LiOH} . \mathrm{H}_{2} \mathrm{O}, \mathrm{MeOH}$, $\mathrm{H}_{2} \mathrm{O}$, reflux, $24 \mathrm{~h}$ for compound VIe, (b) Na metal, EtOH, amine, reflux, 24 h. (c) Dry DCM, $\mathrm{SOCl}_{2}$, reflux, 2-4 h (d) Amine, dry DCM, TEA, rt, 48-72 h (e) Amine, TBTU, DMAP, dry DMF, under $\mathrm{N}_{2}$, rt, $24 \mathrm{~h}$. 
Table 1. R and R1 substitutions of the designed compounds (VII a-x), (VIII a-h) and (IXa, b)

\begin{tabular}{|c|c|c|c|c|c|}
\hline Compound ID & $\mathrm{R}$ & $\mathrm{R}_{1}$ & Compound ID & $\mathrm{R}$ & $\mathrm{R}_{1}$ \\
\hline VIIa & $\mathrm{H}$ & & VIIr & $2-\mathrm{OCH}_{3}$ & \\
\hline VIIb & $\mathrm{H}$ & & VIIs & $2-\mathrm{OCH}_{3}$ & \\
\hline VIIc & $\mathrm{H}$ & & VIIt & $2-\mathrm{OCH}_{3}$ & \\
\hline VIId & $\mathrm{H}$ & & VIIu & $2-\mathrm{OCH}_{3}$ & \\
\hline VIIe & $\mathrm{H}$ & & VIIv & $4-\mathrm{NO}_{2}$ & \\
\hline VIIf & $\mathrm{H}$ & & VIIw & $4-\mathrm{NO}_{2}$ & \\
\hline VIIg & $\mathrm{H}$ & & VIIx & $4-\mathrm{NO}_{2}$ & \\
\hline VIIh & $\mathrm{H}$ & & VIIIa & $2-\mathrm{OCH}_{3}$ & \\
\hline VIIi & $\mathrm{H}$ & & VIIIb & $4-\mathrm{OCH}_{3}$ & \\
\hline VIIj & $\mathrm{H}$ & & VIIII & $\mathrm{H}$ & \\
\hline VIIk & $4-\mathrm{OCH}_{3}$ & & VIIId & $\mathrm{H}$ & \\
\hline
\end{tabular}




VIIp

\subsection{Biological evaluation}

Antiviral activity was first assessed against YFV using the human hepatoma Huh-7 cells, most of the compounds exhibited antiviral activity against YFV in the low micromolar range, as shown in table 2. Next, the activity against YFV was evaluated using a different cell line, i.e. Vero cells (African green monkey kidney). Similar very good antiviral activity was confirmed for 5 compounds, i.e. VIId, VIIe, VIIh, VIIn, and VIIt (Table 2), indicating that antiviral activity of these compounds does not rely on the cell line used in the antiviral assay, but is specific for YFV.

To explore broad-spectrum potential, 14 compounds (VII d, e, g, h, n, t, v, w, VIII c, e-h, and IXa) were evaluated against the related ZIKV.10 Compounds out of the 14 ones showed potential activity against $\mathrm{YFV}$ with $\mathrm{EC}_{50}$ values $<3.5 \mu \mathrm{M}$ (as determined on Huh-7 cells). None of the tested compounds were active against ZIKV, except for compound VIId, which showed ZIKV $\mathrm{EC}_{50}=4.5 \pm 2.1 \mu \mathrm{M}$ (Table 2). 
Table 2. Antiviral and anti-metabolic activity of $1 \mathrm{H}-$-benzo $[d]$ imidazole-5-carboxamide derivatives. Va, VIa, VIIa-x, VIIIa-h and IXa, b

\begin{tabular}{|c|c|c|c|c|c|c|c|c|}
\hline \multirow[b]{3}{*}{ Compound ID } & \multicolumn{2}{|c|}{ Compounds Va, VIa } & \multicolumn{6}{|c|}{ Compounds (VIIa-x), (VIIIa-h) and (IXa,b) } \\
\hline & \multirow[b]{2}{*}{$\mathbf{R}$} & \multirow[b]{2}{*}{$\mathbf{R} 1$} & \multicolumn{2}{|c|}{ YFV Huh-7 cells } & \multicolumn{2}{|c|}{ YFV Vero cells } & \multicolumn{2}{|c|}{ ZIKV VeroE6 cells } \\
\hline & & & $\mathrm{EC}_{50}(\mu \mathrm{M})$ & $\begin{array}{l}\mathrm{CC}_{50} \\
(\mu \mathrm{M})\end{array}$ & $\begin{array}{l}\mathbf{E C}_{50} \\
(\mu \mathrm{M})\end{array}$ & $\begin{array}{l}\mathrm{CC}_{50} \\
(\mu \mathrm{M})\end{array}$ & $\begin{array}{l}\mathbf{E C}_{50} \\
(\mu \mathrm{M})\end{array}$ & $\begin{array}{l}\mathrm{CC}_{50} \\
(\mu \mathrm{M})\end{array}$ \\
\hline Va & $\mathrm{H}$ & $\mathrm{OCH}_{2} \mathrm{CH}_{3}$ & $>100$ & $N D$ & $N D$ & $N D$ & $N D$ & $N D$ \\
\hline VIa & $\mathrm{H}$ & $\mathrm{OH}$ & $>211$ & 211.4 & $N D$ & $>300$ & $N D$ & $N D$ \\
\hline VIIa & $\mathrm{H}$ & & $2.5 \pm 1.3$ & 11.93 & $N D$ & 5.4 & $N D$ & $N D$ \\
\hline VIIb & $\mathrm{H}$ & & $9.3 \pm 7.7$ & 26.1 & $N D$ & 6.4 & $N D$ & $N D$ \\
\hline VIIc & $\mathrm{H}$ & & $7.8 \pm 3.7$ & 25.7 & $N D$ & 6.0 & $N D$ & $N D$ \\
\hline VIId & $\mathrm{H}$ & & $1.7 \pm 0.8$ & $>60$ & $\begin{array}{l}1.2 \pm \\
0.02\end{array}$ & $>12.5$ & $4.5 \pm 2.1$ & $>20$ \\
\hline VIIe & $\mathrm{H}$ & & $2.4 \pm 0.7$ & $>60$ & $<0.8$ & $>50$ & $>20$ & $>20$ \\
\hline VIIf & $\mathrm{H}$ & & $>5.7$ & 5.7 & $N D$ & 9.9 & $N D$ & $N D$ \\
\hline VIIg & $\mathrm{H}$ & & $12.1 \pm 6.4$ & $>20$ & $N D$ & $N D$ & $>7.5$ & $>7.5$ \\
\hline
\end{tabular}


VIIh

$\mathrm{H}$

VIIi

VIIj

VIIk 4- $-\mathrm{OCH}_{3}$

VIII $\quad 4-\mathrm{OCH}_{3}$

VIIm

$4-\mathrm{OCH}_{3}$

VIIn

4- $\mathrm{OCH}_{3}$

VIIo

4- $-\mathrm{OCH}_{3}$

VIIp 4- $-\mathrm{OCH}_{3}$

VIIq

2- $-\mathrm{OCH}_{3}$

VIIr

$2-\mathrm{OCH}_{3}$

VIIs

$2-\mathrm{OCH}_{3}$

VIIt

$2-\mathrm{OCH}_{3}$<smiles>Cc1ccc(F)cc1</smiles><smiles>CC(C)(C)Cc1cccc(Cl)c1</smiles><smiles>CCCCC(C)(C)C</smiles>

$11.5 \pm 14.3 \quad>60 \quad N D$

$3.0 \pm 1.4$

12.4

$N D$

6.9

$N D$

$N D$<smiles>c1ccccc1</smiles>

$11.8 \pm 0.9$

70.3

$N D$

46.3<smiles>CC(C)(C)c1ccccc1</smiles>

$5.6 \pm 5.6$

31.7

$N D$

20.0

$N D$

ND<smiles>[Y]c1ccc([N+](=O)[O-])cc1C</smiles>

$2.1 \pm 0.6 \quad>300$

$1.6 \pm$

0.01

$>6.3$

$>20$

$>20$<smiles>C[As]C(C)C</smiles>

$>20$

$N D$

$N D$

$N D$

ND

$N D$<smiles>C[Te]1([Te])CC1</smiles>

$>100$

$N D$

$N D$

$N D$

$N D$

ND<smiles>c1ccccc1</smiles>

$8.2 \pm 4.0$

53.9

ND

66.0

$N D$

$N D$

$8.6 \pm 4.5$

51.5

$N D$

35.1

$N D$

ND<smiles>Cc1cc([N+](=O)[O-])ccc1I</smiles>

$>276$

276.5

$N D$

147

$N D$

$N D$

$2.2 \pm 0.6$

$>60$

$0.8 \pm$
0.04

$>20$

$>20$ 
VIIu

VIIIa 2- $\mathrm{OCH}_{3}$

VIIIb $4-\mathrm{OCH}_{3}$

VIIIc

$\mathrm{H}$<smiles>Clc1ccc2nc(I)sc2c1</smiles>

$\begin{array}{lllll}8.7 \pm 3.7 & >20 & N D & N D & >30\end{array}$

VIIId

$\mathrm{H}$<smiles>[Y][Z]1nc2ccc([N+](=O)[O-])cc2s1</smiles>

$>20$

$N D \quad N D$

VIIIe

$4-\mathrm{OH}$<smiles>CC1CCCCC1</smiles>

$1.6 \pm 0.2$

$>20$

$N D$

$N D$

$>15$

$>15$

VIIIf

$4-\mathrm{OH}$<smiles>c1ccccc1</smiles>

$3.0 \pm 1.7$

35.2

$N D$

$N D$

$>7.5 \quad>7.5$

VIIIg 4-OH<smiles>CC(C)(C)c1ccccc1</smiles>

$1.6 \pm 0.7$

$>20$

$N D$

$N D$

$>7.5$

$>7.5$

VIIIh

$4-\mathrm{OH}$<smiles>Cc1ccc([N+](=O)[O-])cc1C</smiles>

$1.3 \pm 0.2 \quad>20$

$N D$

ND

$>15$

$>15$ 
IXa

$4-\mathrm{NO}_{2}$

$$
4-\mathrm{NO}_{2}
$$

Ribavarin<smiles>Cc1ccc([N+](=O)[O-])cc1C</smiles>

\section{9}

$>100$

$N D$

$N D$

$>15$

$>15$<smiles>[Y]c1ccc(Cl)c(Cl)c1</smiles>

5.5

$>37.5$
$>100$

$>50$

$>100$

$>37.5$

$>100$

$N D$, not determined

From the previous results, we can conclude that:

Compounds Va and VIa bearing the ester and acid moieties respectively showed no YFV inhibition with $\mathrm{EC}_{50}>100 \mu \mathrm{m}$.

Compounds VIIa, VIId, VIIe, VIIh, VIIi, VIIk, VIIn, VIIt, VIIv, VIIIe, VIIIf, VIIIg, and VIIIh showed potent antiviral activity againstYFV with $\mathrm{EC}_{50}$ below $3.5 \mu \mathrm{M}$.

So, modification of the 5-carboxylate ester and 5-carboxylic acid groups into the amide group potentiated the anti-YFV activity.

Compounds VIIa-j with unsubstituted 2phenyl showed the best anti-YFV activity with 5 compounds (out of 10 compounds) exhibiting $\mathrm{EC}_{50}$ values below $3.5 \mu \mathrm{M}$.

Compounds VIIk-p with 2-(4methoxyphenyl) group showed good anti-YFV activity with 2 compounds (out of 6 compounds) exhibiting $\mathrm{EC}_{50}$ values below $3 \mu \mathrm{M}$.

Compounds VIIq-u with 2-(2methoxyphenyl) group showed moderate antiYFV activity with 1 compound (out of 5 compounds) exhibiting $\mathrm{EC}_{50}$ value below 2.2 $\mu \mathrm{M}$.

Compounds VIIIe-h with the 2-(4hydroxyphenyl) group were the most potent compounds with YFV $\mathrm{EC}_{50}$ values of below $3 \mu \mathrm{M}$.
Compounds VIIv-x and IXa, b bearing the 2(4-nitrophenyl) group showed moderate antiYFV activity with one compound (out of 5 compounds) exhibiting $\mathrm{EC}_{50}$ value below 3.3 $\mu \mathrm{M}$.

Further investigation among the previously obtained results revealed:

In compounds (VIIa-j) (unsubstituted 2phenyl) substitutions on the amidic $\mathrm{N}$ with phenyl ring bearing electron-withdrawing group as nitro, chloro, and fluoro groups at the para position in compounds VIId, VIIe and VIIh, respectively, showed very good anti-YFV activity (huh-7 cells) with YFV $\mathrm{EC}_{50}$ values of $1.7 \pm 0.8,2.4 \pm 0.7$ and $3.5 \pm 1.6 \mu \mathrm{M}$, respectively. Cyclic aliphatic cyclohexyl substitution in compound VIIa also showed the same good activity with YFV (huh-7 cells) $\mathrm{EC}_{50}$ value of 2.5 $\pm 1.3 \mu \mathrm{M}$. The other aromatic substitutions as phenyl, benzyl, and phenethyl in compounds VIIb, VIIc, and VIIf, respectively, and the aliphatic substitution, isobutyl and butyl chains in compounds VIIg and VIIj, respectively, showed poor anti-YFV activity.

In compounds (VIIk-p) (2-(4methoxyphenyl) group), substitutions on the amidic $\mathrm{N}$ with phenyl ring bearing the nitro electron-withdrawing group at the para position in compound VIIn and the aliphatic cyclohexyl substitution in compound VIIk showed very good anti-YFV activity with $\mathrm{YFV} \mathrm{EC}_{50}$ values of 
$2.1 \pm 0.6$ and $3.0 \pm 1.4 \mu \mathrm{M}$, respectively. The other aromatic substitutions as benzyl and phenyl in compounds VIIm and VIIl, respectively, showed poor anti-YFV activity. While the aliphatic isobutyl and cyclopropyl substituents in compounds VIIo and VIIp, respectively, showed no anti-YFV activity.

In compounds (VIIq-u) (2-(2methoxyphenyl) group), only the $\mathrm{N}-3$,4dichloro phenyl derivative VIIt, showed very good antiYFV activity with YFV $\mathrm{EC}_{50}$ value of $2.2 \pm 0.6$ $\mu \mathrm{M}$. The other aromatic substitutions as phenyl, benzyl, and phenethyl in compounds VIIq, VIIr, and VIIu, respectively, showed poor anti-YFV activity. Surprisingly the N-2-methyl-4nitrophenyl group in compound VIIs showed no anti-YFV activity.

In compounds (VIIv-x) and (IXa, b) (2-(4nitrophenyl) group), only compound VIIv bearing N-cyclohexyl group showed very good anti-YFV activity with $\mathrm{YFV} \mathrm{EC}_{50}$ value of 3.3 $\pm 0.9 \mu \mathrm{M}$, compound IXb featuring N-3,4 dichloro-phenyl substitution showed moderate anti-YFV activity with YFV $\mathrm{EC}_{50}$ value of 5.5 $\mu \mathrm{M}$. The other aromatic substitutions as phenyl and 2-methyl-4-nitrophenyl in compounds VIIw and IXa, respectively, showed poor anti-YFV activity and benzyl substitutions in compound VIIx showed no anti-YFV activity.

In compounds (VIIIa-d), compound VIIIc with the 6-Chlorobenzo[ $[d]$ thiazol substitution showed poor anti-YFV activity, and compounds VIIIa, VIIIb and VIIId showed no anti-YFV activity

Compounds (VIIIe-h) with the 2-(4hydroxyphenyl) group were the most active compounds. Both para-substitution on the Nsubstituted phenyl ring with the nitro electronwithdrawing group in compound VIIIh and the cyclic aliphatic cyclohexyl substitution in compound VIIIe showed very good anti-YFV activity with $\mathrm{YFV} \mathrm{EC}_{50}$ values of $1.3 \pm 0.2$ and $1.6 \pm 0.2 \mu \mathrm{M}$, aromatic substitutions as benzyl and phenyl in compounds VIIIg and VIIIf, respectively also showed very good anti-YFV activity with $\mathrm{YFV} \mathrm{EC}_{50}$ values of $1.6 \pm 0.7$ and $3.0 \pm 1.7 \mu \mathrm{M}$, respectively.

In an attempt to elucidate a SAR study from the previously discussed results, it was clear that the nature of the amidic-N substitution contributes the most to the biological activity, the phenyl ring (substituted with electronwithdrawing groups on its para-position) and the cyclohexyl ring were the most active ones. The variations in the 2-position substituents did not influence the activity much except for the $4-\mathrm{OH}$ phenyl substitution.

\subsection{Molecular Modelling}

To understand the interesting SAR of our compound series, we conducted different molecular modeling experiments. The goal of our experiments was to explore the potential target of compound VIId which showed very good activity against YFV (Huh-7 and Vero cells) and also against ZIKV VeroE6 cells and to investigate the possible binding mode to its target.

As has been mentioned, the design rationale relied on retaining the benzimidazole scaffold and exploring various substituents on the phenyl ring to improve activity against members of the Flaviviridae family. An important observation is that the synthesized compound series has a high structural similarity with $\mathrm{CMF}$, a potent $\mathrm{HCV}$ NS5b inhibitor reported by Di Marco et al.[51].

The structures show scaffold similarity differing only in one extra nitrogen atom within the benzimidazole nucleus of compound VIId. Both CMF and compound VIId contain phenyl and cyclohexyl on the fused bicyclic nucleus. The major differences between both compounds are an extra morpholine amide found in the CMF 
structure, and compound VIId contains an amide substituent on the benzimidazole nucleus instead of the carboxylic acid found in CMF. Fig. 4. shows the field alignment of key features of CMF and compound VIId.

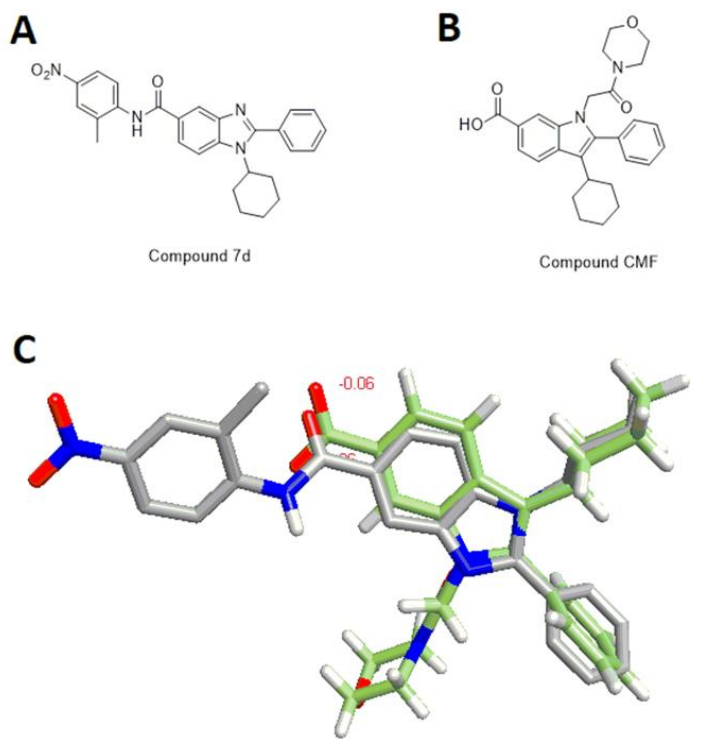

Fig. 4. (A), (B) Structures of compounds VIId and compound CMF respectively. (C) Molecular field alignment of VIId (grey) and CMF (green) with the superposition of key features such as the bicyclic fused nucleus, the cyclohexyl and phenyl moieties

From the previous observations, and due to high structural conservancy among the proteins of the Flaviviridae family, the Zika virus NS5 polymerase was predicted to be a potential target of compound VIId [52, 53]. We conducted several molecular modeling experiments to predict the potential binding mode of compound VIId to Zika virus NS5 polymerase. It is worth mentioning that no co-crystal structure of the Zika virus NS5 polymerase and an inhibitor had been determined yet.

\subsubsection{Molecular Docking}

Due to the high similarity between CMF and compound VIId, we anticipated the co-crystal structure between CMF and HCV NS5b (PDB ID: 2BRK) as a good starting point to explore the potential target and its binding to compound
VIId [51] Fig. 5 shows the 2D interactions between CMF and HCV NS5b.

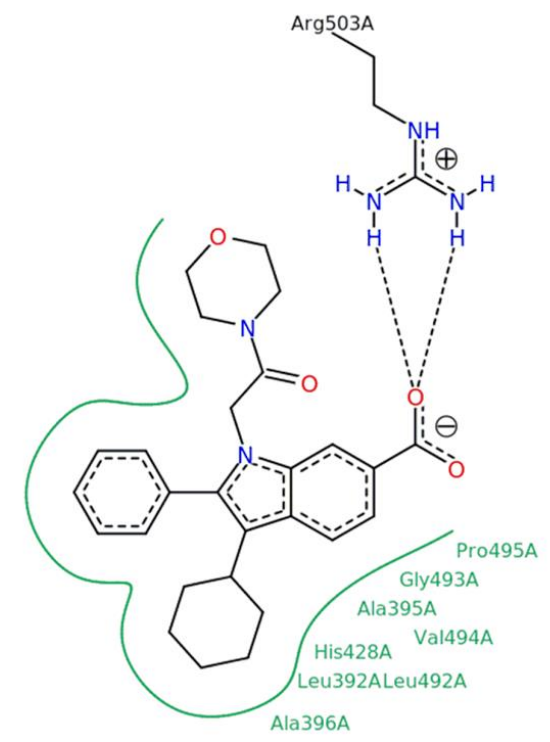

Fig. 5. 2D representation of the interactions between CMF and HCV NS5b (PDB ID: 2BRK)

By examining this crystal structure, it is observed that $\mathrm{CMF}$ binds to an allosteric site in the thumb domain of HCV NS5b, this binding relies mainly on Van der Waal's forces with hydrophobic residues. The only charge interaction found is between Arg503 and the carboxylate of CMF. The morpholine amide of CMF does not contribute to binding but protrudes towards the solvent (Fig. 5).

molecular docking was utilized to study the possible binding mode of compound VIId to Zika virus NS5 polymerase. Zika virus NS5 crystal structure was prepared (PDB ID: 5WZ3) and docking of compound VIId was performed using AutoDock Vina molecular docking software. The best binding pose showed a binding affinity of $-5.6 \mathrm{kcal} / \mathrm{mol}$. Compound VIId occupied a groove within the thumb domain of the protein where the phenyl and cyclohexyl substituents showed hydrophobic contacts with residues at the tip of the priming loop. The nitrotolyl moiety showed pi-pi stacking with Tyr885 as shown in (Fig. 6). 
This binding mode gives insight into key features that improve the binding and activity of the tested compound. Pi-pi stacking with Tyr885 is strengthened with electron-withdrawing groups as the p-nitro group found in compound VIId. Compound binding depends mainly on hydrophobic contacts with the side chains of Val787, Asp810, Met883, Asp884, and Tyr885. This is also observed to be the driving force for the binding of CMF with HCV NS5b [51].

This binding mode also suggests a possible mechanism of action for compound VIId by allosterically influencing the geometry of the binding site. It was observed that VIId forms hydrophobic contact with Val787 and Asp810. These two residues are at the tip of the priming loop of the protein which extends from Val785 to Asp810 (Fig. 6). The dynamics of this loop is crucial for the activity of the NS5 protein as it regulates the allosteric positioning of the 3 ' terminus of the RNA template at the active site ${ }^{[52]}$ Binding of VIId to the tip of the priming loop could lead to a dynamic cascade which leads to disruption of the priming loop and active site deformity. To test this hypothesis, we conducted molecular dynamics simulations.

A

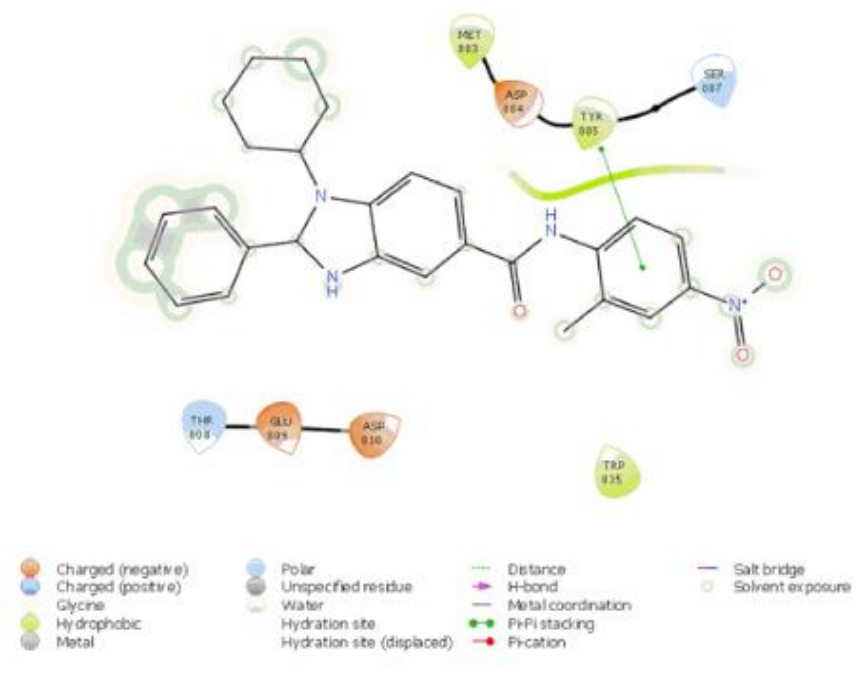

B

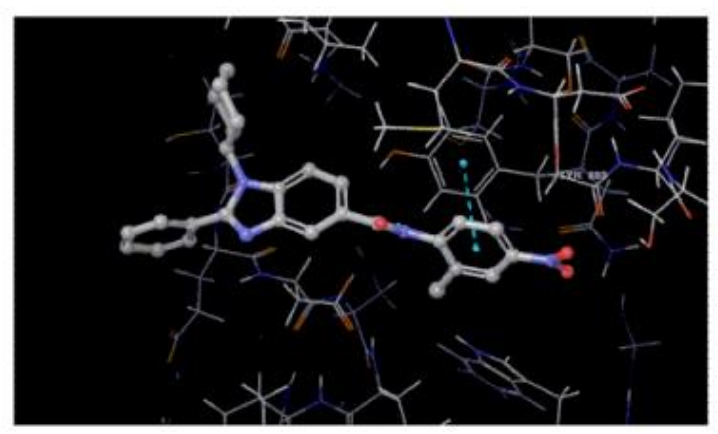

Fig. 6. (A) 2D Representation of the binding mode of compound VIId. (B) 3D Representation of the binding mode of compound VIId. Note that pi-pi stacking with Tyr885 is shown as a cyan dashed line 


\subsubsection{Molecular Dynamics Simulations}

The binding pose generated from our docking experiments suggests a possibility of an allosteric remodeling of the priming loop triggered by hydrophobic contact of VIId with the loop tip residues. To test this hypothesis, we conducted molecular dynamics simulations of the Zika virus NS5 protein (PDB ID: 5WZ3) with compound VIId bound to it using Sybyl-X molecular modeling software. The simulation showed the stabilization of total energy after 500 ps (Fig. 7). The priming loop was shown to have been moved significantly throughout the simulation showing an RSMD of 9.59 when compared to its conformation in the protein crystal structure (Fig. 8). This significant motility of the priming loop upon binding of VIId could explain the inhibitory mechanism of VIId.

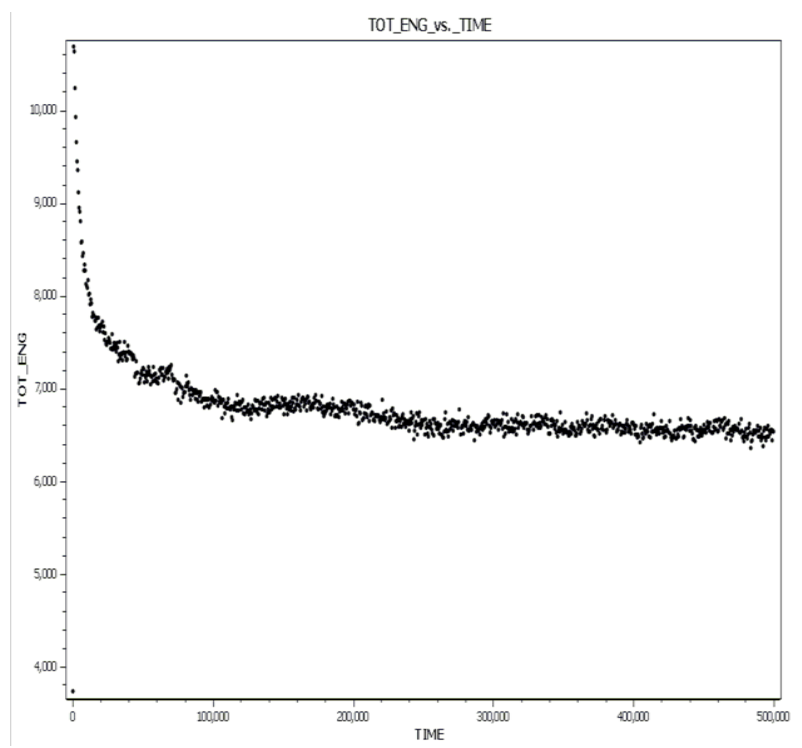

Fig. 7. Plot showing the change of total energy of the system vs. time throughout a 500 ps molecular dynamics simulation

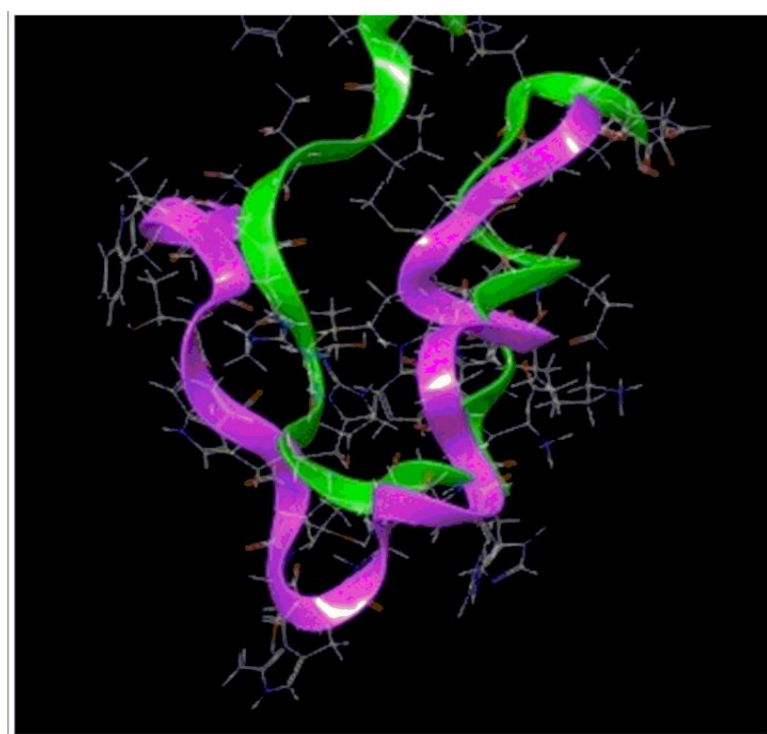

Fig. 8. Conformation Difference of the priming loop in the inhibitor VIId-bound protein (green) and the apoprotein (magenta), the crystal structure (PDB ID: 5WZ3). Residues from both loops are shown as sticks and the rest of the protein structures are hidden for simplicity

\section{Conclusion}

34 new compounds of $1 \mathrm{H}-$ benzo $[d]$ imidazole5-carboxamide derivatives were designed, synthesized, and evaluated for their anti-YFV activity, Compounds VIId, VIIe, VIIh, VIIn, VIIt, VIIv, VIIIe, VIIIf, VIIIg, and VIIIh which showed good activity on YFV were also evaluated for their anti-ZIKV activity.

SAR study among the compounds showed that modification of the 5-carboxylate ester and 5-carboxylic acid groups into amide group potentiated the anti-YFV activity, Variation of 2position substituents between phenyl, 4-methoxy phenyl, 2-methoxy phenyl, 4-hydroxy phenyl, and 4-nitro phenyl didn't influence too much in the anti-YFV activity except 4-hydroxy phenyl derivatives (VIIIe-h) which demonstrated very good activity. Variation of 5-position carboxamide derivatives had a bigger influence on the anti-YFV activity. The variation of the anti-YFV activity of the carboxamide derivatives depends on the nature of the $\mathrm{N}$-substitution. 
Compound VIId was proven to be a hit with YFV $\mathrm{EC}_{50}=1.7 \pm 0.8 \mu \mathrm{M}$ on Huh-7 cells, YFV $\mathrm{EC}_{50}=1.2 \pm 0.02 \mu \mathrm{M}$ on Vero cells, and ZIKV $\mathrm{EC}_{50}=4.5 \pm 2.1 \mu \mathrm{M}$. Molecular docking and molecular dynamics simulations studies for the synthesized compound confirmed the ZIKV NS5 polymerase to be the probable target.

\section{Declarations}

Not applicable.

\section{Consent to publish}

Not applicable.

\section{Conflict of interest}

The authors have declared no conflict of interest.

\section{Funding Statement}

No funding source was received.

\section{Authors' contributions}

All authors shared in the design of the study, collection, analysis, interpretation of data, and in writing the manuscript.

\section{Acknowledgment}

We thank the pharmaceutical chemistry department, faculty of pharmacy, King Abdulaziz University (Professor Moustafa El-Araby) for permission to perform molecular modeling on their licensed Sybyl-X package.

The authors are also thankful to the laboratory of Virology and Chemotherapy, Department of Microbiology, Immunology and Transplantation,
Rega Institute for Medical Research, Herestraat 49, 3000 Leuven, Belgium for performing the antiviral activity.

\section{REFERENCES}

1. Rima B, Collins P, Easton A, Fouchier R, Kurath G, Lamb RA, Lee B, Maisner A, Rota P, Wang L, Lefkowitz EJ, Davison AJ, Simmonds P, Sabanadzovic S, Smith DB, Orton RJ, Siddell SG. ICTV Virus Taxonomy Profile Pneumoviridae. J. Gen. Virol. 2017; 98:2912-2913. DOI :10.1099/jgv.0.000959.

2. Smith BD, Becher P, Bukh J, Gould EA, Meyers G, Monath T, Muerhoff AS, Pletnev A, Rico-Hesse R, Stapleton JT, Simmonds P. Proposed update to the taxonomy of the genera Hepacivirus and Pegivirus within

the Flaviviridae family. J. Gen. Virol. 2016; 97: 2894-2907. DOI: :10.1099/jgv.0.000612.

3. Smith BD, Meyers G, J. Bukh, Gould EA, Monath T, Muerhoff AS, Pletnev A, RicoHesse R, Stapleton JT, Simmonds P, Becher P. Proposed revision to the taxonomy of the genus Pestivirus, family Flaviviridae. J. Gen. Virol. 2017; 98:2106-2112. DOI: 10.1099/jgv.0.000873.

4. Monath TP. Yellow fever as an endemic/epidemic disease and priorities for vaccination. Bull. La Soc. Pathol. Exot. 2006; 99:341-347.

5. Barnett ED. Yellow Fever: Epidemiology and Prevention. Clin. Infect. Dis. 2007; 44: 850856. DOI: $10.1086 / 511869$.

6. P-Chippaux J, Chippaux A. Yellow fever in Africa and the Americas: a historical and epidemiological perspective. J venom. anim. toxins incl. Trop. dis. 2018; 24:20, 114. DOI: 10.1186/s40409-018-0162-y.

7. Litvoc MN, Novaes CTG, Lopes MIBF. Yellow fever. Rev. Assoc. Med. Bras. 2018; 64:106-113. DOI: 10.1590/1806- 
9282.64.02.106.

8. Song BH, Yun SI, Woolley M, Lee YM. Zika virus: History, epidemiology, transmission, and clinical presentation. J. Neuroimmunol. 2017; 308:50-64. DOI: 10.1016/j.jneuroim.2017.03.001.

9. Bueno-Marí R, Saiz JC, Salomón OD, Villamil-Jiménez LC, Heukelbach J, Alencar $\mathrm{CH}$, Armstrong PK, Rosado-de-Castro PH, Pimentel-Coelho PM. Editorial: Zika Virus Research. Front. Neurol. 2018; 9:9-10. DOI: 10.3389/fneur.2018.00168.

10. Beck AS, Barrett ADT. Current status and prospects of yellow fever vaccines. Expert Rev. Vaccines. 2015; 14:1479-1492. DOI: 10.1586/14760584.2015.1083430.

11. Oliveira ERA, Mohana-Borges R, De Alencastro RB, Horta BAC. The flavivirus capsid protein: Structure, function, and perspectives towards drug design. Virus Res. 2017; 227: 115-123. DOI: 10.1016/j.virusres.2016.10.005.

12. Roby JA, Setoh YX, Hall RA, Khromykh AA. Post-translational regulation and modifications of flavivirus structural proteins. J. Gen. Virol. 2015; 96:1551-1569. DOI: 10.1099/vir.0.000097.

13. Li L, Lok SM, Yu IM, Zhang Y, Kuhn RJ, Chen J, Rossmann MG. The flavivirus precursor membrane-envelope protein complex: Structure and maturation. Science. 2008; 319:1830-1834. DOI: 10.1126/science. 1153263.

14. Akey DL, Brown WC, Jose J, Kuhn RJ, Smith JL. Structure-guided insights on the role of NS1 in flavivirus infection. BioEssays. 2015; 37:489-494. DOI: 10.1002/bies.201400182.

15. Leung JY, Pijlman GP, Kondratieva N, Hyde J, Mackenzie JM, Khromykh AA. Role of Nonstructural Protein NS2A in Flavivirus Assembly. J. Virol. 2008; 82:4731-4741. DOI: 10.1128/JVI.00002-08.
16. Li Z, Zhang J, Li H. Flavivirus NS2B / NS3 Protease: Structure, Function, and Inhibition. Elsevier Inc. 2017; 163-188. DOI: 10.1016/B978-0-12-809712-0/00007-1.

17. McLean JE, Wudzinska A, Datan E, Quaglino D, Zakeri Z. Flavivirus NS4A-induced autophagy protects cells against death and enhances virus replication. J. Biol. Chem. 2011; 286:22147-22159. DOI: 10.1074/jbc.M110.192500.

18. Zou J, Xie X, Lee LT, Chandrasekaran R, Reynaud A, Yap L, Wang QY, Dong H, Kang C, Yuan Z, Lescar J, Shi PY. Dimerization of Flavivirus NS4B Protein. J. Virol. 2014; 88:3379-3391. DOI: 10.1128/JVI.02782-13.

19. Davidson AD. Chapter 2 New Insights into Flavivirus Nonstructural Protein 5, 1st ed. Elsevier Inc. 2009; 41-101. DOI: 10.1016/S0065-3527(09)74002-3.

20. Thimmegowda NR, Nanjunda Swamy S, Ananda Kumar CS, Sunil Kumar YC, Chandrappa S, Yip GW, Rangappa KS. Synthesis, characterization, and evaluation of benzimidazole derivative and its precursors as inhibitors of MDA-MB-231 human breast cancer cell proliferation. Bioorganic Med. Chem. Lett. 2008; 18:432-435. DOI:10.1016/j.bmcl.2007.08.078.

21. Kuş C, Ayhan-Kilcigil G, Özbey S, Kaynak FB, Kaya M, Çoban T, Can-Eke B. Synthesis and antioxidant properties of novel N-methyl1,3,4-thiadiazol-2-amine and 4-methyl-2H1,2,4-triazole-3(4H)-thione derivatives of benzimidazole class. Bioorganic Med. Chem. 2008; $\quad 16: 4294-4303 . \quad$ DOI: 10.1016/j.bmc.2008.02.077.

22. Sharma MC, Kohli DV, Sharma S. Synthesis and biological evaluation of some new benzimidazoles derivatives 4'-\{5-amino-2-[2substituted-phenylamino)-phenyl-methyl]benzimidazol-1 ylmethyl -biphenyl-2carboxylic acid: Nonpeptide angiotensin II receptor antagonists. Int. J. Drug Deliv. 2010; 
$2: 265-277$.

DOI: 10.5138/ijdd.2010.0975.0215.02038.

23. Kim MK, Shin H, Park KS, Kim H, Park J, Kim K, Nam J, Choo H, Chong Y. Benzimidazole Derivatives as Potent JAK1Selective Inhibitors. J. Med. Chem. 2015; 58:7596-7602.

DOI: 10.1021/acs.jmedchem.5b01263.

24. Achar KCS, Hosamani KM, Seetharamareddy HR. In-vivo analgesic and anti-inflammatory activities of newly synthesized benzimidazole derivatives. Eur. J. Med. Chem. 2010; 45:2048-2054.

DOI: 10.1016/j.ejmech.2010.01.029.

25. Bansal Y, Silakari O. The therapeutic journey of benzimidazoles: A review. Bioorganic Med. Chem. 2012; 20:6208-6236. DOI: 10.1016/j.bmc.2012.09.013.

26. Hernández-Luis F, Hernández-Campos A, Castillo R, Navarrete-Vázquez G, SoriaArteche O, Hernández-Hernández M, YépezMulia L. Synthesis and biological activity of 2-(trifluoromethyl)-1H-benzimidazole derivatives against some protozoa and Trichinella spiralis. Eur. J. Med. Chem. 2010; 45:3135-3141.

DOI: 10.1016/j.ejmech.2010.03.050.

27. Shingalapur RV, Hosamani KM, Keri RS, Hugar MH. Derivatives of benzimidazole pharmacophore: Synthesis, anticonvulsant, antidiabetic, and DNA cleavage studies. Eur. J. Med. Chem. 2010; 45:1753-1759. DOI: 10.1016/j.ejmech.2010.01.007.

28. El-Masry AH, Fahmy HH, Ali Abdelwahed SH. Synthesis and antimicrobial activity of some new benzimidazole derivatives. Molecules. 2000; 5:1429-1438. DOI: $10.3390 / 51201429$.

29. Tonelli M, Simone M, Tasso B, Novelli F, Boido V, Sparatore F, Paglietti G, Pricl S, Giliberti G, Blois S, Ibba C, Sanna G, Loddo R, La Colla P. Antiviral activity of benzimidazole derivatives. II. Antiviral activity of 2-phenylbenzimidazole derivatives. Bioorganic Med. Chem. 2010, 18, 29372953. DOI: 10.1016/j.bmc.2010.02.037.

30. Shah K, Chhabra S, Shrivastava SK, Mishra P. Benzimidazole: A promising pharmacophore. Med. Chem. Res. 2013; 22:5077-5104. DOI: 10.1007/s00044-0130476-9.

31. Zhan P, Li D, Li J, Chen X, Liu X. Mini. Benzimidazole Heterocycle as a Privileged Scaffold in Antiviral Agents. Rev. Org. Chem. 2012; 9:397-410. DOI: $10.2174 / 157019312804699456$.

32. Ishida T, Suzuki T, Hirashima S, Mizutani K, Yoshida A, Ando I, Ikeda S, Adachi T, Hashimoto $\mathrm{H}$. Benzimidazole inhibitors of hepatitis C virus NS5B polymerase: Identification of 2-[(4-diarylmethoxy)phenyl]benzimidazole. Bioorganic Med. Chem. Lett. 2006; 16:1859-1863. DOI: 10.1016/j.bmcl.2006.01.032.

33. Hirashima S, Oka T, Ikegashira K, Noji S, Yamanaka H, Hara Y, Goto H, Mizojiri R, Niwa $Y$, Noguchi $T$, Ando I, Ikeda $S$, Hashimoto H. Further studies on hepatitis $\mathrm{C}$ virus NS5B RNA-dependent RNA polymerase inhibitors toward improved replicon cell activities: Benzimidazole and structurally related compounds bearing the 2morpholinophenyl moiety. Bioorganic Med. Chem. Lett. 2007; 17: 3181-3186. DOI: 10.1016/j.bmcl.2007.03.027.

34. Goulet S, Poupart MA, Gillard J, Poirier M, Kukolj G, Beaulieu PL. Discovery of benzimidazole-diamide finger loop (Thumb Pocket I) allosteric inhibitors of HCV NS5B polymerase: Implementing parallel synthesis for rapid linker optimization. Bioorganic Med. Chem. Lett. 2010; 20:196-200. DOI: 10.1016/j.bmcl.2009.10.136.

35. Vitale G, Corona P, Loriga M, Carta A, Paglietti G, Giliberti G, Sanna G, Farci P, Marongiu ME, La Colla P. 5-Acetyl-2- 
arylbenzimidazoles as antiviral agents. Part 4. Eur. J. Med. Chem. 2012; 53:83-97. DOI: 10.1016/j.ejmech.2012.03.038.

36. Vitale G, Carta A, Loriga M, Paglietti G, La Colla P, Busonera B, Collu D, Loddo R. 2-

Arylbenzimidazoles as antiviral and antiproliferative agents. Part 1. Med. Chem. 2008; 4:605-15. DOI: 10.2174/157340608786241990.

37. Vitale G, Corona P, Loriga M, Carta A, Paglietti G, Colla P, Busonera B, Marongiu E, Collu D, Loddo R. 2-Arylbenzimidazoles as Antiviral and Antiproliferative Agents-Part 2. Med. Chem. (Los. Angeles). 2009; 5:507-516. DOI: $10.2174 / 157340609790170542$.

38. Vitale G, Corona P, Loriga M, Carta A, Paglietti G, Ibba C, Giliberti G, Loddo R, Marongiu E, La Colla P. Styrylbenzimidazoles. Synthesis and biological activity - part 3. Med. Chem. (Los. Angeles). 2010; 6:70-78. DOI: 10.2174/157340610791321514.

39. Sun LQ, Zhu L, Qian K, Qin B, Huang L, Chen $\mathrm{CH}$, Lee KH, Xie L. Design, synthesis, and preclinical evaluations of novel 4substituted 1,5-diarylanilines as potent HIV-1 non-nucleoside reverse transcriptase inhibitor (NNRTI) drug candidates. J. Med. Chem. 2012; 55:7219-7229. DOI: 10.1021/jm3007678.

40. Yoon YK, Choon TS. Structural Modifications of Benzimidazoles via MultiStep Synthesis and Their Impact on SirtuinInhibitory Activity. Arch. Pharm. (Weinheim). 2016; 349:1-8. DOI: 10.1002/ardp.201500337.

41. Beaulieu PL, Haché B, Moos E. von. A practical Oxone ${ }^{\circledR}$-mediated, high-throughput, solution-phase synthesis of benzimidazoles from 1, 2-phenylenediamines and aldehydes and its application to preparative scale synthesis. Synthesis (Stuttg). 2003; 2003:1683-1692. DOI: 10.1055/s-2003-
40888.

42. Hattori T, Tsubone A, Sawama Y, Monguchi Y, Sajiki H. Systematic evaluation of the palladium-catalyzed hydrogenation under flow conditions. Tetrahedron. 2014; 70:47904798. DOI: 10.1016/j.tet.2014.05.038.

43. Oda S, Shimizu H, Aoyama Y, Ueki T, Shimizu S, Osato H, Takeuchi Y. Development of Safe One-Pot Synthesis of N -1- and C -2-Substituted Benzimidazole via Reductive Cyclization of O-Nitroarylamine Using $\mathrm{Na}_{2} \mathrm{~S}_{2} \mathrm{O}_{4}$, Org. Process Res. Dev. 2012; 16:96-101. DOI: 10.1021/op200251c.

44. Kaptein SJF, De Burghgraeve T, Froeyen M, Pastorino B, Alen MMF, Mondotte JA, Herdewijn P, Jacobs M, De Lamballerie X, Schols D, Gamarnik AV, Sztaricskai F, Neyts $\mathrm{J}$. A derivate of the antibiotic doxorubicin is a selective inhibitor of dengue and yellow fever virus replication in vitro. Antimicrob. Agents Chemother. 2010; 54:5269-5280. DOI: 10.1128/AAC.00686-10.

45. Zmurko J, Marques RE, Schols D, Verbeken E, Kaptein SJF, Neyts J. The Viral Polymerase Inhibitor 7-Deaza-2'-CMethyladenosine Is a Potent Inhibitor of In Vitro Zika Virus Replication and Delays Disease Progression in a Robust Mouse Infection Model. PLoS Negl. Trop. Dis. 2016; 10:1-15. DOI: 10.1371/journal.pntd.0004695.

46. Trott O, Olson A. Autodock vina: improving the speed and accuracy of docking. J. Comput. Chem. 2010; 31:455-461. DOI: 10.1002/jcc.21334.AutoDock.

47. Alaqeel SI. Synthetic approaches to benzimidazoles from o-phenylenediamine: A literature review. J. Saudi Chem. Soc. 2017; 21:229-237. DOI: 10.1016/j.jscs.2016.08.001.

48. Dayal B, Salen G, Toome B, Tint GS, Shefer S, Padia J. Lithium hydroxide / aqueous methanol: mild reagent for the hydrolysis of bile acid methyl esters. Steroids. 1990; 55:233-237. DOI: $\quad 10.1016 / 0039-$ 
128X(90)90021-3

49. Leggio A, Belsito EL, De Luca G, Di Gioia ML, Leotta V, Romio E, Siciliano C, Liguori A. One-pot synthesis of amides from carboxylic acids activated using thionyl chloride. RSC Adv. 2016; 6:34468-34475. DOI: $10.1039 / \mathrm{c} 5 \mathrm{ra} 24527 \mathrm{c}$.

50. Han X, Zhong Y, Zhou G, Qi H, Li S, Ding Q, Liu Z, Song Y, Qiao X. Synthesis and biological evaluation of $\mathrm{N}$-(carbobenzyloxy)L-phenylalanine and $\mathrm{N}$-(carbobenzyloxy)-Laspartic acid- $\beta$-benzyl ester derivatives as potent topoisomerase II $\alpha$ inhibitors. Bioorganic Med. Chem. 2017; 25:3116-3126. DOI: 10.1016/j.bmc.2017.03.065.

51. Di Marco S, Volpari C, Tomei L, Altamura S, Harper S, Narjes F, Koch U, Rowley M, De Francesco R, Migliaccio G, Carfí A. Interdomain communication in hepatitis $\mathrm{C}$ virus polymerase abolished by small molecule inhibitors bound to a novel allosteric site. J. Biol. Chem. 2005; 280:29765-29770. DOI: 10.1074/jbc.M505423200.

52. Godoy AS, Lima GMA, Oliveira KIZ, Torres NU, Maluf FV, Guido RVC, Oliva G. Crystal structure of Zika virus NS5 RNA-dependent RNA polymerase. Nat. Commun. 2017; 8:1-6. DOI: $10.1038 /$ ncomms 14764 .

53. Zhao B, Yi G, Du F, Chuang YC, Vaughan RC, Sankaran B, Kao CC, Li P. Structure and function of the Zika virus full-length NS5 protein. Nat. Commun. 2017; 8:1-9. DOI: 10.1038/ncomms 14762 . 